\title{
Simulation of a Rocket Base Combined Cycle Exchange Inlet at Subsonic Conditions
}

by

\author{
Tommy Shi Chun Yuen
}

\author{
A Thesis submitted to \\ the Faculty of Graduate Studies and Research \\ in partial fulfilment of \\ the requirements for the degree of \\ Master of Applied Science \\ in
}

Aerospace Engineering

Carleton University

Ottawa, Ontario, Canada

April 2012

Copyright (C)

2012 - Tommy Shi Chun Yuen 
Library and Archives

Canada

Published Heritage

Branch

395 Wellington Street

Ottawa ON K1A ON4

Canada
Bibliothèque et

Archives Canada

Direction du

Patrimoine de l'édition

395 , rue Wellington

Ottawa ON K1A ON4

Canada
Your file Votre référence

ISBN: 978-0-494-91495-3

Our file Notre référence

ISBN: $978-0-494-91495-3$
NOTICE:

The author has granted a nonexclusive license allowing Library and Archives Canada to reproduce, publish, archive, preserve, conserve, communicate to the public by telecommunication or on the Internet, loan, distrbute and sell theses worldwide, for commercial or noncommercial purposes, in microform, paper, electronic and/or any other formats.

The author retains copyright ownership and moral rights in this thesis. Neither the thesis nor substantial extracts from it may be printed or otherwise reproduced without the author's permission.
AVIS:

L'auteur a accordé une licence non exclusive permettant à la Bibliothèque et Archives Canada de reproduire, publier, archiver, sauvegarder, conserver, transmettre au public par télécommunication ou par l'Internet, prêter, distribuer et vendre des thèses partout dans le monde, à des fins commerciales ou autres, sur support microforme, papier, électronique et/ou autres formats.

L'auteur conserve la propriété du droit d'auteur et des droits moraux qui protege cette thèse. $\mathrm{Ni}$ la thèse ni des extraits substantiels de celle-ci ne doivent être imprimés ou autrement reproduits sans son autorisation.
In compliance with the Canadian Privacy Act some supporting forms may have been removed from this thesis.

While these forms may be included in the document page count, their removal does not represent any loss of content from the thesis.
Conformément à la loi canadienne sur la protection de la vie privée, quelques formulaires secondaires ont été enlevés de cette thèse.

Bien que ces formulaires aient inclus dans la pagination, il n'y aura aucun contenu manquant. 


\section{Abstract}

Rocket Based Combined Cycle (RBCC) engines combine the high specific impulses of air breathing engines and the large operation envelop of rockets. Such engines incorporate 4 modes of operation with the first three modes relying on the performance of a mixing duct. The performance improves with a longer mixing duct but the problem with a long mixing duct is that it increases the overall engine weight. Thus, there have been studies done by other research groups to decrease this mixing duct length.

Research has been ongoing at Carleton University to design a RBCC engine concept that can potentially reduce the mixing duct length by improving mixing. This is done by using a design that expands the rocket exhaust from a singular throat through multiple clovers to a semi-annular profile. The current study focuses on the subsonic free stream flight conditions in order to analyze the rocket air interaction by using this profile.

From simulations performed in ANSYS CFX 12.1, it is clear that any abrupt changes to the geometry should be avoided when designing the rocket flow path. Then in the exchange inlet / mixing duct simulations, by varying the mixing duct outlet pressure, it is found that mixing improves since the mass flow rate of air and Mach number decreases. Moreover, a comparison is done with a more conventional design that places a single rocket along the centerline (SRC). It is found that the current design outperforms the SRC configuration in terms of mixing for up to 4 mixing duct diameters downstream. 
"It is difficult to say what is impossible, for the dream of yesterday is the hope of today and the reality of tomorrow."

- Robert H. Goddard 


\section{Acknowledgments}

Thank you Professor Jason Etele for the opportunity and support over the course of my Masters. I really appreciate the chance to present at San Diego. I would also like to give my thanks to the department faculty and staff.

I would also like to give thanks to my family for all their support. Moreover, I'm thankful for all the friends that have stuck with me for so long even though I never had much time to talk with them. Many thanks to Project.R, the Mississauga crew and Uncle.

Finally I would like to give special thanks to my roommates John Polansky and Sriram Venkataramanan, for all their help, recommendations, and jokes. Mahna Mahna...Do Doo Do Do Doo... 


\section{Table of Contents}

$\begin{array}{ll}\text { Abstract } & \text { iii }\end{array}$

Acknowledgments . $\quad$ v

Table of Contents vi vi

List of Tables $\quad$ viii

List of Figures $\quad$ ix

List of Acronyms $\quad$ xii

List of Symbols $\quad$ xiv

1 Introduction $\quad 1$

1.1 Brief History of Trans-Atmospheric Vehicle Propulsion . . . . . . . . 1

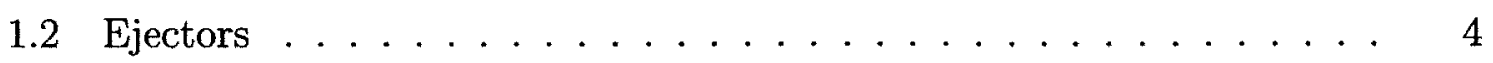

1.2.1 Mixing Method ................. 4

1.3 RBCC Engines . . . . . . . . . . . . . . . . 5

1.3.1 Types of RBCC Engines . . . . . . . . . . . . 5

1.3.2 Areas of Improvement . . . . . . . . . . . . 8

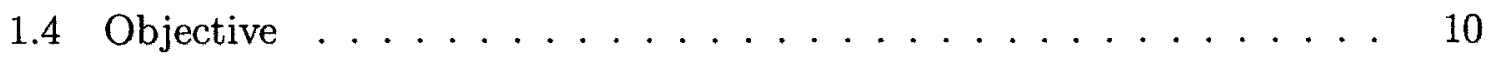


2 Rocket Flow Path Simulation $\quad 12$

2.1 Rocket Flow Path Creation . . . . . . . . . . . . . . . . 12

2.1.1 Single Rocket along the Centerline Creation . . . . . . . . . 15

2.2 Fluid Model . . . . . . . . . . . . . . . . . 17

2.3 Domain .............................. 18

2.4 Grid Convergence Study . . . . . . . . . . . . . . . . . . 19

2.5 Results and Comparison . . . . . . . . . . . . . . 22

2.5.1 RFP $P_{W}$ Results .................... 22

2.6 Shock Alleviated Rocket Flow Path . . . . . . . . . . . . . . . 26

2.6.1 Single Rocket along the Centerline . . . . . . . . . . . . 29

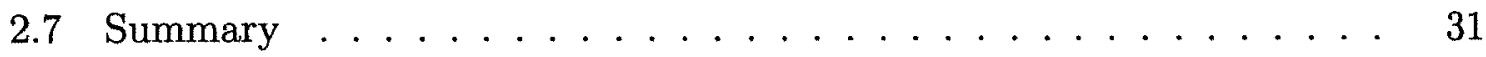

3 Exchange Inlet and Mixing Duct $\quad 35$

3.1 Intake Creation . . . . . . . . . . . . . . 36

3.2 SRC Intake Creation . . . . . . . . . . . . . . . . . . . . 39

3.3 Ejectors ............................ 41

3.4 Model .............................. 43

3.5 Results ......................... 48

3.5.1 Outlet Pressure Variation . . . . . . . . . . . . . 49

3.5.2 Flight Condition 1 at $80[\mathrm{kPa}] \ldots \ldots$. . . . . . . 56

3.5.3 RNG and $k-\omega$ Turbulence Models . . . . . . . . . . . . . . 63

3.5.4 Other Flight Conditions . . . . . . . . . . . 65

3.5.5 Single Rocket along the Centerline . . . . . . . . . . 70

3.6 Summary ............................. 75

$\begin{array}{lll}4 & \text { Conclusion } & \mathbf{7 9}\end{array}$

$\begin{array}{lr}\text { List of References } & 81\end{array}$ 


\section{List of Tables}

1 Rocket Flow Path Parameters . . . . . . . . . . . . . 15

2 Rocket Exhaust Species by Mass . . . . . . . . . . . . 19

3 Rocket Flow Path Mesh Sizes . . . . . . . . . . . . . 21

4 Rocket Flow Path Mesh Sizes _. . . . . . . . . . . . . . 21

5 Rocket Flow Path Parameters . . . . . . . . . . . . . 26

6 Rocket Flow Summary . . . . . . . . . . . . . . . . 34

$7 \quad$ Selected Air Intake Geometry $\ldots \ldots \ldots$

$8 \quad$ Flight Profile . . . . . . . . . . . . . . . 45

$9 \quad$ Mixing Duct Outlet Pressures . . . . . . . . . . . . . 46

10 Mixing Duct Outlet Reference Pressures . . . . . . . . . . 56

11 Exchange Inlet and Mixing Duct Summary . . . . . . . . . . 77 


\section{List of Figures}

1 Ramjet and Scramjet Engine . . . . . . . . . . . . . 3

2 Typical Ejector Layout . . . . . . . . . . . . . . . . 4

3 Typical RBCC Layout with Centralized Rocket . . . . . . . . . 6

4 Typical Ejector Layout . . . . . . . . . . . . . . . 7

$5 \quad$ RBCC Rocket Profiles . . . . . . . . . . . . . . . . 9

$6 \quad \mathrm{RBCC}$ Engine with Exchange Inlet $\ldots \ldots \ldots$

$7 \quad$ Vehicle concepts . . . . . . . . . . . . . . . . . 10

8 Mach Number Distribution (Design Outlet at Mach 3.95) . . . . . . 13

9 Rocket Flow Path Design Layout . . . . . . . . . . . . . . 13

10 Rocket Flow Path Configuration and Parameters . . . . . . . . 15

11 Addition of Displacement Thickness $\delta^{*}$ along Wall Surfaces . . . . . 16

12 SRC - Layout . . . . . . . . . . . . . . . . . 17

13 Rocket Flow Path Domain . . . . . . . . . . . . . . . . . 18

14 Rocket Flow Path Mesh . . . . . . . . . . . . . . . . . 19

15 Mass Flow averaged Variations along $Z_{r} \ldots \ldots \ldots \ldots$

16 Mach Distribution Comparison $\ldots \ldots \ldots . \ldots . \ldots 23$

17 Contour Plot: Pressure Gradient . . . . . . . . . . . . . . 24

18 Mach Number Contour Plot for Sections along z-axis . . . . . . . 25

19 Total Pressure Contour Plot for Sections along z-axis . . . . . . . 25

20 Geometry of the two Rocket Flow Path Designs . . . . . . . . . 27 
21 Contour Plot: Pressure Gradient _ . . . . . . . . . . . . . . 28

22 Mach Number Comparison between $R F P_{W}$ and $R F P_{S A} \ldots \ldots 29$

23 Mach Distribution Comparison, SRC . . . . . . . . . . . . . . 30

24 SRC Mach Number Cross Section Contour Plots . . . . . . . . . . . . 30

25 Contour Plots along Symmetry Plane in Z Direction . . . . . . . . . 31

26 Mach Number Comparison between $R F P_{W}$ and $S R C \ldots \ldots$

27 Total Pressure Comparison . . . . . . . . . . . . . . . . . . 33

28 Intake Geometry $\ldots \ldots \ldots \ldots \ldots \ldots \ldots$

29 Exchange Inlet and Mixing Duct $\ldots \ldots \ldots \ldots$

30 RBCC Engine with Exchange Inlet . . . . . . . . . . . . . . 39

31 Layout of Mixing Duct Domain . . . . . . . . . . . . . . . . . 44

32 Ejector/Mixing Duct Domain Mesh . . . . . . . . . . . . . 45

33 Exchange Inlet/Mixing Duct Locations . . . . . . . . . . . . . 48

34 Mach Number Contour Plot in Exchange Inlet at FC1 (65 [kPa]) . . 49

35 Mach Number Contour Plot in Exchange Inlet at FC1 (100 [kPa]) . . 50

36 Mach Number Contour Plot in Mixing Duct at FC1 (65[kPa]) . . . 51

37 Mach number Contour Plot of the Mixing Duct at FC1 (100 [kPa]) . 52

38 The Minimum, Mean and Maximum Values in the Mixing Duct . . . 53

39 SMEE at 5 [Dia] Downstream . . . . . . . . . . . . . . . . 54

40 Entrainment Ratio for Different Outlet Pressures _ . . . . . . . . 55

41 EM values for Total Pressure, Temperature and $\mathrm{H}_{2} \mathrm{O}$ Mass Fraction at

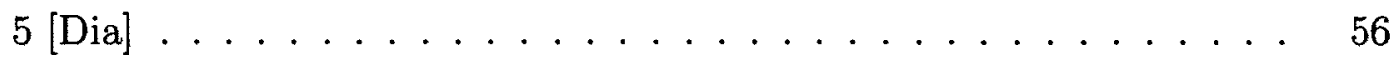

42 Mach Number Contour Plot in Exchange Inlet $(80[\mathrm{kPa}]) \ldots \ldots 7$

43 Mach Number Contour Plots in Mixing Duct $(80[\mathrm{kPa}]) \ldots . . . .58$

44 Other Contour Plots in Mixing Duct $(80[\mathrm{kPa}]) \ldots \ldots \ldots$

45 Mass flow Averaged EM along Z . . . . . . . . . . . . . . 60

46 EM Contour Plots for Cross Sections at every Diameter Downstream 62 
47 Mach Number Contour Plot in Exchange Inlet, RNG . . . . . . . . . 63

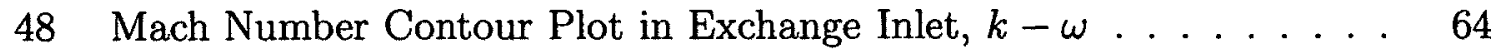

49 Mixing Duct Comparisons for Symmetry Plane 1 . . . . . . . 65

50 Mixing Duct Comparisons for Symmetry Plane 2 . . . . . . . . 65

51 Mach Number Contour Plot in the Exchange Inlet at Flight Condition 266

52 Mach number Contour Plot in the Mixing Duct at Flight Condition 267

53 Mach number Contour Plot in the Exchange Inlet at Flight Condition 368

54 Mach number Contour Plot in the Mixing Duct at Flight Condition 368

55 EM Values for 3 Flight Conditions . . . . . . . . . . . . 70

56 Mach number Contour Plot in the Exchange Inlet (SRC) . . . . . . . 71

57 Mach number Contour Plot in the Mixing Duct (SRC) . . . . . . . 72

58 SRC Pressure Contours within Mixing Duct . . . . . . . . . . . 72

59 SRC Temperature Contours within Mixing Duct . . . . . . . . . 73

60 EM values for Different Configurations . . . . . . . . . . . 74

61 Total Pressure and Mach Number at Various Mixing Duct Outlet Pressures $[5 \mathrm{Dia}] \ldots \ldots \ldots \ldots \ldots$

62 Temperature and $\mathrm{H}_{2} \mathrm{O}$ Mass Fractions at Various Mixing Duct Outlet

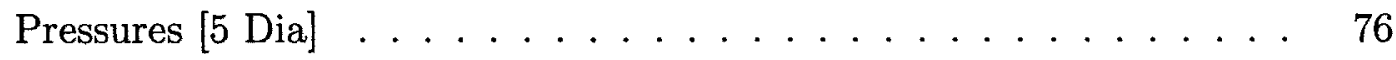

63 Min Mean Max of Temperature and $\mathrm{H}_{2} \mathrm{O}$ Mass Fraction (80[kPa]) . . 78 


\section{List of Acronyms}

\section{Acronyms Definition}

\begin{tabular}{ll}
\hline \hline CFD & Computational Fluid Dynamics \\
DAB & Diffusion and After Burning \\
EM & Extent of Mixing \\
GRF & Grid Refinement Factor \\
GCI & Grid Convergence Index \\
ISP & Specific Impulse [s] \\
IRS & Independent Ramjet Stream, a type of RBCC engine \\
$k-\omega$ & k-omega , a turbulence model \\
RBCC & Rocket Based Combined Cycle \\
$R F P_{W}$ & Test case using a specific set of parameters used to produce a semi- \\
& annular rocket profile \\
$R F P_{S A}$ & Test case using a specific set of parameters used to alleviate the \\
& presence of a shockwave \\
& Test case using a single rocket along the centerline configuration
\end{tabular}


RNG ReNormalization Group k-epsilon, a turbulence model

RPNCC Rocket Plug Nozzle Combined Cycle, a type of RBCC engine

SEE Stagnation Energy Effectiveness

SMC Simultaneous Mixing and Combustion

SMEE Stagnation Momentum Exchange Effectiveness

SST Shear Stress Transport, a turbulence model 


\section{List of Symbols}

\begin{tabular}{|c|c|c|}
\hline Symbol & Description & Units \\
\hline$\alpha$ & $\begin{array}{l}\text { Entrainment ratio, mass flow rate of air to mass flow rate } \\
\text { of rocket exhaust }\end{array}$ & - \\
\hline$\alpha_{\max }$ & $\begin{array}{l}\text { Maximum entrainment possible, when given flow proper- } \\
\text { ties } A^{*}\end{array}$ & - \\
\hline$\beta$ & Momentum flux correction factor & - \\
\hline$\delta h$ & Representative cell length & {$[\mathrm{m}]$} \\
\hline$\gamma$ & Ratio of specific heats & - \\
\hline$\Gamma$ & Used to represent a calculation involving $\gamma$ & - \\
\hline$\phi_{e}$ & Turning angle of the flow at the rocket flow path exit & {$[\mathrm{deg}]$} \\
\hline$\Psi_{e}$ & Circumferential width of the rocket flow path exit & {$[\operatorname{deg}]$} \\
\hline$\Psi_{g}$ & Circumferential width of the gate & {$[\mathrm{deg}]$} \\
\hline$\sigma$ & Ratio of rocket flow area to the total flow area & - \\
\hline$A^{*}$ & Critical area & {$\left[m^{2}\right]$} \\
\hline
\end{tabular}


$A_{2-3} \quad$ Determines the airflow area distribution between planes 2 and 3

$A_{\text {air }} \quad$ Intake area distribution $\quad\left[\mathrm{m}^{2}\right]$

$A_{r}\left(Z_{r}\right) \quad$ Rocket area distribution along $Z_{r} \quad \cdot \quad\left[m^{2}\right]$

$A R \quad$ Area ratio of air stream between planes 2 and 3

$C \quad$ Ratio of critical area to mass flow rate of rocket exhaust $\quad\left[\frac{m^{2} s}{k g}\right]$

$\tilde{c}_{f a i r_{\max }}$ Determines the maximum length of the fairing -

$C_{p} \quad$ Specific heat at constant pressure $\quad\left[\frac{J}{k g K}\right]$

$C R \quad$ Area ratio at leading edge of cowl

Dia Unit to measure length in terms of mixing duct diameters -

$\begin{array}{ll}D_{m i x} & \text { Diameter of mixing duct }\end{array}$

$\begin{array}{lll}D_{r} & \text { Diameter of rocket flow path } & {[m]}\end{array}$

M Mach number

$\dot{m}_{a i r} \quad$ Mass flow rate of air $\quad\left[\frac{k g}{s}\right]$

$M_{f} \quad$ Mass fraction

$\dot{m}_{\max } \quad$ Choked mass flow rate $\quad\left[\frac{\mathrm{kg}}{\mathrm{s}}\right]$

$M_{r}\left(Z_{r}\right) \quad$ Rocket Mach number distribution along $Z_{r}$

$\dot{m}_{r} \quad$ Mass flow rate of rocket exhaust $\quad\left[\frac{k g}{s}\right]$

$\begin{array}{lll}P_{0} & \text { Total Pressure } & {[\mathrm{Pa}]}\end{array}$ 


\begin{tabular}{|c|c|c|}
\hline$R$ & Gas constant & {$\left[\frac{J}{k g K}\right]$} \\
\hline$\tilde{r}_{C B_{1}}$ & Centrebody radius ratio at plane 1 & - \\
\hline$r_{e}$ & $\begin{array}{l}\text { Radial location of the rocket flow path exit from the ori- } \\
\text { gin }\end{array}$ & {$[m]$} \\
\hline$r_{f}$ & Fillet radius of the rocket flow path & {$[m]$} \\
\hline$r_{g}$ & Radial location of the gate geometry from the origin & {$[m]$} \\
\hline$r_{t h}$ & Radius of the throat & {$[m]$} \\
\hline$T_{0}$ & Total Temperature & {$[K]$} \\
\hline$\tilde{t}_{3}$ & Used to control the thickness of cowl & - \\
\hline$v$ & Velocity & {$\left[\frac{m}{s}\right]$} \\
\hline$\tilde{z}_{2}$ & Used to control the throat location of the intake & - \\
\hline$Z_{r}$ & Percentage of rocket flow path length & - \\
\hline$Z_{D}$ & Length along $\mathrm{Z}$-axis over the mixing duct diameter ratio & - \\
\hline$z_{g}$ & $\begin{array}{l}\text { Axial location of the gate geometry from the origin along } \\
Z_{r}\end{array}$ & - \\
\hline$z_{e}$ & $\begin{array}{l}\text { Axial location of the rocket flow path exit from the origin } \\
\text { along } Z_{r}\end{array}$ & - \\
\hline
\end{tabular}




\section{Chapter 1}

\section{Introduction}

\subsection{Brief History of Trans-Atmospheric Vehicle Propulsion}

It has been a long found dream for mankind to voyage into space. Even after 50 years since Yuri Gargarin first reached the stars, spaceflight is still not easily accessible to the general public. One of the major obstacles is cost. Rocket propulsion costs about $\$ 10,000 / \mathrm{lb}$ to go to low earth orbit because of its low specific impulse (ISP) between 300 seconds to 400 seconds. The ISP is a measure of engine efficiency and is used to determine the mass of fuel required. The higher the ISP the lower the amount of fuel that is required. Thus, it is desirable to maximize this value. Different engines currently exist with higher ISPs but they are not readily applicable. For example, ion engines can achieve a much higher ISP but do not produce enough thrust to be feasible for ground to space missions. On the contrary, air breathing engines can produce a high amount of thrust but can only operate within the atmosphere. A nuclear thermal engine is able to produce sufficient thrust as well as have a high ISP, but safety and radioactive concerns prohibit its development. Thus, rocket engines remain as the only choice for ground to space launch systems at this stage of launch 
vehicle development.

As a compromise, there have been systems in which ground to space missions have been broken up into two stages: a ground to air segment and an air to space segment. An example of this type of system can be found in SpaceShipOne for the Ansari X prize [1]. For the first segment, an air breathing turbofan jet engine was utilized. After reaching a certain altitude, a second vehicle would detach itself and rockets would then propel the vehicle into space. An air breathing engine was selected for the first stage because it can operate at a higher ISP than rockets and do not need to carry as much weight in terms of oxidizers. Engines like the turbofan jet, ramjets and scramjets all operate on this philosophy. Ramjets have existed since 1913 and it operates on the principle of compressing the incoming air to subsonic speeds via an inlet before injecting fuel and igniting the mixture [2]. Ramjets can also be combined with rockets to form a combined cycle engine called ducted rockets. It is a type of ramjet which uses solid rocket propellant to generate fuel rich gases and burns when mixed with incoming air at subsonic speeds [3]. Scramjets do not need the inlets to slow the incoming air down to subsonic speeds and combustion can occur at supersonic speeds. As such, the geometry of the engine is considerably different between a ramjet and scramjet as shown in Figure 1. Even so, there have been efforts in combining these two types of engines together such that the final product would operate using one flow path and therefore minimizing engine redundancies and overall engine weight. These engines lack the ability to operate at speeds below a Mach number of 2 since ramjets can not operate below this number. Fry [2] provides a plethora of examples of these air breathing engines.

Due to the higher ISP of air breathing engine cycles but limited operation envelope, there have been studies on how to combine rocket engine together with ramjet and scramjet cycles. At low speeds the ramjet cycle would not work and in order to make use of the surrounding air at launch, an additional cycle is needed. In a 


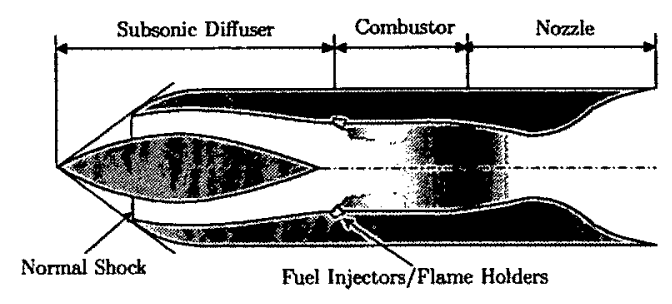

(a) Generic Ramjet Design

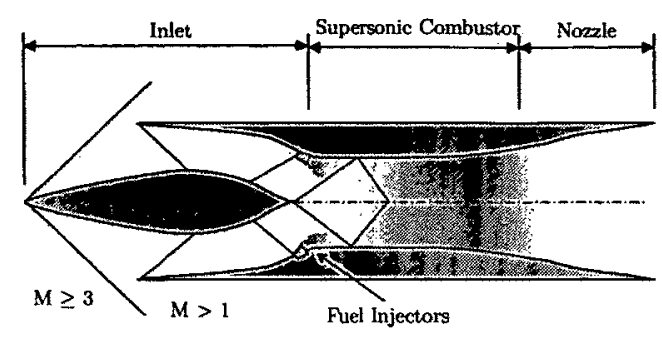

(b) Generic Scramjet Design

Figure 1: Ramjet and Scramjet Engine

study awarded by NASA in the 1960's, Marquardt, Lockheed and Rocketdyne analyzes several different types of these combined cycle engines suitable for space launch applications [4]. One of those launch options is the Rocket Based Combined Cycle (RBCC) engine. To make up for the lack of ramjet operation at low speeds the rocket motor is activated and the engine operates on the ejector effect. The increase in mass flow augments the achievable thrust. Another study by Trefny [5], looks into single stage to orbit options and considers a RBCC engine as its primary propulsion unit. It suggests that the vehicle has the potential to have an effective specific impulse of 500 seconds, implying the feasibility of such an engine to reduce launch costs $[5,6]$.

An RBCC engine is designed to incorporate four modes of operation that are traditionally treated as separate engines. These include the ejector, ramjet, scramjet and pure rocket modes of operation. A clear comparison of each mode of operation can be found in McClinton [7]. McClinton also shows a different approach in combining the cycles together. The ejector geometry can be replaced with a turbine and therefore the engine operates initially in the turbine mode instead. This combination is called the turbine based combined cycle [TBCC] engine. The TBCC engine uses a turbine to compress incoming air and thus has a high initial specific impulse. Since the air is mechanically compressed by the turbine, it requires more components adding complexity and weight to the engine. Once the engine goes into ramjet operation the 
turbine stage deactivates and becomes extra mass that does not contribute thrust $[7,8]$. In addition, since the turbine would be obstructing the air flow, either a secondary flow path would need to be incorporated or the fan blades would have to retract.

\subsection{Ejectors}

Ejectors are commonly used as mechanism to induce vacuums and compress secondary fluids. Ejectors are also applicable to supersonic jets in reducing noise pollution [9]. They are simple mechanisms with no moving parts and thus a major advantage is its simplicity. Another quality that ejectors have is that it can be used to entrain a secondary flow by an exchange of momentum using a primary flow. Figure 2 shows a typical ejector design where a higher momentum primary stream pumps the lower momentum secondary stream via momentum exchange. Thus, the performance of an ejector is based on its ability to adequately mix and equalize the momentum between the two streams [10].

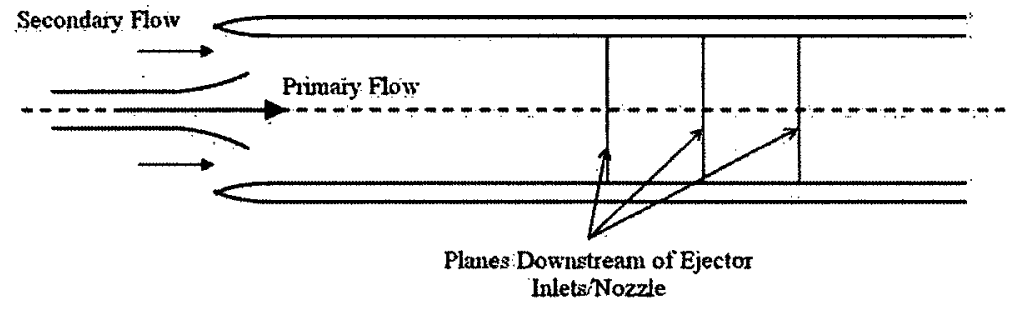

Figure 2: Typical Ejector Layout

\subsubsection{Mixing Method}

During the initial phase of flight a RBCC engine operates in the ejector mode where air is entrained by firing the rocket motor and allowing the exhaust to mix with entrained air. The extra thrust due to the increase in mass flow is called thrust augmentation. 
To further increase thrust, combustion can occur either after the mixing is complete, known as diffusion and after burning (DAB), or during mixing, known as simultaneous mixing and combustion (SMC). For efficient combustion in ejector mode, one requires a mixing duct long enough for complete mixing to occur. In $\mathrm{DAB}$ operation the rocket burns oxygen rich to prevent premature combustion and tends to lower the specific impulse. In SMC operation, air entrainment decreases due to thermal choking $[8,11]$. Therefore, depending on the mixing method chosen, different approaches can be taken to improve mixing characteristics and lead to different RBCC engine designs.

\subsection{RBCC Engines}

Given the importance of mixing to RBCC performance, and the relationship between the length of the engine to it's size and weight, researchers have found numerous innovative means to achieve high mixing in short lengths. These methods to minimize engine weight have been studied by Samitha et al. [12], Wood [13], Yungster et al. [14], Munipalli et al. [15] and Siebenhaar et al. [8]. The following section provides an overview of each type of RBCC engine and how it operates. It is by no means an exhaustive list that encompasses all existing designs, but it serves as a good summary to the various designs that exist today.

\subsubsection{Types of RBCC Engines}

A centralized rocket ejector design is shown in Figure 3. A centralized rocket design is relatively simple compared with other RBCC concepts. The rocket exhaust is simply injected into the mixing duct and an opening around the rocket allows for the entrainment of air. The figure also shows the required nozzle geometry required for each stage of operation. The top portion shows the nozzle in Ramjet/Ejector operation while the bottom shows the nozzle in Scramjet operation. Thus, an existing 
rocket engine can easily be adapted to this configuration. In an experiment using a centralized rocket stream the length of the mixing duct is predicted to be about 39 nozzle exit heights or 5 duct heights by Lehman et al. [16]. The primary flow at a Mach number of about 3.0 is injected into a rectangular prism chamber with the rocket flow at the center axis.

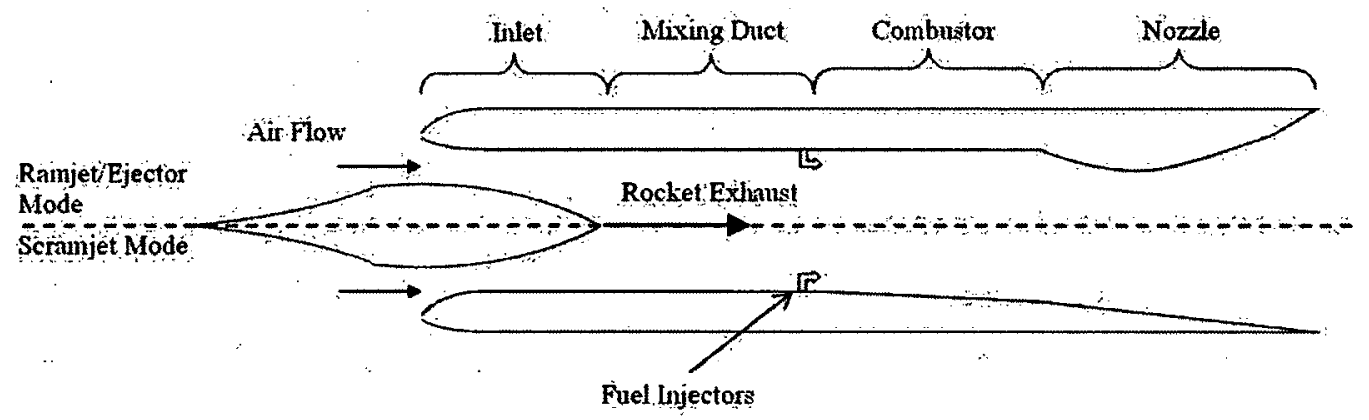

Figure 3: Typical RBCC Layout with Centralized Rocket

There are many methods to decrease the mixing duct length and some of these methods are depicted in Figure 4. Each engine is designed to improve on various aspects that ultimately decreases the engine weight. Two main approaches are taken, one is to improve the rocket air interaction and the other is by adjusting the engine configuration.

One approach for improving the rocket air interaction is by generating large vortices as shown in Figure 4a. To induce such vortices Samitha et al. [17] suggests the use of lobed nozzles. A lobed nozzle, is a nozzle design incorporating a petal shape outlet. Compared to a conventional rocket nozzle, Samitha found that mixing is improved at a rocket exhaust velocity of Mach 1.5. In his simulations and experiments, air is used to simulate both the rocket exhaust and the entrained air stream. Thus, Samitha bases his conclusion on a more uniform property distribution compared with a centralized rocket. These distributions are taken along the radial direction at certain distances downstream of the nozzle $[12,17]$. 


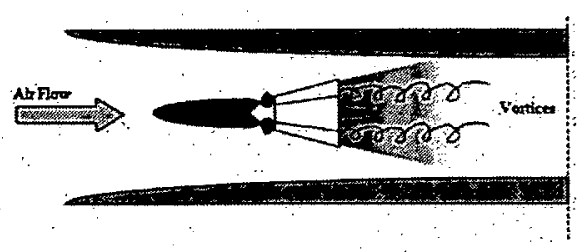

(a) Lobed Nozzle

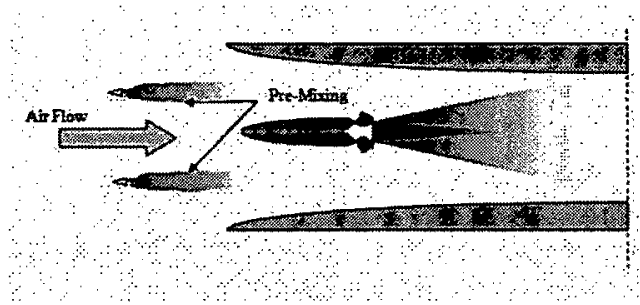

(c) Independent Ramjet Stream

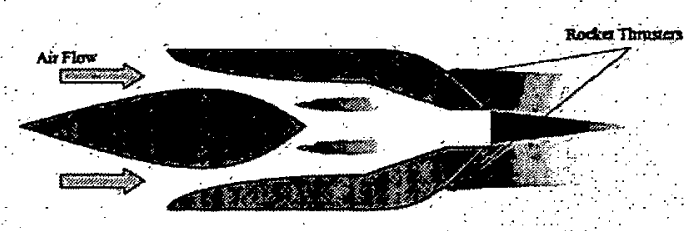

(b) Rocket Plug Nozzle Combined Cycle

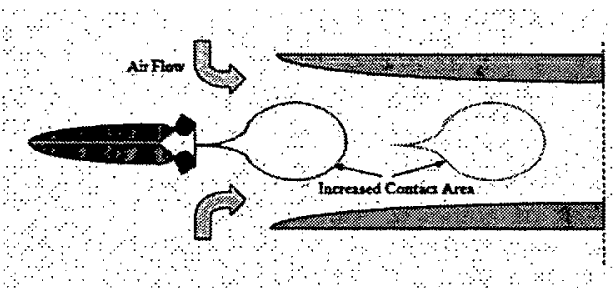

(d) Pulse Detonation RBCC

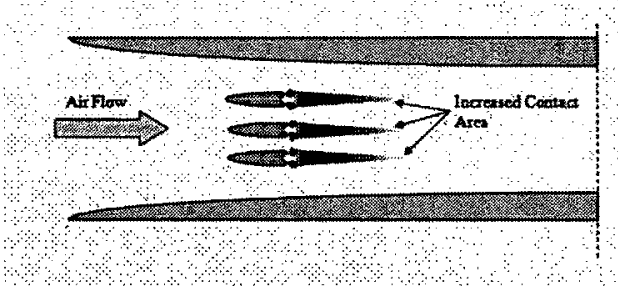

(e) Strutjet

Figure 4: Typical Ejector Layout

As opposed to improving rocket air interaction, the aerospike design uses a different engine configuration. With a slightly truncated plug nozzle [18], Wood looks into a design that combined ramjet, scramjet and rocket modes together (see Figure 4b) [13]. The Rocket Plug Nozzle Combined Cycle (RPNCC) engine does not incorporate a single flow path for the engine, but instead places the rocket in an annular fashion on the outside and the ejector effect is not considered. Since the design does not consider ejector operation, at low flight velocities the majority of the thrust comes from the rocket alone.

In the Independent Ramjet Stream (IRS) cycle, the design uses a different engine configuration to ensure complete mixing between injected fuel and air stream without increasing the duct length as shown in Figure 4c. This design is used by the GTX 
vehicle concept study by NASA [5]. Upstream of the rocket exhaust, fuel is injected into the air stream and ignites when it reaches the hot exhaust gases from the rocket. With this design the mixing duct length is significantly reduced because it does not need to be fully mixed, but Yungster et al. [14] shows that at subsonic speeds, there is no benefit to injecting fuel. Moreover he states that the IRS method's performance was lower compared to other SMC methods.

Figure 4d shows a concept that uses pulse detonation on RBCC engines. Pulse detonation is unlike conventional cycles where the process occurs at constant volume instead of constant pressure and is shown to give $10 \%$ to $40 \%$ increases in specific impulse [19]. The goal of this type of engine is to increase the shear layer between the entrained air and rocket exhaust through pulsing the exhaust gases. When the exhaust gas is pulsed, the exhaust forms in a circular shape as seen in Yi's simulations [20].

In the strutjet engine (see Figure 4e), the inlet and mixing duct are lined with struts that span the flow to increase structural rigidity and to provide hard points from which fuel can be injected. These struts are also used for flow compression and to separate the exhaust flow from the incoming air. Altogether, it enhances mixing by increasing the shear contact area and thus help to reduce the length of the mixing duct [8].

\subsubsection{Areas of Improvement}

Research has been ongoing to develop a means to produce an annular or semi-annular rocket configuration. By increasing the contact area between the rocket exhaust and entrained air, it is shown in Etele et al. [21] that mixing can be enhanced within a shorter distance. Different methods of performing this using different rocket profiles are shown in Figure 5. These profiles aim to increase contact area between the air stream and rocket stream in order to facilitate quicker mixing. [22] 


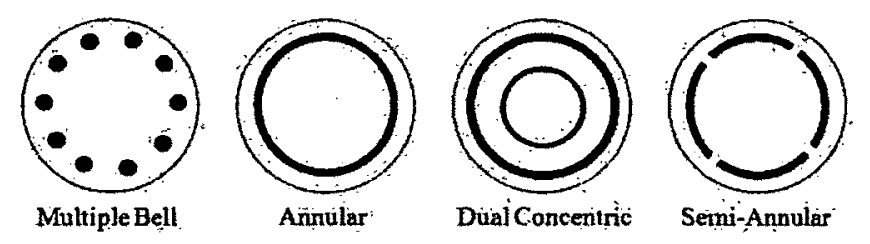

Figure 5: RBCC Rocket Profiles

In order to avoid using multiple rockets which lead to redundant systems that add to engine weight. A design that expands the rocket exhaust from a singular circular throat through multiple branches, or clovers to a semi-annular exit is proposed. This allows air to be entrained through openings between the clovers toward the center of the flow as shown in Figure 6 (Cerantola, Waung et al. $[23,24]$ ).

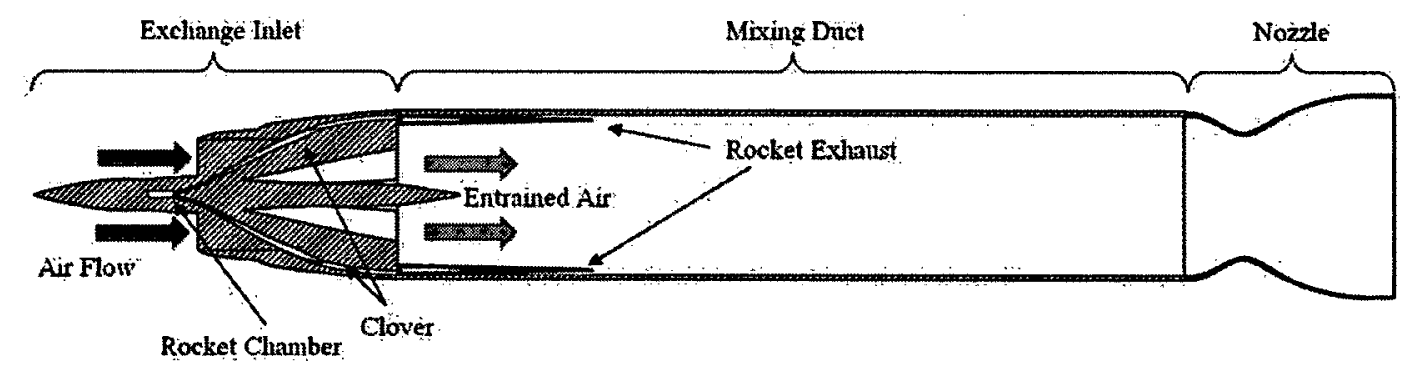

Figure 6: RBCC Engine with Exchange Inlet

In this fashion, one could use this "exchange inlet" design with existing rockets or in a dedicated RBCC vehicle as shown in Figure 7.

To obtain a semi-annular rocket exhaust profile, the exhaust gases must follow a pathway that is different from that of conventional nozzles. In a conventional rocket nozzle the rocket exhaust is allowed to expand radially. For the design in question, the rocket exhaust also needs to be guided away from the centerline while it is expanding. This resulting rocket flow geometry is called the rocket flow path (RFP). 


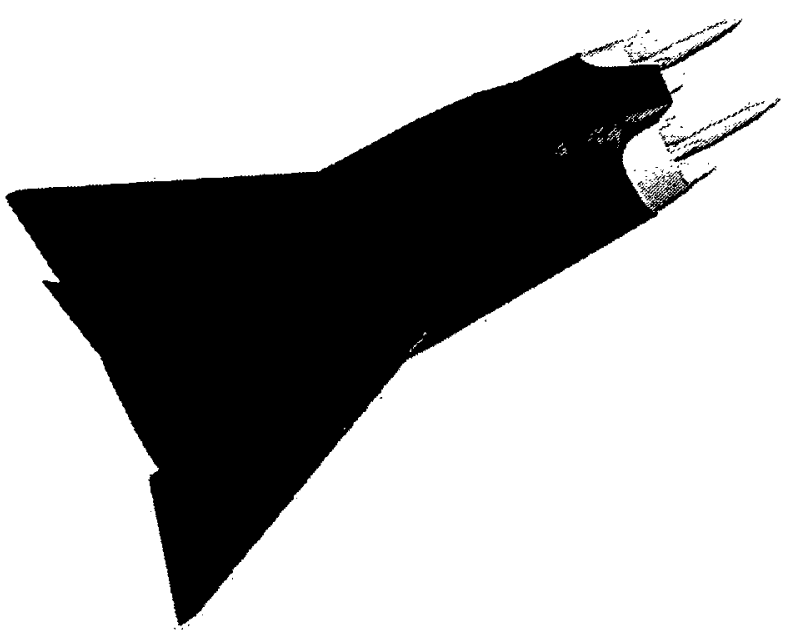

(a) RBCC Vehicle Concept

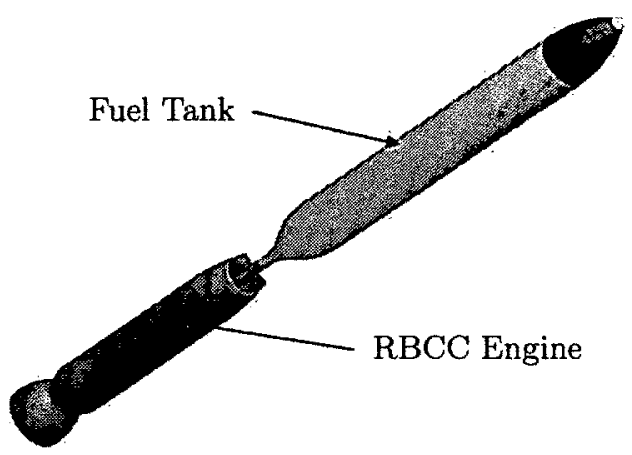

(b) Conventional Rocket Configuration RBCC Engine

Figure 7: Vehicle concepts

\subsection{Objective}

Currently the design of the exchange inlet is complete and software exists that will produce an exchange inlet geometry when given appropriate parameters. In addition, there is also an optimization program that uses a genetic algorithm to search for one of the better solution when requirements are given [25]. After designing the rocket flow path geometry for the exchange inlet, Cerantola ran several simulations using Ansys CFX for a particular set of rocket parameters [26]. Waung, after designing the intake that houses the rocket flow path, used the panel method and computational fluid dynamics (CFD) to look at the entrainment ratio of the exchange inlet [27]. Currently there is a lack of information regarding the interactions between the rocket

exhaust and entrained air within the mixing duct. Thus, this thesis will try to get data from simulations which can be used to evaluate the flow properties both within the exchange inlet itself and further downstream within the mixing duct. In addition, a parameter that can gauge the level of mixing will then be applied to the results. The goal is then to shorten the mixing duct length by determining the minimum 
required duct length for a certain level of mixing.

In this study, the parameters found in Waung are used because it produces a rocket flow path with performance similar to that of LE-7A, a Japanese first stage booster rocket [27]. Thus the goal of this research is to look into the ejector effect and study the rocket air interactions within the mixing duct in order to shorten its length. As such, the current study will be focusing on the subsonic free stream flight conditions since this is where the ejector effect is dominant. At supersonic speeds ramjet operations begins and the rocket would either shut down and have fuel injection downstream (DAB operation) or be burning at fuel rich conditions (SMC operation). 


\section{Chapter 2}

\section{Rocket Flow Path Simulation}

The rocket flow path is simulated separately from the entrained air and mixing duct segment to alleviate node quantity and distribution within the domain. The outlet profile from the rocket flow path is then used as a boundary condition to a second set of simulations involving the entire exchange inlet and mixing duct (thus including the entrained airstream). Moreover, the rocket flow path is not removed completely and replaced with a one dimensional analysis because of its unique flow geometry. In a one dimensional analysis, non-uniformities in the flow caused by the geometry are unaccounted for. This is why a one dimensional analysis would cause unrealistic shear layers to form between the rocket exhaust and entrained air. Thus, the outlet profile of the rocket flow path must first be determined using CFD before performing a rocket-air simulation within the mixing duct.

\subsection{Rocket Flow Path Creation}

The design of the rocket flow path requires a Mach number distribution, $M_{r}\left(Z_{r}\right)$, similar to the one shown in Figure 8. Here, $Z_{r}$ is the ratio of the axial location to the total rocket flow path length. The Mach number distribution is created using the theory described in Etele [28] and reproduces the performance of the LE-7A booster 
rocket. The LE-7A is part of the first stage for the H-IIA rocket from Japan [27]. Moreover, the Mach number distribution is highest at the outlet with a Mach number of 3.95 .

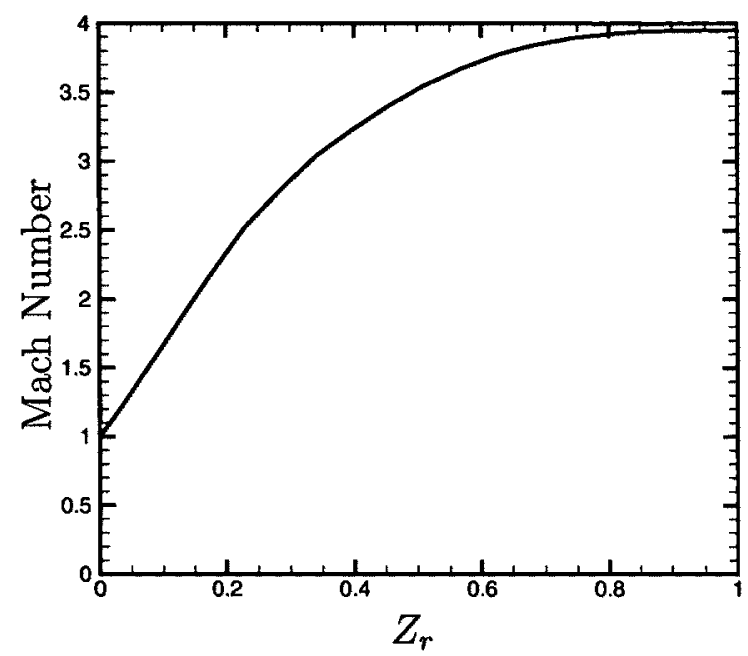

Figure 8: Mach Number Distribution (Design Outlet at Mach 3.95)

In addition, the flow is divided in circumferential sections by the number of clovers as shown in Figure 9. A gate then dictates the rocket flow path geometry by restricting the flow circumferentially at a certain distance downstream from the throat. The restricted flow geometry allows for the entrainment of air by creating an opening between the clovers.

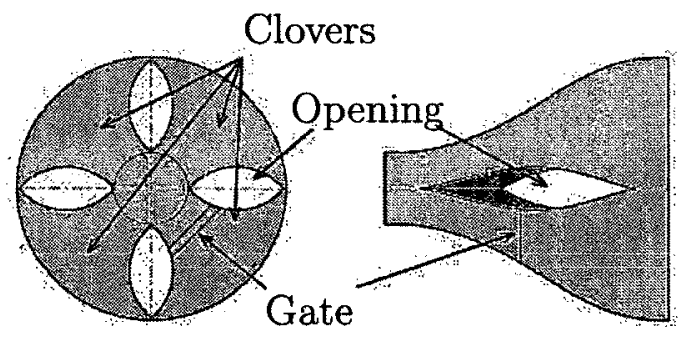

Figure 9: Rocket Flow Path Design Layout

In addition to $M_{r}\left(Z_{r}\right)$ and the number of clovers, the overall rocket flow path is controlled using eight additional variables. There is one for the throat geometry, 
four for the gate geometry and three more for the exit geometry. These variables are shown in Figure 10a and 10b. Here, $r_{t h}$ defines the radius of the throat. Then $z_{g}$ and $r_{g}$ determine the location of the gate with respect to the origin and the centerline axis. The parameter $z_{e}$ is not one of the eight variables because it is calculated from the Mach number distribution when given $r_{t h}$. Then, $r_{e}$ determines the location of the outlet of the rocket exhaust with respect to the centerline axis. In addition, $\psi_{g}$ and $\psi_{e}$ define the circumferential width of the gate and outlet respectively. The exit angle of the flow is then controlled by $\phi_{e}$. Finally, $r_{f}$ is the fillet radius and it is needed to piece the remaining geometry together. Moreover, for a fully annular exhaust, the multiple between $\psi_{e}$ and the number of clovers must be exactly $2 \pi$. Since the gate geometry is what creates the opening for the incoming air, the circumferential width of the gate $\left(\psi_{g}\right)$ has a significant effect on the resulting area available for air entrainment. This is also true for $r_{f}$. The parameter $\phi_{e}$ is also important since it can control at what angle the flow enters the mixing duct and as well control how much the flow is turned. For a more information regarding the rocket flow path design parameters please refer to Cerantola [26].

Then applying theory described in Cerantola [26], a Matlab program first solves the isentropic equation using a one-dimensional analysis. The analysis assumes that the flow is compressible, at steady state and in the absence of chemical reactions. In going from the one dimensional analysis to the three dimensional geometry, viscous considerations are also given and a displacement thickness is added to the inviscid geometry profile. 


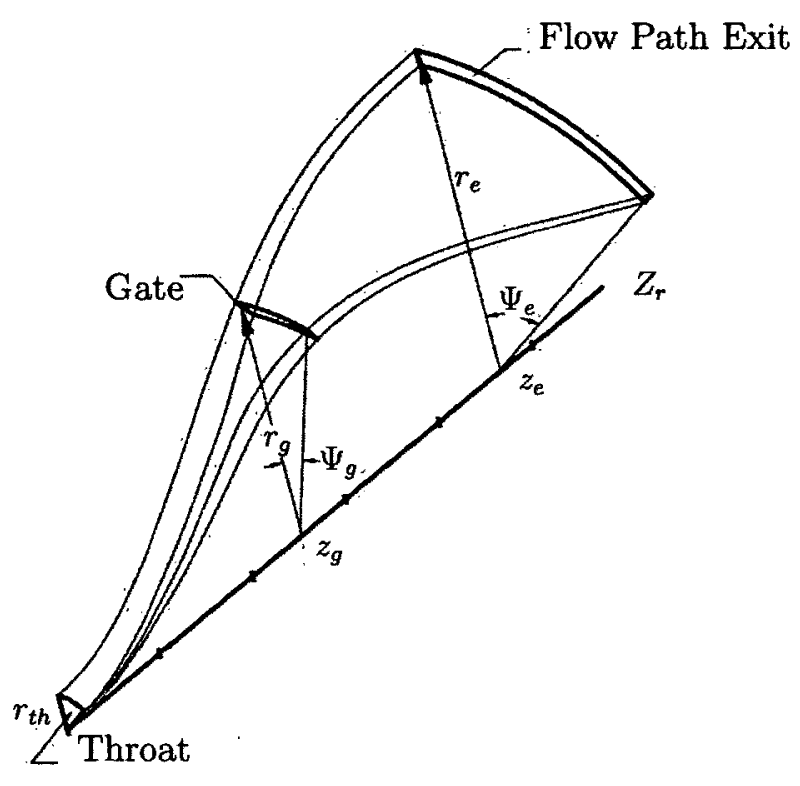

(a)

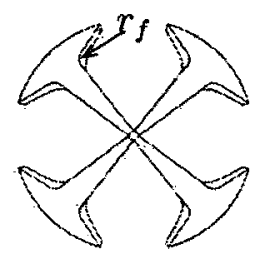

(b)

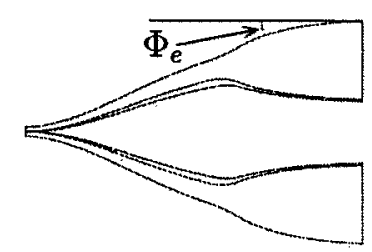

Figure 10: Rocket Flow Path Configuration and Parameters

The input parameters that define the rocket flow path for the current study are shown in Table 1. This particular rocket flow path configuration is shown in Figure 10 and the set of parameters used will be referred to $R F P_{W}$ in later sections.

Table 1: Rocket Flow Path Parameters

\begin{tabular}{r|rrrrrrrr} 
Parameter & $r_{t h}[\mathrm{~m}]$ & $r_{f}[\mathrm{~m}]$ & $r_{g}[\mathrm{~m}]$ & $z_{g}[\mathrm{~m}]$ & $\psi_{g}[\mathrm{deg}]$ & $r_{e}[\mathrm{~m}]$ & $\psi_{e}[\mathrm{deg}]$ & $\phi_{e}[\mathrm{deg}]$ \\
\hline Value & 0.121 & 0.27 & 2.5 & 3.9 & 10 & 3.1 & 28 & 1
\end{tabular}

\subsubsection{Single Rocket along the Centerline Creation}

The single rocket along the centerline $(S R C)$ flow geometry as the name suggest will not direct the exhaust gases out to form an annular rocket profile but will use a more conventional approach. This is done to determine the differences with mixing behaviour between the $R F P_{W}$ design and the $S R C$ design. This comparison will help 
determine the changes in mixing characteristics due to difference in shear layer and highlight any improvements $R F P_{W}$ has on the $S R C$.

It is found that when creating the $S R C$ rocket area distribution $\left(A_{r}\left(Z_{r}\right)\right)$, the original distribution from the $R F P_{W}$ case should not be used since it has a circular profile shape instead of a annular profile. The reason for this originates from the viscous consideration. When a displacement thickness is added, a certain boundary layer growth is calculated based on the inviscid flow conditions [26]. This displacement thickness is added to all wall surfaces. This is shown in Figure 11a for the $R F P_{W}$ flow path. In a circular nozzle configuration, this creates a difference in the resulting area as shown in Figure $11 \mathrm{~b}$ for the $S R C$ flow path. Since the $R F P_{W}$ flow path follows a semi-annular profile, the resulting area is much higher than with the case with a circular nozzle. Comparing the areas at the outlet plane, the $R F P_{W}$ flow path had an area that is $26.4 \%$ higher. Thus the area distribution for the $S R C$ flow path is calculated based on the configuration shown in Figure $11 \mathrm{~b}$ instead of matching $A_{r}\left(Z_{r}\right)$. The $S R C$ flow path would then be placed along the centerline and be part of the centrebody.

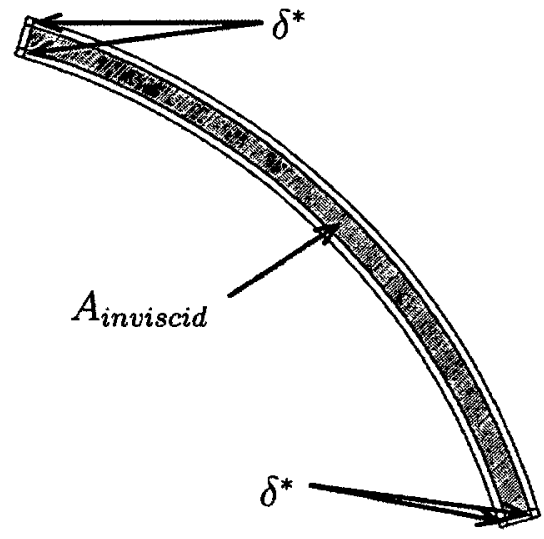

(a) $R F P_{W}$

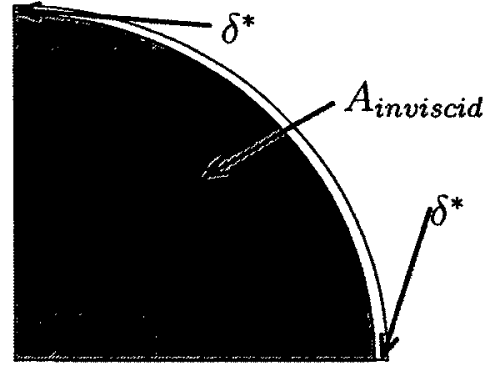

(b) SRC

Figure 11: Addition of Displacement Thickness $\delta^{*}$ along Wall Surfaces 
By comparison, the $S R C$ rocket flow path has a lower contact surface area and it allows the flow to expand radially without turning the flow outwards. These changes affect the properties of the flow and thus should be incorporated in the comparison. Therefore, the $S R C$ flow path will also be simulated and the resulting rocket profile is used in a modified exchange inlet simulation. The layout of the $S R C$ flow path is then shown in Figure 12.

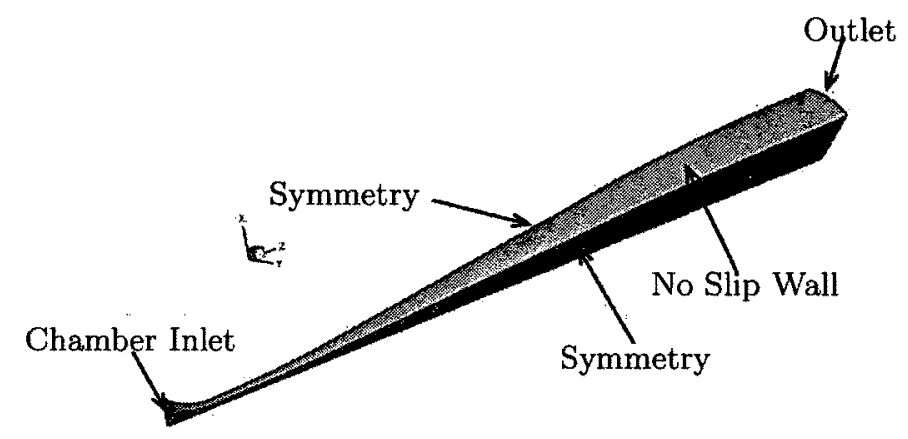

Figure 12: SRC - Layout

\section{$2.2 \quad$ Fluid Model}

All numerical results are obtained using ANSYS CFX 12.1 which is a three dimensional Reynolds Averaged Navier-Stokes solver. An first order accurate upwind scheme is used and the steady state solution is obtained. Moreover, a convergence criteria of $10^{-6}$ for RMS values was utilized.

Menter's Shear Stress Transport (SST) turbulence model [29] is used for all simulations unless specified otherwise. For supersonic ejectors, Bartosiewicz et al. [30] shows that the ReNormalization Group (RNG) $k-\epsilon$ and the SST models are best suited to predict shock phase and strength compared to other turbulence models. Furthermore, it is known that the k-epsilon model is computationally quicker than the SST model, but it is also known that for regions of reverse flow the k-epsilon model over predicts separation [31]. In addition, the SST model is also used as the 
turbulence model for many other RBCC studies $[17,32,33]$. Thus, for these reasons the SST model is chosen.

For the Menter's SST turbulence model, it is desirable to have at least 10 nodes within the boundary layer. The results are checked to ensure that this condition is satisfied. This model will also be compared with two other models to identify its behaviour. The other models studied are the RNG and $k-\omega$ turbulence model and the results are shown in Chapter 3.

\subsection{Domain}

The computation domain for the rocket flow path is shown in Figure 13. A chamber is added upstream of the throat to avoid having to specify sonic conditions. A structured grid is used for the simulations and is shown in Figure 14. At the inlet of the chamber, the total pressure and total temperature are specified as $121[\mathrm{MPa}]$ and $3660[\mathrm{~K}]$ to resemble the performance of the LE-7A booster rocket [27].

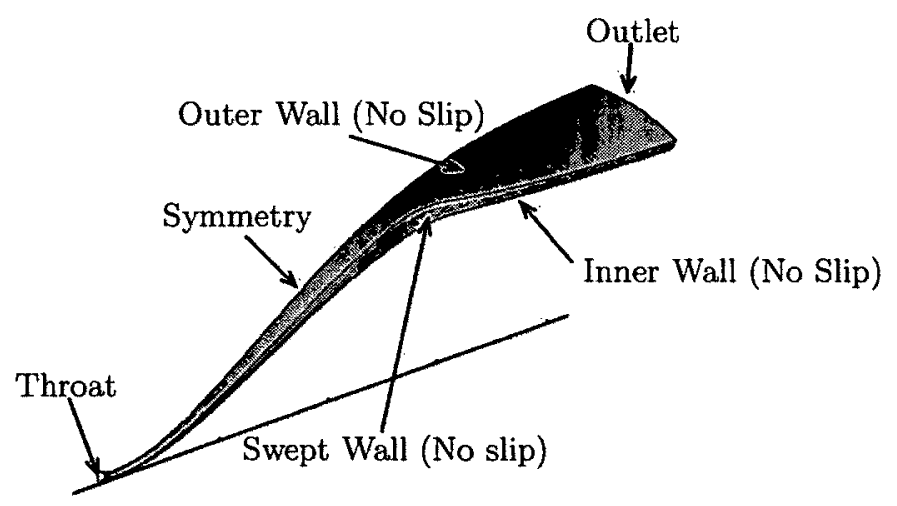

Figure 13: Rocket Flow Path Domain

Referring to the labels shown in Figure 13, the outlet plane is set as supersonic and the walls are set to no-slip except for the symmetry plane. For a supersonic outlet condition all values are dependent variables and are extrapolated from upstream values [34]. Therefore, since the outlet is supersonic no additional boundary conditions 
Table 2: Rocket Exhaust Species by Mass

\begin{tabular}{crrrr} 
Chemical Specie & $\mathrm{H}_{2}$ & $\mathrm{O}_{2}$ & $\mathrm{OH}$ & $\mathrm{H}_{2} \mathrm{O}$ \\
\hline Percentage (\%) & 4 & 1 & 7 & 88
\end{tabular}

are required.

Table 2 lists the composition of the rocket exhaust used in the simulations as obtained using Gibbs minimization technique [35]. The combustion of $\mathrm{H}_{2}$ and $\mathrm{O}_{2}$ is considered at an equivalence ratio of 1.33 and a chamber pressure of 121 [MPa]. Then the species thermodynamic data is taken from NASA polynomials [36]. Finally, no reactions are incorporated in the simulations.

\subsection{Grid Convergence Study}

An example of the structured grid is shown in Figure 14. In the first figure, the entire grid is shown. In Figure 14b, a close up of the mesh can be seen. The first node is kept at $0.0001[\mathrm{~m}]$ away from the wall and a spline distribution is set to put additional nodes close to the wall.

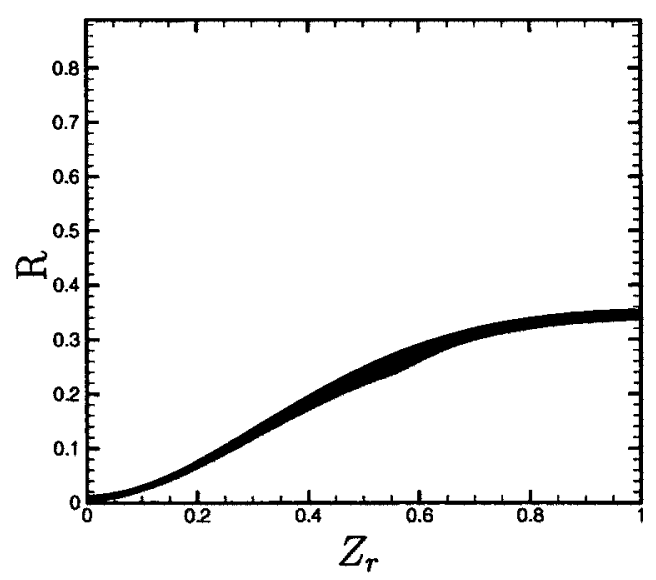

(a) Domain

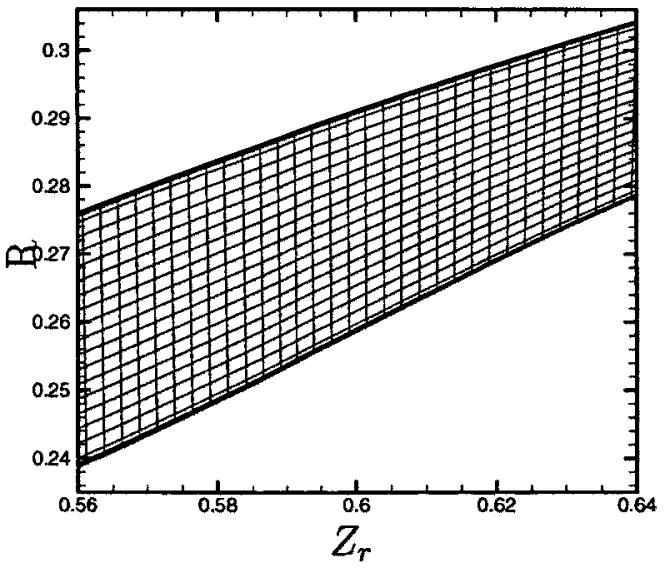

(b) Closeup of Structured Mesh

Figure 14: Rocket Flow Path Mesh 
Then starting from the coarse grid, additional nodes are added to each dimension for each level of refinement resulting in an overall finer mesh. Meanwhile the quality of the mesh for each resulting level of refinement is checked to make sure that there are no elements that have a mesh quality of less than $70 \%$. The mesh quality measures an individual element's orthogonality, expansion and aspect ratio. Here, orthogonality is a measure of how far off from perpendicular an internal angle is. Expansion relates the rate of change of an element comparing it to adjacent elements. The aspect ratio looks at the elongation of the element. In other words, mesh quality essentially determines if a element is inverted, folded or tangled and if it has excessively small or large angles that can lead to poor shape and other undesirable properties [34,37]. When a simulation uses a mesh with a poor mesh quality, it can produce erroneous results and thus should be avoided. For each level of refinement Freitas et al. [38] suggests a Grid Refinement Factor (GRF) of 1.3 or greater where GRF is a function of the representative cell length $\Delta h$ as shown in equation 1.

$$
G R F=\frac{\Delta h_{\text {coarse }}}{\Delta h_{\text {medium }}}=\frac{\Delta h_{\text {medium }}}{\Delta h_{\text {fine }}}
$$

where for a structured mesh, $\Delta h$ is defined as

$$
\Delta h=\left[\Delta x_{\max } \Delta y_{\max } \Delta z_{\max }\right]^{1 / 3}
$$

The three grid sizes for the $R F P_{W}$ are shown in Table 3. The GRF value between the coarse and medium mesh is found to be 1.48 and for the medium and fine mesh the GRF value is calculated to be 1.39. Both of which are higher than the recommended value.

Table 4 compares the mass averaged conditions at the outlet across the three meshes. Out of the variables shown, the maximum difference between the coarse and medium mesh is $1.24 \%$ and for the medium and fine mesh the maximum difference 
Table 3: Rocket Flow Path Mesh Sizes

\begin{tabular}{rrrr} 
& Coarse & Medium & Fine \\
\hline Nodes & 278400 & 887600 & 2460150 \\
Elements & 258951 & 848776 & 2378816
\end{tabular}

Table 4: Rocket Flow Path Mesh Sizes

\begin{tabular}{rrrr} 
& Mach Number [\%] & Pressure [\%] & Mass Flow Rate [\%] \\
\hline Coarse to Medium & 1.24 & 1.05 & 0.34 \\
Medium to Fine & 0.34 & 0.58 & 1.06
\end{tabular}

is $1.06 \%$. Figure 15 shows the variation of Mach number and pressure along Z. As shown, the figure suggests that even by tripling the amount of nodes each time, the finer meshes do not visibly cause large variations in the selected properties.

Using the GRF values, Table 4 and a suggested safety factor of 1.25 , a Grid Convergence Index (GCI) value can be calculated to access the uncertainty with the grid [38]. This value is calculated for Mach number, pressure and massflow rate at the outlet with a $95 \%$ confidence interval. The highest GCI value is with the Mach number and is reported to be $4.4 \%$. This translate into an uncertainty of $3.37 \pm 0.15$ (4.4\%). The uncertainty for pressure and massflow rate are then $40.3 \pm 1.01(2.5 \%)$ $[\mathrm{kPa}]$ and $31.3 \pm 0.06(0.2 \%)[\mathrm{kg} / \mathrm{s}]$. 


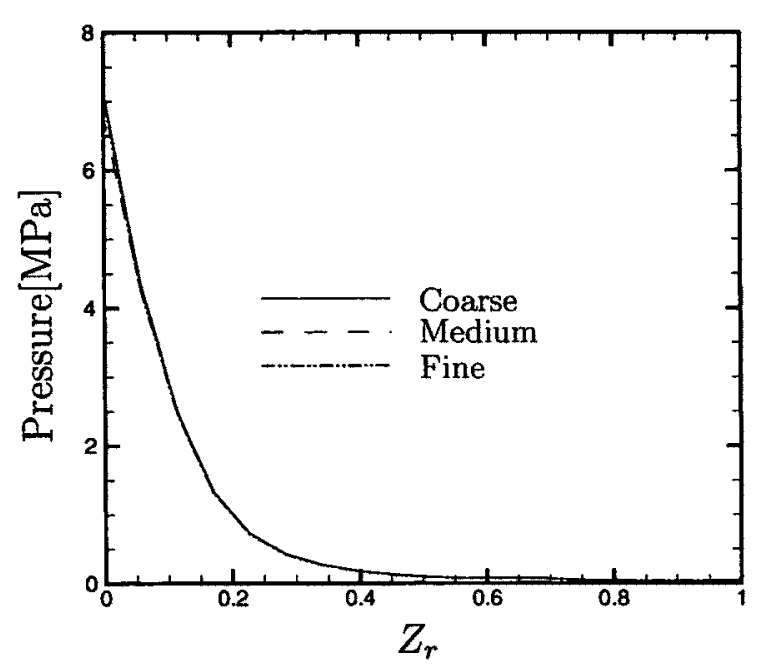

(a) Pressure

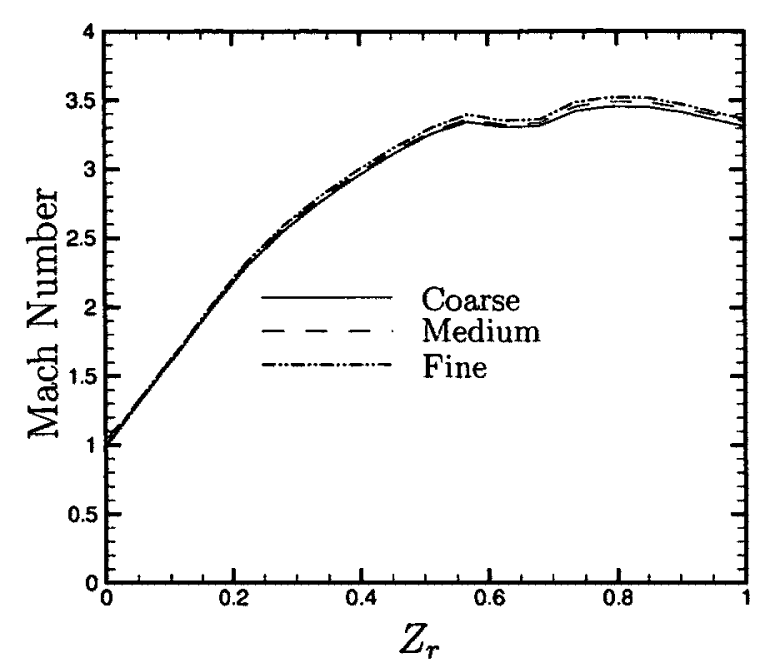

(b) Mach Number

Figure 15: Mass Flow averaged Variations along $Z_{r}$

\subsection{Results and Comparison}

The first two sections will look at each rocket flow path separately, after which a comparison will be made. To analyze the results for each rocket flow path simulation, plots using the Mach number and total pressure will be used. The selected properties are used to show the behaviour of the flow as it expands along the rocket flow path. Moreover, the mass averaged Mach number distribution will also be used to assess the performance. Meanwhile, contour plots will be used to highlight flow characteristics unique to the rocket flow path geometry.

\subsubsection{RFP $P_{W}$ Results}

For the $R F P_{W}$ design, the mass flow averaged Mach number at the outlet is found to be lower than the design Mach number by 0.58 (14.7\%). Moreover, the Mach number 
distribution along $Z_{r}$ is shown in Figure 16. Comparing with the reference distribution, the $R F P_{W}$ simulation shows that the Mach number does not vary smoothly from the throat to exit. At a $Z_{r}$ value of approximately 0.57 , there is a noticeable decrease in the Mach number. This drop occurs between $Z_{r}$ of about 0.57 to 0.67 . At which point the Mach number begins to increase once again until up to about a $Z_{r}$ of 0.85 . After this point the Mach number starts decreasing again. This can be explained by looking at Figure 17. It shows the pressure gradient for a portion of the rocket flow path along the symmetry plane. Looking at the abrupt increases in this gradient, a weak oblique shock wave that is reflected along the rocket flow path is the most probable cause. This decreases the total pressure and thus lowers the Mach number at the rocket outlet plane.

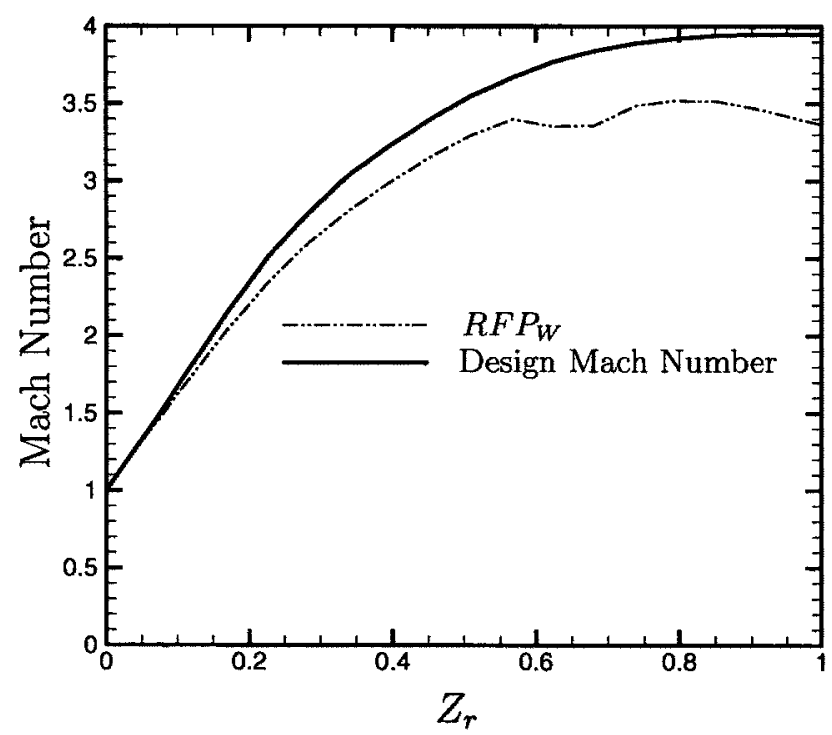

Figure 16: Mach Distribution Comparison

The Mach number profile at the different cross sections along $Z_{r}$ is shown in Figure 18. As expected the Mach number profiles are significantly different from that of a uniform profile using a one dimensional analysis. Since the Mach number along the shear layer between the rocket exhaust and entrained air is critical when 


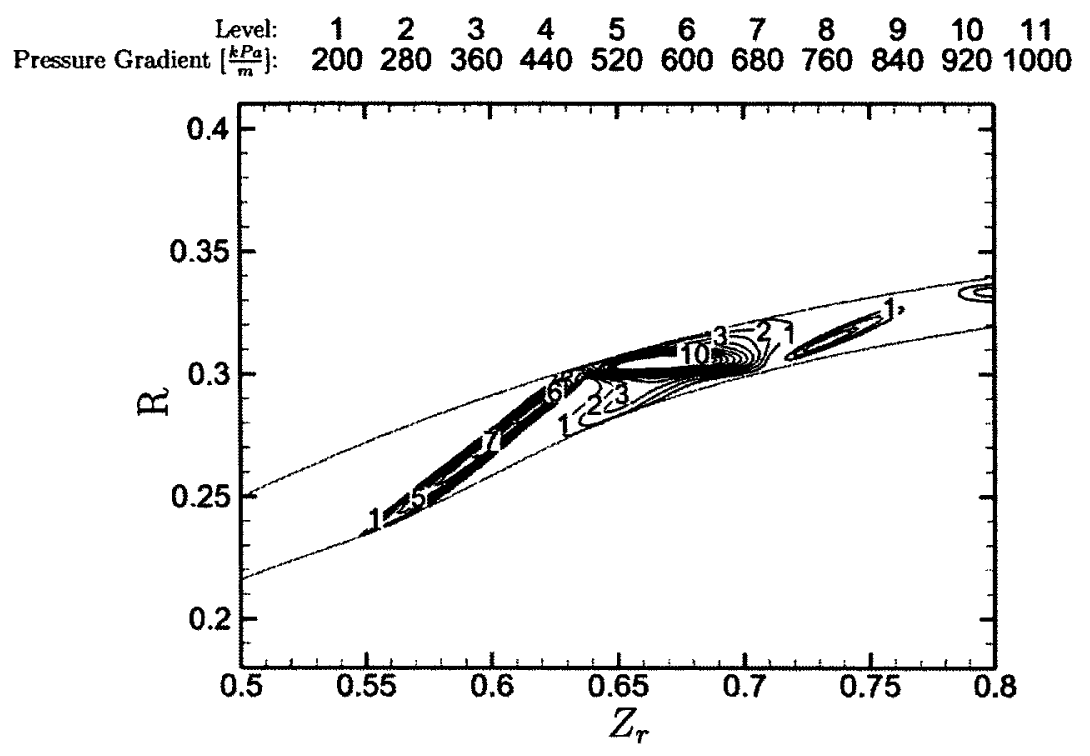

Figure 17: Contour Plot: Pressure Gradient

studying the mixing characteristics, this means that the rocket flow path simulation can not be ignored. Looking at the Mach number profile and the pressure profile in Figures 18 and 19, it is seen that the flow has unique characteristics. In Figure 18 , the flow accelerates uniformly until $Z_{r}$ equals to about 0.5 . The contour shows that a non-uniform flow behaviour is starting to emerge in the region where the flow is accelerated more than the rest. The flow accelerates in this manner since the geometry profile at $Z_{r}$ equal to 0.5 changes more rapidly in the radial direction than the circumferential direction. As the geometry profile extends in the circumferential direction, the flow expands outwards circumferentially and accelerates more quickly closer to the side walls. In the radial direction, contraction occurs and since the flow is supersonic it would tend to decelerate. This phenomenon is seen in the cross section at 0.6 where the Mach 3.5 contour line skews towards the side walls. At 0.7 , the accelerated flow continues to expand in the circumferential direction and the region where the Mach number is greater than 3.5 is skewed even more leaving behind a region of flow that is below Mach 3.5 at the symmetry plane. At 0.8 , the geometry 
profile start to change less rapidly in the circumferential direction and as such the geometry stops contracting in the radial direction. This is apparent considering how the Mach 3.5 region spreads all the way to the symmetry plane. At 0.9 and at the outlet, the flow decelerates closer to the side walls since there is very little expansion in the circumferential direction. It is also affected by the boundary layer growth and this effect is increased further closer to the corners since the boundary layers interact in this region.

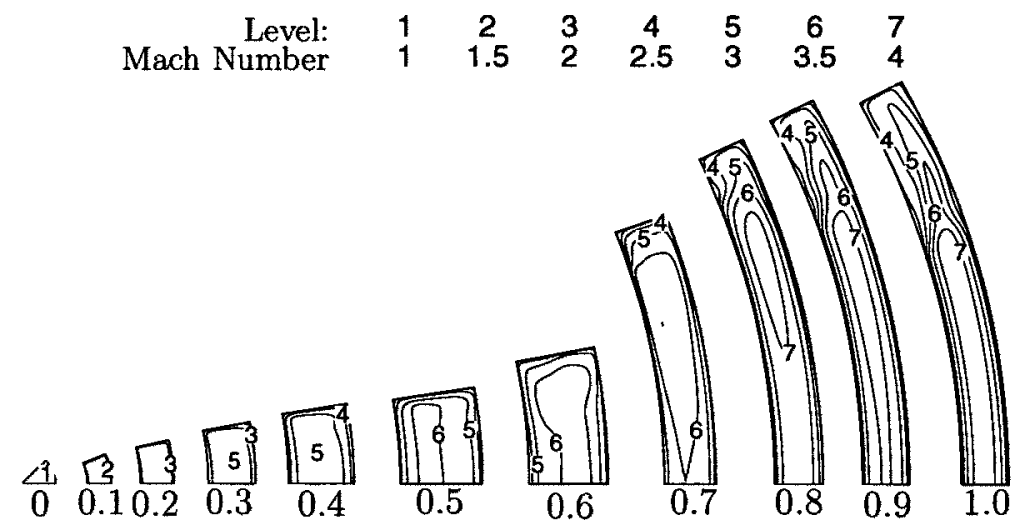

Figure 18: Mach Number Contour Plot for Sections along z-axis

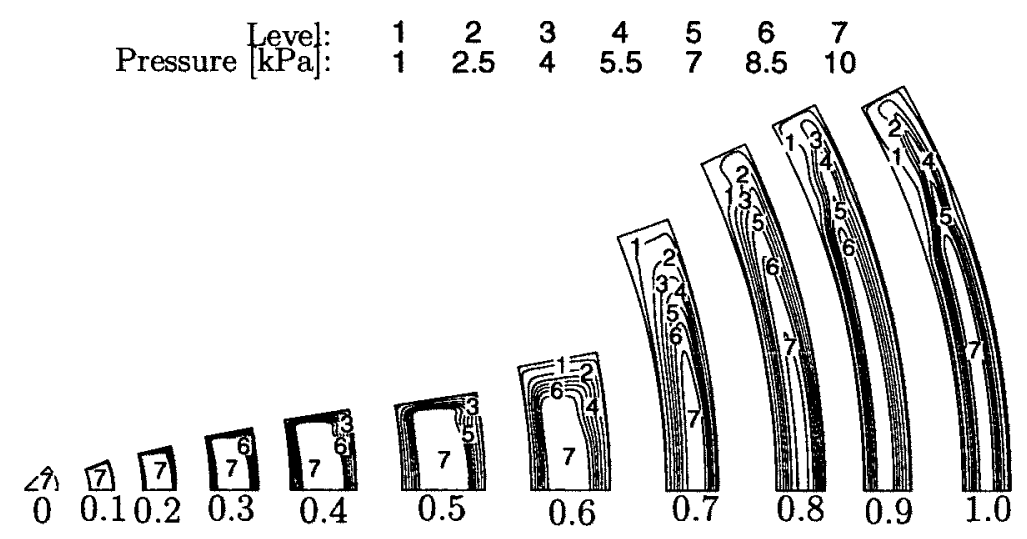

Figure 19: Total Pressure Contour Plot for Sections along z-axis 


\subsection{Shock Alleviated Rocket Flow Path}

In an attempt to negate the shockwave found in Figure 17, a different rocket flow path is created using different input parameters. The goal of the exercise is to demonstrate that even if the $R F P_{W}$ design creates some undesirable flow structures it does not necessarily mean that it can not be avoided or alleviated. The design of the rocket flow path is flexible enough to account for this.

Table 5: Rocket Flow Path Parameters

\begin{tabular}{r|rrrrrrrr} 
Parameter & $r_{t h}[\mathrm{~m}]$ & $r_{f}[\mathrm{~m}]$ & $r_{g}[\mathrm{~m}]$ & $z_{g}[\mathrm{~m}]$ & $\psi_{g}[\mathrm{deg}]$ & $r_{e}[\mathrm{~m}]$ & $\psi_{e}[\mathrm{deg}]$ & $\phi_{e}[\mathrm{deg}]$ \\
\hline Value & 0.121 & 0.3 & 2.5 & 3.9 & 18 & 3.1 & 28 & 1
\end{tabular}

The shock alleviated rocket flow path $\left(R F P_{S A}\right)$ is generated using the parameters in Table 5. Comparing this geometry with the $R F P_{W}$ flow path in Figure 20, it can be seen that the new flow path is wider circumferentially. Furthermore looking at Figure $20 \mathrm{a}$, the rate of expansion in the circumferential direction along $Z_{r}$ is more uniform with the $R F P_{S A}$ flow path. In Figure 20b, it is shown that the $R F P_{W}$ flow path is thickest at the halfway point between the throat and the outlet. This causes the thickness to initially increase and then decrease. This is different from the $R F P_{S A}$ flow path which is more slender and the thickness does not increase and decrease noticeably. The region where the thickness decreases is also the region where the high pressure gradients occur in Figure 17. 


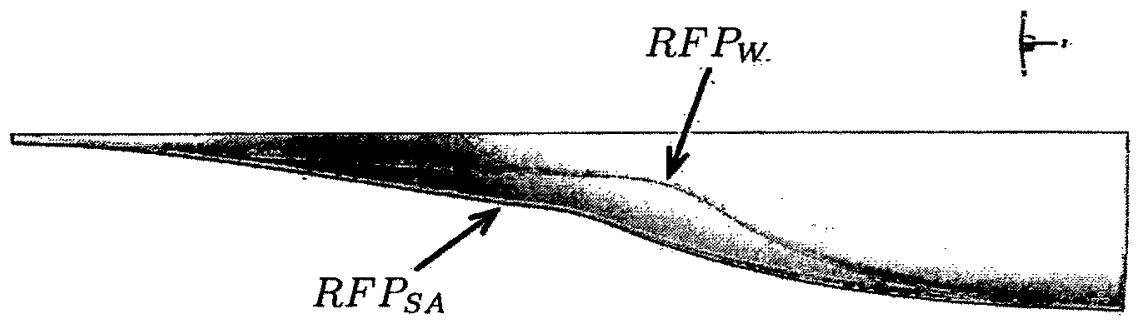

(a) Circumferential View

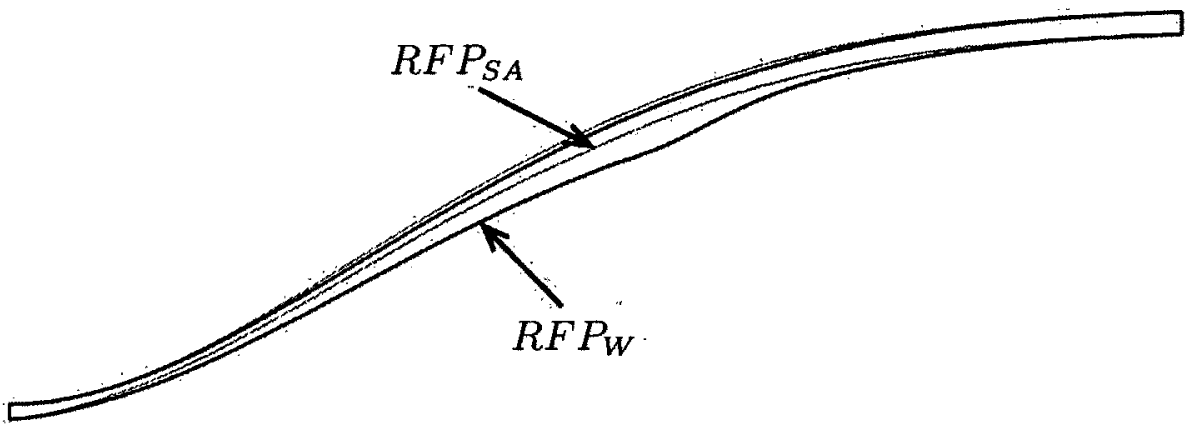

(b) Symmetry Plane

Figure 20: Geometry of the two Rocket Flow Path Designs

Figure 21 plots the pressure gradient for the $R F P_{S A}$ in the same region as Figure 17. It shows that the pressure gradient has lowered with the maximum gradient being only $18.3 \%$ of that in the $R F P_{W}$ flow path. Moreover, the oblique shock pattern observed previously is also absent. 


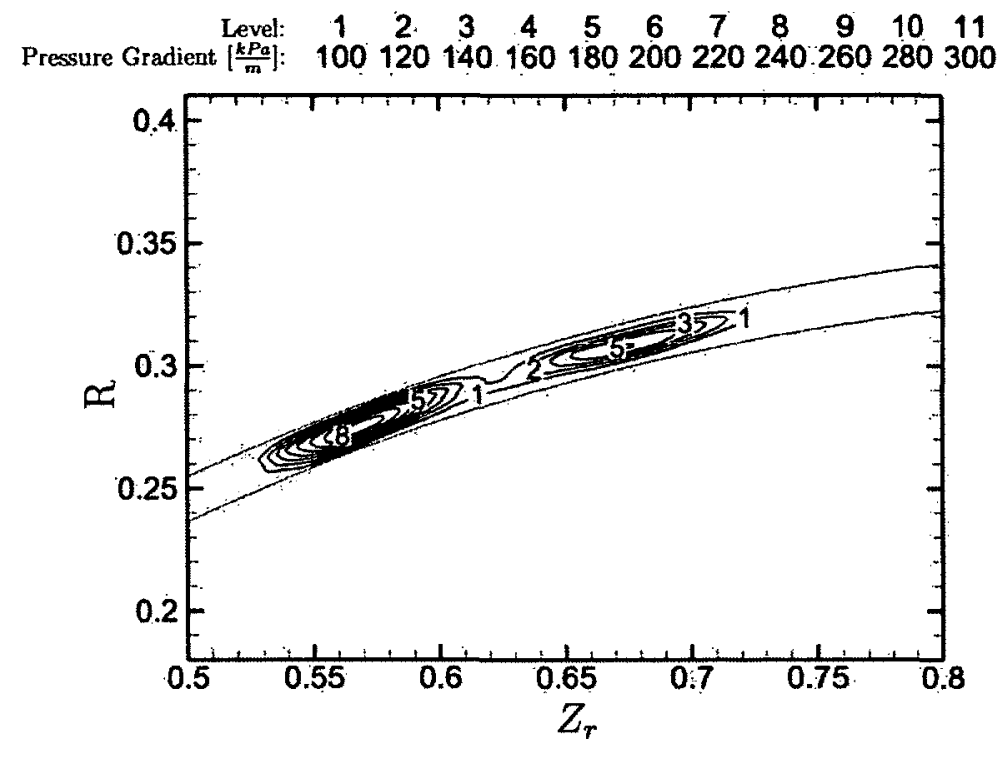

Figure 21: Contour Plot: Pressure Gradient

The Mach number variation along $Z_{r}$ is plotted in Figure 22. In the case of the $R F P_{S A}$ design, the flow structure that causes the Mach number to decrease between 0.57 and 0.67 is not present. Even so, the performance of the $R F P_{S A}$ design is not as good as expected. The rocket flow expands smoothly until $Z_{r}$ equal 0.2 . After this point the mass flow averaged Mach number becomes lower than that of the $R F P_{W}$ design. The only exception to this is when the Mach number drops at 0.57 for the $R F P_{W}$ case.

The lower overall Mach number is due to an increase in the wall surface area. The original rocket flow path has a wall surface area of $12.8\left[\mathrm{~m}^{2}\right]$ and the $R F P_{S A}$ has a wall surface area of $15.8\left[\mathrm{~m}^{2}\right]$. Thus, more of the flow is affected by boundary layer growth and it therefore lowers the Mach number at the outlet. 


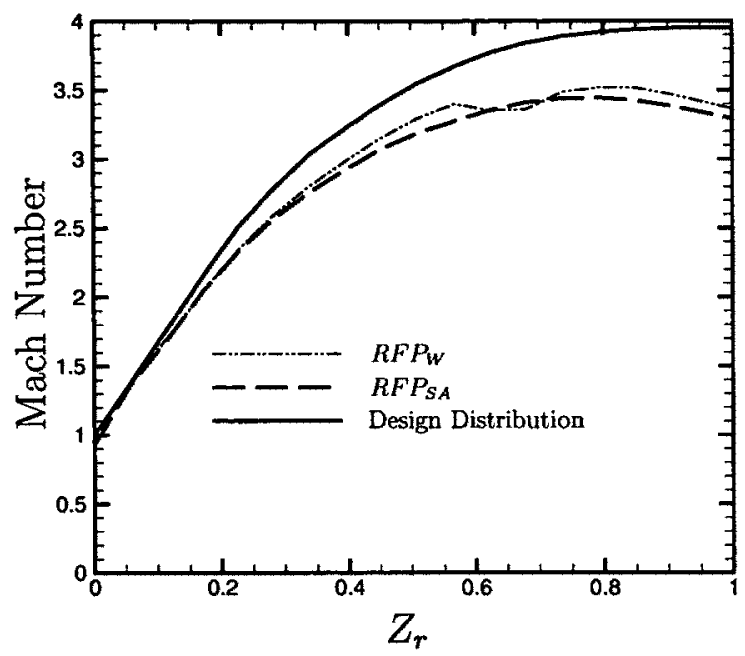

Figure 22: Mach Number Comparison between $R F P_{W}$ and $R F P_{S A}$

As such when designing the rocket flow path, the designer should also account for the wall surface area and try to minimize this. Moreover, the geometry should not contain abrupt changes as shown by the $R F P_{W}$ design in Figure 20. The geometry should be allowed to expand gradually without abrupt changes to the circumferential angle and thickness.

\subsubsection{Single Rocket along the Centerline}

The Mach number distribution for the SRC flow path is shown in Figure 23. The shockwave found in the $R F P_{W}$ flow path is not present in the $S R C$ flow path and is one of the reasons why the Mach number is higher. The $S R C$ flow path has a wall surface area of $3.41\left[\mathrm{~m}^{2}\right]$ while the $R F P_{W}$ flow path has a wall surface area of 12.8 $\left[\mathrm{m}^{2}\right]$. The difference in wall surface area is apparent when comparing Figure 12 with Figure 13. The lower wall surface area means that less total pressure is lost to wall shear and as such it also contributes to the higher exit Mach number.

Figure 24 show the Mach number cross sectional plot similar to the analysis done for the $R F P_{W}$ design. In this case there are no complex flow structures present. The 


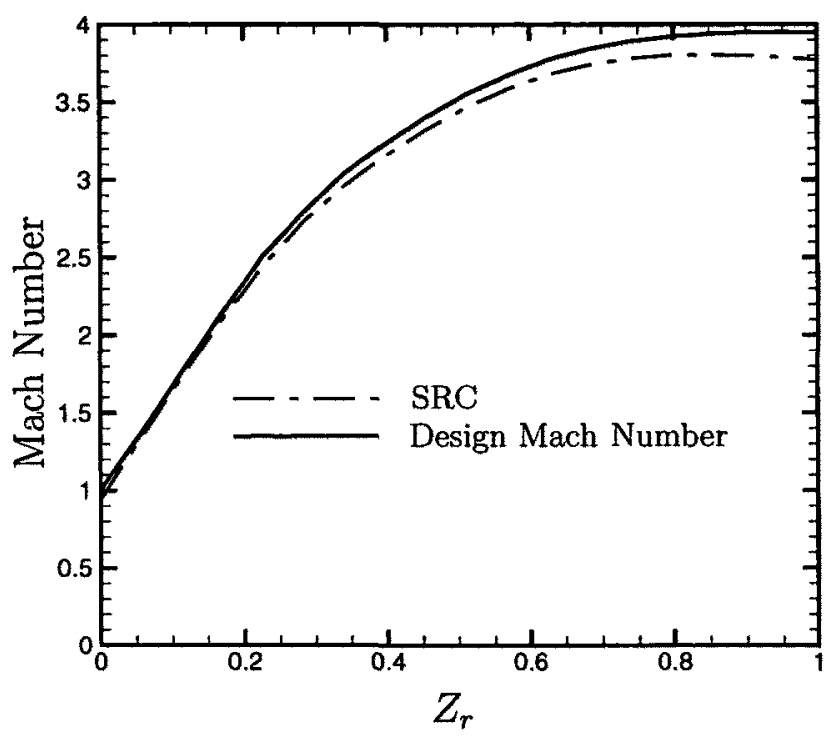

Figure 23: Mach Distribution Comparison, SRC

circular contour lines suggest that the flow has a axis-symmetrical behaviour.

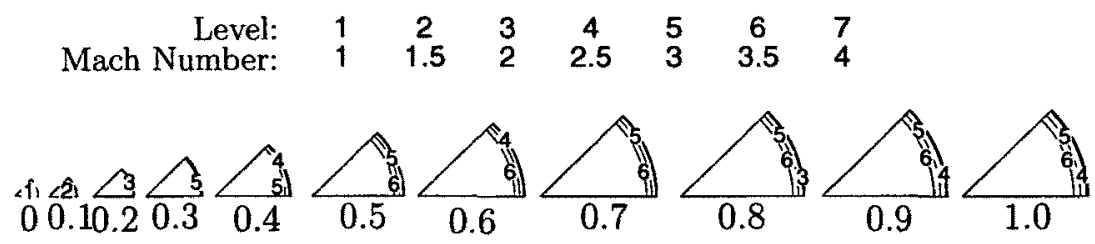

Figure 24: SRC Mach Number Cross Section Contour Plots

The Mach number and total pressure variations along the symmetry plane in the axial direction $Z_{r}$ are shown in Figures $25 \mathrm{a}$ and $25 \mathrm{~b}$ respectively. The Mach number profile shows that only a small portion of the flow is affected by boundary layer growth and does not reach the design Mach number. 


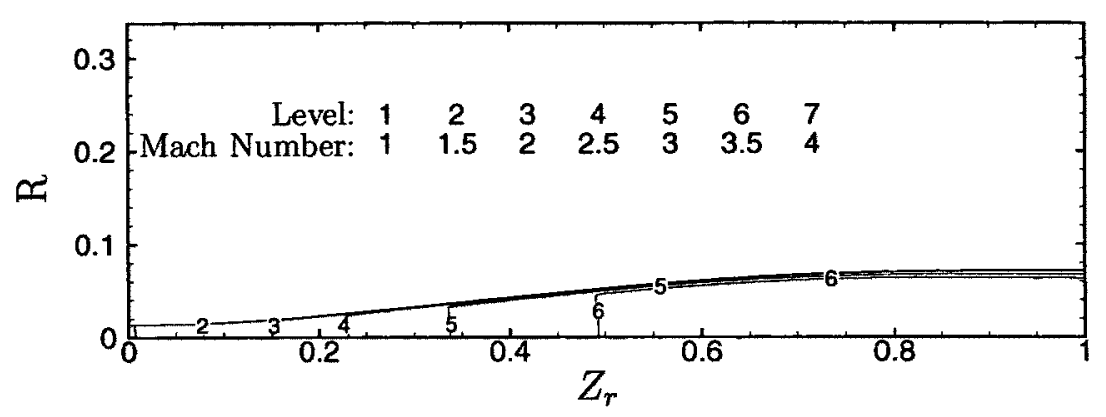

(a) Mach Number

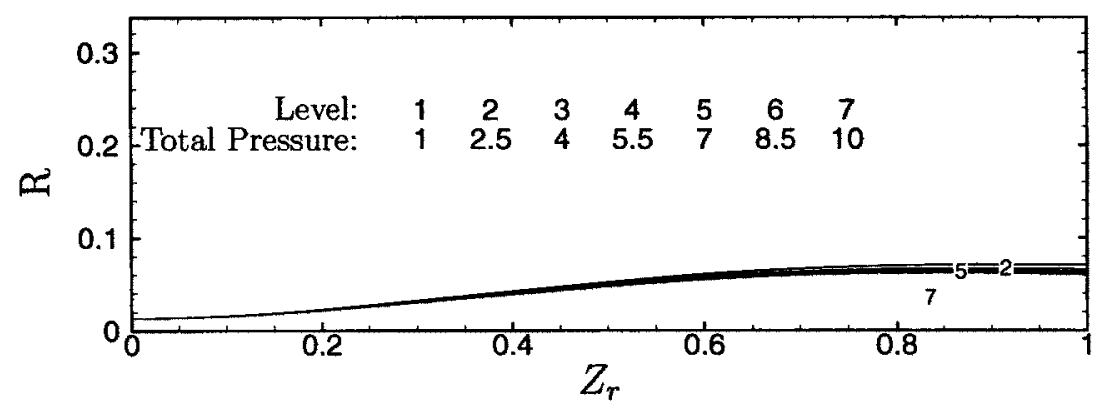

(b) Total Pressure

Figure 25: Contour Plots along Symmetry Plane in Z Direction

The total pressure contour plot shown in Figure 25b shows that with a decrease in wall surface area, the mass flow averaged total pressure ratio increases to $82.7 \%$ from $36.8 \%$ for the $R F P_{W}$ design. Moreover, from the contour plot it can be seen that the dominant loss in this case comes from the wall interaction as the total pressure decreases as the flow nears the wall. At the center of the flow there are no abrupt changes and the majority of the flow stays above a total pressure of 10 [MPa].

\subsection{Summary}

The $R F P_{W}$ configuration is found to be affected by a shockwave structure. This shock can be alleviated by ensuring that the rate of expansion of the flow in either the radial or circumferential direction is kept smooth. 
A comparison between the $R F P_{W}$ results with the $S R C$ results show that the Mach number at the exit differs by 0.41 (12.2\%). This difference is evident in Figure 26 , which is a plot of the mass averaged Mach number with respect to $Z_{r}$. The design Mach number is also added for reference. The difference in outlet Mach number is attributed to the rocket flow path design and is therefore a design choice. Thus, it is desirable to compare the two engines using the same chamber conditions and design Mach number. In this way, the comparison is more realistic since it includes the losses within the rocket flow paths. Therefore as long as the chamber conditions and design Mach numbers are the same, the comparison is valid since any difference in performance is attributed to the RBCC engine design.

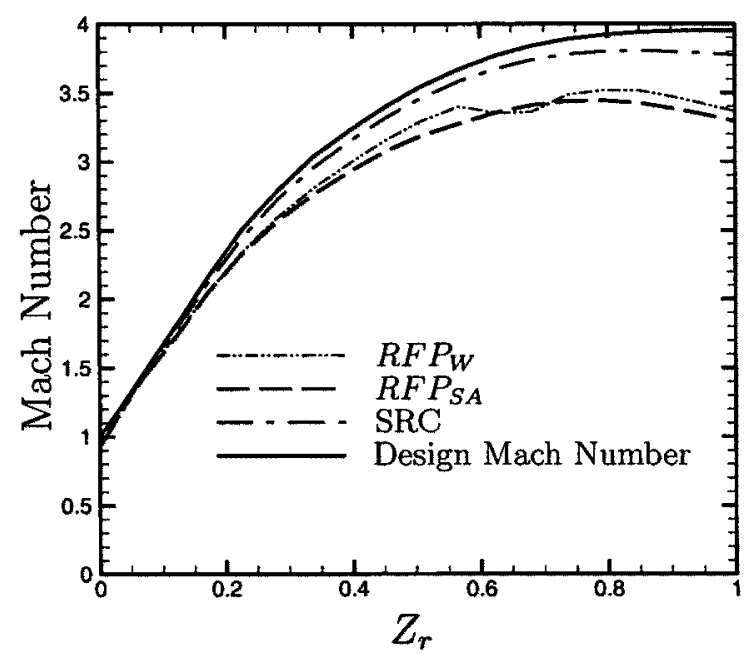

Figure 26: Mach Number Comparison between $R F P_{W}$ and $S R C$

Figure 27 shows the total pressure comparison between $R F P_{W}, R F P_{S A}$ and $S R C$ flow paths. The $S R C$ flow path experiences a lower total pressure drop and no sharp decreases are present. With the $R F P_{S A}$ flow path, the total pressure decreases more rapidly than the $S R C$ test case because of the large surface area. In the $R F P_{W}$ flow path, the total pressure initially decreases more slowly than with the $R F P_{S A}$ case. Then in the interval where the shock structures are present, between $Z_{r}$ equal to 0.57 
and 0.67 , the total pressure decreases rapidly. The slope is then slightly increased but the total pressure continues to decrease until it exits the rocket flow path.

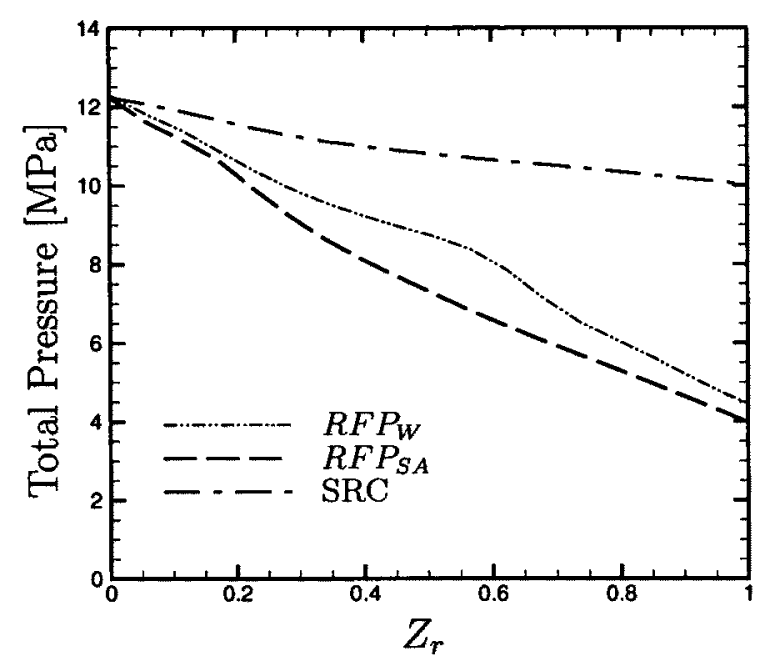

Figure 27: Total Pressure Comparison

Table 6 highlight the differences between the $S R C$ and $R F P_{W}$ designs at the outlet plane. The Mach number and total pressure are higher for the $S R C$ case and the exhaust leaves at a lower temperature. The Mach number is about $12.2 \%$ higher for the $S R C$ flow path. This change is relatively small when compared with the total pressure increase of $125 \%$. Even so, the ejector effect is more dependent on the Mach number than the total pressure [10]. Thus for the exchange inlet design, an increase in mixing characteristic can still potentially offset this loss in total pressure. Moreover, the temperature is $14.6 \%$ lower and the mass flow rate are about the same with a decrease of $0.2 \%$.

Finally, from the simulations it is clear that when configuring the rocket flow path, the designer should be cautious of any abrupt or large changes in the geometry as this creates favourable conditions for shockwaves to form. Moreover, the wall surface area should be minimized as it lowers the total pressure lost due to wall shear. Considering the losses in total pressure as shown in Figure 27, it is preferable to minimize the wall 
Table 6: Rocket Flow Summary

\begin{tabular}{rrrrr} 
& Mach Number & $\begin{array}{r}\text { Mass Flow Rate } \\
{[\mathrm{kg} / \mathrm{s}]}\end{array}$ & $\begin{array}{r}\text { Total Pressure } \\
{[\mathrm{MPa}]}\end{array}$ & $\begin{array}{r}\text { Temperature } \\
{[\mathrm{K}]}\end{array}$ \\
\hline$R F P_{w}$ & 3.36 & 247.6 & 4.45 & 1688 \\
$S R C$ & 3.77 & 247.1 & 10.01 & 1442 \\
Difference & $0.41(12.2 \%)$ & $-0.5(-0.2 \%)$ & $5.56(125 \%)$ & $-246(-14.6 \%)$
\end{tabular}

surface area while avoiding abrupt changes in the geometry. 


\section{Chapter 3}

\section{Exchange Inlet and Mixing Duct}

In this chapter, the conditions at the outlet of the $R F P_{W}$ flow path are used as the inlet conditions to the mixing duct. Moreover, the exchange inlet is included since it is used to determine the quantity of the air that is entrained by the rocket exhaust. Furthermore, this allows for the determination of the air flow properties from the entrance of the intake to the beginning of the mixing duct. Then by analyzing the rocket air interactions in the mixing duct it will help determine some of the mixing characteristics for the current design and allow for recommendations to be given about the engine. The next section describes the creation of the air intake. Equations are then given to gauge ejector performance, measure the level of mixing, and determine engine performance based on specific parameters. The specific parameters include Mach number, temperature, total pressure and mass fraction of water. The first three parameters are useful in directly determining the engine performance. The mass fraction of water is significant since it is only introduced to the domain at the rocket exhaust inlet and is not part of the freestream air. This can be used to track the movement of rocket exhaust inside the mixing duct. 


\subsection{Intake Creation}

The exchange inlet consists of the rocket flow path and the inlet geometry. The inlet geometry is designed around the rocket flow path to improve air entrainment, provide structural rigidity and generate conditions that will lead to rapid mixing for a range of operating conditions. The inlet includes three main components: the centrebody, the fairing and the cowl. The function of the fairing is to ensure that the incoming air flows smoothly around the rocket flow path housed within it. The thickness of the center body allows the intake area to be controlled so as to obtain the best air entrainment possible. The cowl functions similar to the fairings in that it provides smooth contours around the outermost sections of the rocket flow path (see Figure 28).

On top of requiring to be able to house the rocket flow path, the intake geometry is further defined by eight geometry parameters. They are $\sigma, \tilde{z}_{2}, \mathrm{AR}, \tilde{r}_{C B_{1}}, \mathrm{CR}$, $\tilde{t}_{3}, \tilde{c}_{\text {fair } \max }$ and $A_{2-3}$. For the precise definition of each, please refer to Waung [27]. Only a brief statement of each parameter will be provided here. In addition, the geometry of the selected intake with relevant reference planes is shown in Figure 28 (adapted from Waung [27]). These reference planes are important when defining each geometry parameter. Thus, $\sigma$ is the ratio of the rocket flow area to the total flow area (rocket area plus airstream area) at plane 3 . The parameter $\tilde{z}_{2}$ can be used to control where the throat of the air intake is. Then AR is the area ratio of the air stream between planes 2 and 3 . Moreover, $\tilde{r}_{C B_{1}}$ controls the centre body radius at plane 1. In addition, CR determines the area of the airstream at the leading edge of the cowl. Furthermore, $\tilde{t}_{3}$ controls the thickness of the cowl at plane 3. Also, $\tilde{c}_{f a i r_{\max }}$ determines the maximum length of the fairing. Finally, $A_{2-3}$ defines how the area is distributed between planes 2 and 3 , which then determines the shape of the inner surface of the cowl. 

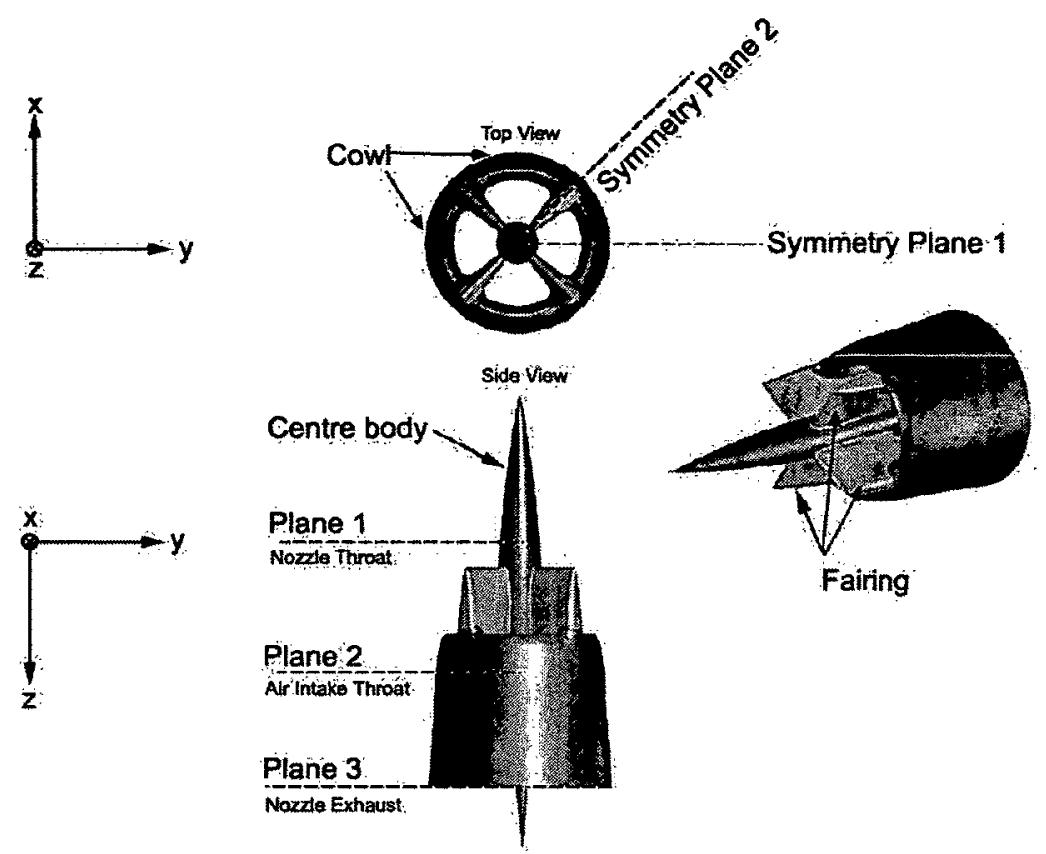

Figure 28: Intake Geometry

For a particular rocket flow path, there is a range of possible combinations of parameter values. To keep the intake definition consistent with the $R F P_{W}$ flow path from the previous chapter the parameters are taken from Waung [27] and these values are shown in Table 7.

Table 7: Selected Air Intake Geometry

\begin{tabular}{rr} 
Parameter & Value \\
\hline$\sigma$ & 0.10 \\
$\tilde{z}_{2}$ & 0.425 \\
$\mathrm{AR}$ & 0.625 \\
$\tilde{r}_{C B_{1}}$ & 5.5 \\
$\mathrm{CR}$ & 1.35 \\
$\tilde{t}_{3}$ & 0.13 \\
$\tilde{c}_{f a i r_{\max }}$ & 0.115 \\
$A_{2-3}$ & Linear
\end{tabular}


After creating the intake geometry, the exchange inlet is then completely defined and a circular mixing duct is added at plane 3, forming the geometry shown in Figure 29. It is known that mixing can be improved with a long duct length, but a long duct would be heavy and its weight would offset any gains. Furthermore, the length of the mixing duct required for complete mixing is a function of the Mach number of the rocket flow [10]. It is also dependent on the interaction mechanism between the two streams in the mixing duct. The mixing duct of RBCC engines are usually measured as a ratio of the rocket diameter $\left(L / D_{r}\right)$ or mixing duct diameter $\left(L / D_{\text {mix }}\right)$. To achieve complete mixing, typical values quoted in literature ranges from a $L / D_{\text {mix }}$ of 5 to $10[10,16,39]$. The RBCC engine shown in Figure 26 has a $L / D_{\operatorname{mix}}$ of 5 which when compared to other studies is relatively short. Increasing the mixing duct length any further is not desirable, considering that this already doubles the volume of material required for the engine. This value is taken from the solid model. Additional work still needs to be done in order to minimize engine weight, but the main focus of this study is with analyzing the mixing interactions that occur within the mixing duct. Thus, anymore mass and structural concerns will be addressed in later studies. Finally to study the rocket air mixing characteristics, the simulations would encompass the flow within the exchange inlet and the mixing duct.

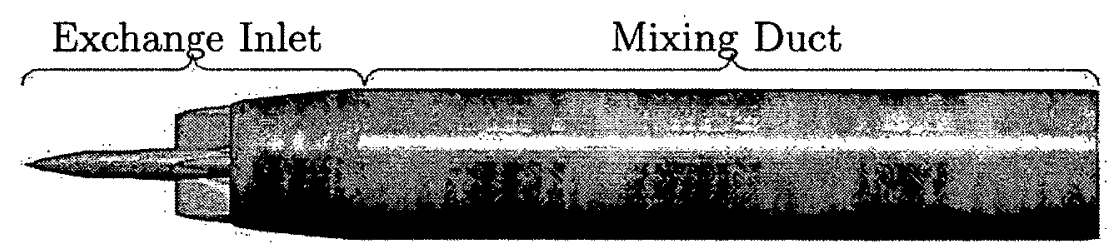

Figure 29: Exchange Inlet and Mixing Duct 


\subsection{SRC Intake Creation}

For the $S R C$ comparison case, the intake geometry from the previous section will be used. This is to ensure that the air stream conditions are similar for both cases. Thus, the SRC flow path is incorporated into the centerbody. This changes the air intake area distribution along the $Z$ axis $\left(A_{\text {air }}(z)\right)$. If this issue is not addressed it could limit the amount of air entrained or the air flow could enter the mixing duct at a much higher velocity affecting validity of the comparison. Thus it is desirable that $A_{\text {air }}(z)$ be the same for both cases. Then to match $A_{\text {air }}(z)$ in the intake, the radius of the inner surface of the cowl is moved to accommodate for the increase in centrebody radius due to the $S R C$ flow path (see Figure 30). The rest of the centrebody and fairing are kept the same since excessive changes to the geometry are undesirable for the comparison.

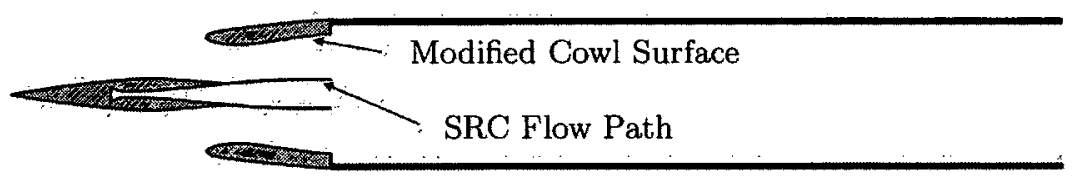

Figure 30: RBCC Engine with Exchange Inlet

One important parameter that is dependent on the intake geometry is the entrainment ratio. It is defined as follows,

$$
\alpha=\frac{\dot{m}_{a i r}}{\dot{m}_{r}}
$$

The entrainment ratio can be used to gauge the performance of the ejector and it is desirable that this be as high as possible. Moreover, since it is dependent on the mass flow rates, the maximum entrainment ratio that can be achieved is when the air stream is choked. The mass flow rate of the rocket exhaust is dependent on the 
geometry of the rocket flow path and thus can not be modified by the intake geometry. For the entrained air, choking occurs when the cross sectional area is minimized and this point is called the throat of the air intake. Thus the maximum air entrainment ratio can be calculated by first solving for the maximum mass flow rate of air using the following equation for choked flow.

$$
\dot{m}_{\max }=\gamma^{1 / 2}\left(\frac{2}{\gamma+1}\right)^{\frac{\gamma+1}{2(\gamma-1)}} A^{*} \frac{P_{0}}{\left(R T_{0}\right)^{1 / 2}}
$$

[40]

Finally substituting in the mass flow rates of air and rocket exhaust into Equation 3 and defining $\Gamma$ as

$$
\Gamma=\gamma^{1 / 2}\left(\frac{2}{\gamma+1}\right)^{\frac{\gamma+1}{2(\gamma-1)}}
$$

Equation 3 then becomes

$$
\alpha_{\text {max }}=\frac{\dot{m}_{a i r_{\max }}}{\dot{m}_{r_{\max }}}=\frac{\Gamma_{a i r}}{\Gamma_{r}} \frac{\sqrt{R_{r}}}{\sqrt{R_{a i r}}} \frac{A_{a i r}^{*}}{A_{r}^{*}} \frac{P_{0 a i r}}{P_{0 r}} \frac{\sqrt{T_{0 r}}}{\sqrt{T_{0 a i r}}}
$$

Here, $\dot{m}_{r_{\max }}$ is used since the rocket flow is supersonic and is therefore choked at the throat of the $S R C$ rocket flow path. As equation 6 shows, the entrainment ratio is really a function of five other ratios. The $\Gamma$ ratio and gas constant $(R)$ ratio are properties of the fluid and do not depend on the geometry of the engine. The throat area ratio is only dependent on the geometry. Finally, the total pressure and total temperature ratios are affected by the geometry and fluid properties. Thus, if one ratio changes the maximum entrainment ratio can still remain the same if other ratios are modified. For the $S R C$ case, the critical area for the air flow path is changed to ensure the maximum entrainment ratios are comparable. 
Changes to $\alpha_{\max }$ can potentially limit the effectiveness of either design. For example, if one design is forced to entrain less air than the other design the final composition of the mixture changes. This in turn affects the mixing characteristics and it would change all the property gradients. In the end the performance of the engine is modified and therefore compromises the validity of the comparison. The main reason for performing this comparison is to look at how the rocket and air interaction changes from having a rocket along the centerline and a rocket that has a semi-annular rocket profile. Thus, $\alpha_{\max }$ is kept the same in order for this comparison to remain valid.

\subsection{Ejectors}

Since the engine will be operating in the ejector mode, it is important to understand how performance in an ejector is measured. With conventional equipment like a pump or turbine, efficiency is measured by comparing the actual process to an ideal process. Roan argues that for an ejector the only mechanism for compression comes from the dissipative forces and therefore an ideal process can not be evaluated [41]. Even so, a measure of the effectiveness of the ejector is obtained by evaluating the useful compression work of the entrained air over the potential expansion work of the rocket exhaust. Thus replacing the ideal compression work of the air with the potential work from the rocket exhaust. This then becomes the stagnation energy effectiveness [41],

$$
S E E=\frac{C_{p, s}}{C_{p, p}} \frac{T_{0, s}}{T_{0, p}} \frac{\dot{m}_{s}}{\dot{m}_{p}}\left[\frac{\left(\frac{P_{0, m}}{P_{0, s}}\right)^{\frac{\gamma_{s}-1}{\gamma_{s}}}-1}{1-\left(\frac{P_{0, m}}{P_{0, p}}\right)^{\frac{\gamma_{p}-1}{\gamma_{p}}}}\right]
$$

Moreover, an ejector behaves more like a momentum exchange device rather than an energy exchange device. Thus by relating the momentum with kinetic energy for both the entrained air and rocket exhaust, Equation 7 becomes [41] 


$$
S M E E=\frac{C_{p, s}}{C_{p, p}} \frac{\dot{m}_{s}}{\dot{m}_{p}} \sqrt{\frac{T_{0, s}}{T_{0, p}}} \sqrt{\frac{\gamma_{p}}{\gamma_{s}}} \sqrt{\frac{M W_{s}}{M W_{p}}}\left[\frac{\left(\frac{P_{0, m}}{P_{0, s}}\right)^{\frac{\gamma_{s}-1}{\gamma_{s}}}-1}{1-\left(\frac{P_{o, m}}{P_{o, p}}\right)^{\frac{\gamma_{p}-1}{\gamma_{p}}}}\right]
$$

A full derivation is found in Roan [41]. The use of the Stagnation Momentum Exchange Effectiveness (SMEE) is to gauge the performance of different ejector designs. Using Equation 8, Young and Idem [42] is able to analyze ejector performance with an air to air conical nozzle ejector and Samitha et al. [17] is able to compare a clover (lobed) nozzle design with a conical one. The equation measures the effectiveness of the momentum exchange between two different fluid flows, namely a primary and secondary flow. For the current study, they are the rocket and entrained air flow, respectively. The SMEE equation is a function of the entrainment ratio $\alpha$ and the compression ratio which is the mixed flow stagnation pressure divided by the free stream air stagnation pressure. High SMEE values are desirable and it ranges between 0 and 1. In addition, this value is typically found between 0.1 to 0.3 for ejectors [10].

The SMEE value provides an indication of the ejector's performance but does not directly gauge the level of mixing. Moreover, it neglects the fact that temperature and mass fractions play an important part in combustion when used in RBCC engines. Thus, a different parameter needs to be defined when comparing the mixing effectiveness between different RBCC engines. The proposed parameter, Extent of Mixing (EM), shown in Equation 9 provides a measure of the level of mixing. The variable $P$ represents a property of interest with the subscript $\mathrm{n}$ denoting different properties. The more uniform the mixture of the flow becomes, the higher the EM value and for a completely uniform flow this parameter is equal to 1 .

$$
E M=1-\sqrt{\frac{1}{n_{\max }} \sum_{n=1}^{n_{\max }}\left(\frac{P_{n}-P_{n, a v g}}{P_{n, a v g}}\right)^{2}}
$$


It is intended that Equation 9 be used to measure the uniformity of the flow by using several properties. The massflow averages are evaluated at each plane downstream in order to analyze how well mixing has improved (Refer to Figure 2). Moreover, the maximum value it can reach is 1 and there is no lower limit. Even so, if the value is below 0 it is reasonable to assume that the flow is far from well mixed since it means that on average the variation differs from the mean value by more than $100 \%$. Then by applying the equation to three important flow properties, it becomes

$$
E M=1-\sqrt{\frac{1}{3}\left[\left(\frac{T-T_{a v g}}{T_{a v g}}\right)^{2}+\left(\frac{P_{0}-P_{0 a v g}}{P_{0 a v g}}\right)^{2}+\left(\frac{M_{f, H_{2} O}-M_{f, H_{2} O_{a v g}}}{M_{f, H_{2} O_{a v g}}}\right)^{2}\right]}
$$

Equation 10 is a function of how far temperature, total pressure and mass fractions vary from the average value at that plane. Only water mass fractions appears in the equation since it is the main constituent of the rocket exhaust analyzed in the current study. It can be replaced easily with hydrogen for SMC operation or by another specie of significance. This is the same with any other property for a given plane.

\subsection{Model}

Similar to the rocket flow path simulations, Ansys CFX 12.1 is used with Menter's SST turbulence model. The computational domain for the exchange inlet and mixing duct is shown in Figure 31a. The geometry is split into eight equal sections about the z-axis as shown in Figure $31 \mathrm{~b}$. The symmetry planes of the domain are set to free slip and this means that both the shear and velocity normal to the boundary are set to zero. The Outerbound is placed at 2.5 times the rocket flow path radius. This was thought to be far enough away from the ejector geometry as to not affect the flow characteristics while alleviating domain size concerns. However, simulations 
using a free slip condition for the Outerbound show that it affects the flow around the outer surfaces of the exchange inlet by accelerating it past sonic velocity. Thus, the outerbound and the freestream outlet boundary are set as an opening instead.

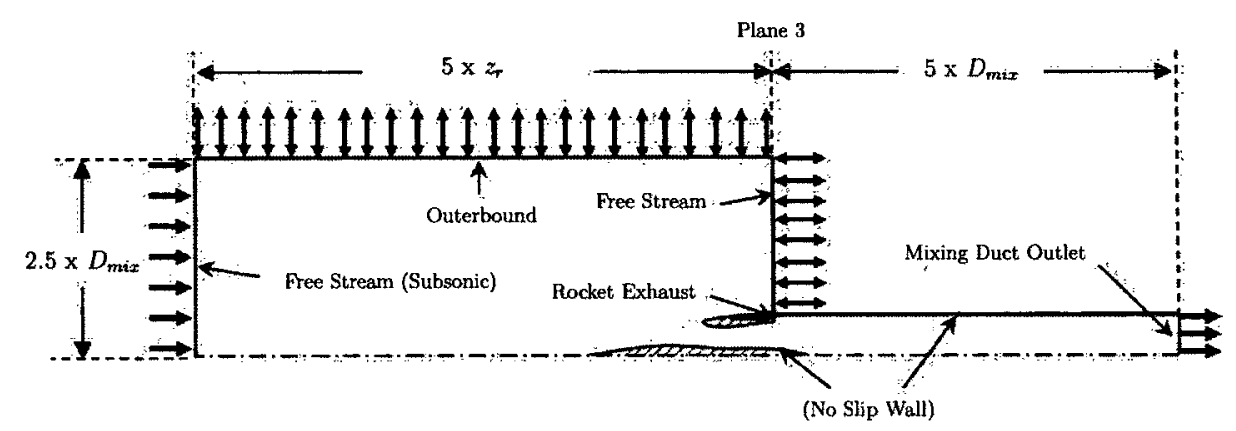

(a) Side View

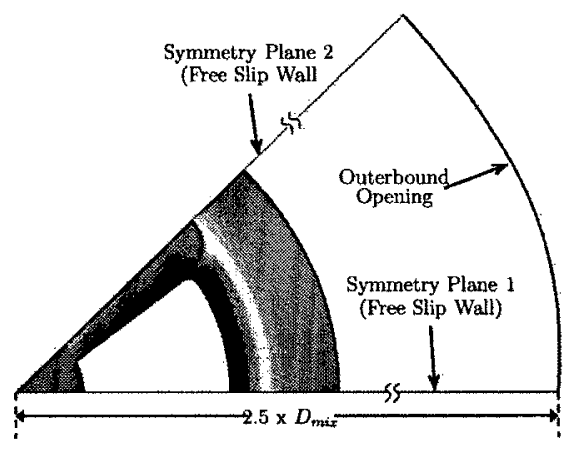

(b) Top View

Figure 31: Layout of Mixing Duct Domain

An unstructured grid is used due to the complex geometry of the exchange inlet. The unstructured grid contains 1,544,259 nodes and 5,558,064 elements and is shown in Figure 32. The mesh also uses 15 prismatic layers and the results are checked to ensure that $y^{+}$is lower than 5 .

The $R F P_{W}$ exchange inlet geometry taken from Waung is created based on the flight profile of the Ariane 4 in mind. Thus for the current study a subsonic section of the Ariane 4 flight profile shown in Table 8 is used.

The pressure, temperature and velocity at the free stream inlet is set according to 


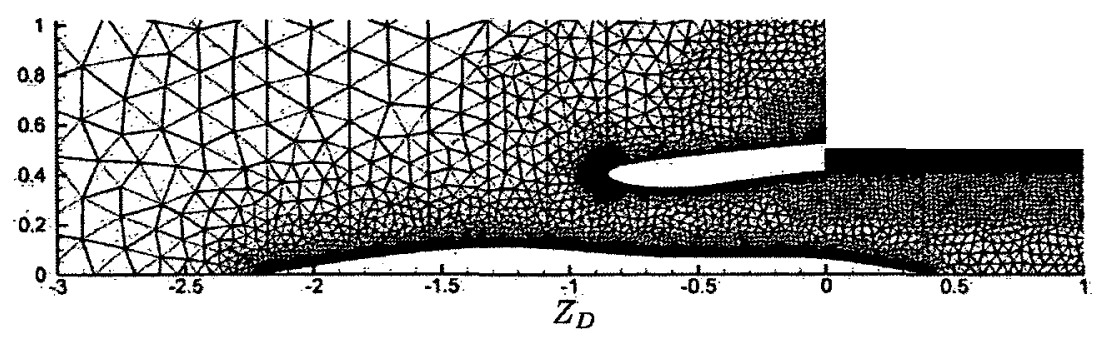

(a) Symmetry Plane 1

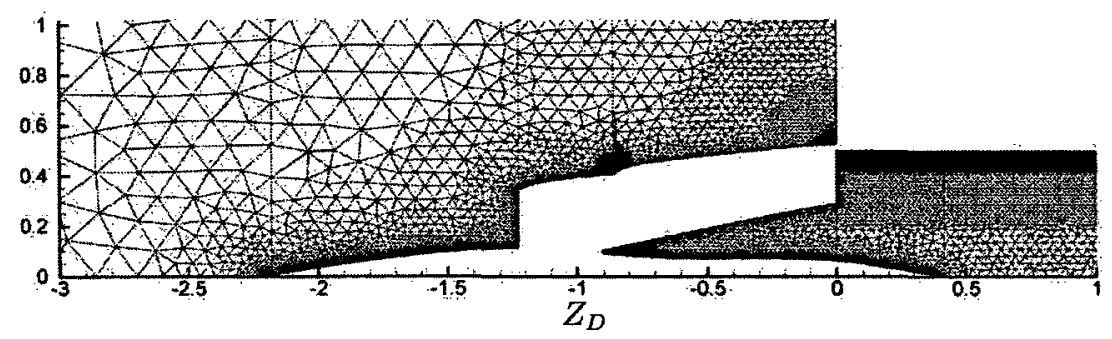

(b) Symmetry Plane 2

Figure 32: Ejector/Mixing Duct Domain Mesh

Table 8: Flight Profile

\begin{tabular}{rrrr} 
Flight Condition & 1 & 2 & 3 \\
\hline Altitude $(\mathrm{m})$ & 2196 & 3800 & 5741 \\
Pressure $(\mathrm{kPa})$ & 77.7 & 63.7 & 49.0 \\
Temperature (K) & 273.9 & 263.5 & 250.9 \\
Flight Mach Number & 0.41 & 0.64 & 0.89
\end{tabular}

flight profile conditions shown in Table 8. Moreover, the pressure and temperature at the outerbound and free stream outlet are the same as the free stream inlet. The pressure at the mixing duct outlet depends on the geometry aft of the mixing duct. Since this geometry is not present in the current study, the mixing duct outlet pressure is varied between $65[\mathrm{kPa}]$ and $100[\mathrm{kPa}]$ as shown in Table 9. This variation mimics the conditions for various nozzle designs. For pressures below the free stream pressure, it represents the conditions where the geometry acts like a diffuser instead of a nozzle. For pressures above the free stream pressure, it represents a design where 
the flow is choked and is impeding the mass flow rate within the engine. This can potentially represent off design points where a constant nozzle geometry is used for the entire flight profile.

Table 9: Mixing Duct Outlet Pressures

\begin{tabular}{rrrrrrrrr} 
& a & b & c & d & e & f & g & h \\
\hline Pressure $(\mathrm{kPa})$ & 65 & 70 & 75 & 80 & 85 & 90 & 95 & 100
\end{tabular}

For other flight profile conditions, the critical area of the geometry aft of mixing $\operatorname{duct}\left(A_{\text {nozzle }}^{*}\right)$ is kept constant for one of the cases in Table 9. Then Equation 4 can be applied when the flow through the engine is choked at this location. Knowing that the total flow rate is the sum of the air and rocket mass flows, the equation can be rearranged to solve for $C$. This parameter is the ratio of the critical area $A_{\text {nozzle }}^{*}$ over the mass flow rate of the rocket exhaust $\dot{m}_{r}$ and is shown in Equation 11. The subscript $e$ is used to denote the conditions at the exit of the mixing duct.

$$
C=\frac{A_{n o z z l e}^{*}}{\dot{m}_{r}}=\frac{(\alpha+1) \sqrt{R_{e} T_{0 e}}}{\Gamma_{e} P_{0 e}}
$$

For different flight conditions, the outlet pressure can be determined by keeping $C$ constant which essentially means that the geometry aft of the nozzle is kept constant. Then by rearranging Equation 11 to solve for the outlet pressure and applying the definition of total pressure for compressible flows, the outlet pressure for other flight conditions can be evaluated. The equation is shown as follows,

$$
P_{e}=\frac{(\alpha+1) \sqrt{R_{e} T_{0 e}}}{\Gamma_{e} C}\left(1+\frac{\gamma_{e}-1}{2} M_{e}^{2}\right)^{\frac{\gamma_{e}}{1-\gamma_{e}}}
$$

The entrainment ratio is determined by keeping $R_{\text {alpha }}$ between different flight conditions the same. The value $R_{\text {alpha }}$ is the ratio of the actual $\alpha$ over $\alpha_{\max }$ based on the geometry of the exchange inlet and flight conditions. Then the fluid properties 
$\left(R_{e}, \gamma_{e}\right.$ and $\left.\Gamma_{e}\right)$ can be calculated by assuming that the flow is fully mixed. Therefore, the equation has 3 unknowns and they are $P_{e}, T_{0 e}$ and $M_{e}$. The total temperature can be determined by using a control volume analysis and equating the energy at the inlet and outlet planes. Therefore,

$$
T_{0 e}=\frac{\alpha C_{p a} T_{0 a}+C_{p r} T_{0 r}}{(\alpha+1) C_{p e}}
$$

This means that Equation 12 now has two unknowns. To solve for the outlet pressure, an additional equation is obtained from conservation of momentum in the mixing duct as shown in the following.

$$
P_{a} A_{a}+P_{r} A_{r}-P_{e} A_{e}=\dot{m}_{e} v_{e} \beta_{e}-\dot{m}_{a} v_{a} \beta_{a}-\dot{m}_{r} v_{r} \beta_{r}
$$

The momentum flux correction factor $\beta$ is used here to account for the fact that the flow might not be uniform. For uniform flow, $\beta$ is equal to 1 and is greater than 1 for non uniform flow. Here the velocity, $v$ can be found by using the definition of the Mach number and sonic velocity, where

$$
v=M \sqrt{\frac{\gamma R T_{0}}{1+\frac{\gamma-1}{2} M^{2}}}
$$

Finally, the outlet pressure can be solved by applying the definition of the entrainment ratio and rearranging Equation 14 as shown below

$$
P_{e}=\frac{\dot{m}_{r}}{A_{e}}\left[(\alpha+1) \beta_{e} v_{e}-\alpha \beta_{a} v_{a}-\beta_{r} v_{r}\right]-P_{a} A_{a}-P_{r} A_{r}
$$

Both $P_{e}$ and $v_{e}$ are unknowns in Equation 16. Furthermore, the velocity at the exit plane is defined by Equation 15. This means that essentially, the two unknowns are instead $P_{e}$ and $M_{e}$. Thus, by solving Equation 12 and 16 simultaneously, the outlet pressure at the end of the mixing duct using different flight conditions can be 
determined. Finally, for all simulations the free stream air composition is composed of $24 \%$ oxygen and $76 \%$ nitrogen by mass.

\subsection{Results}

For each simulation the results are divided into two parts. The first part looks at the flow within the exchange inlet along the two symmetry planes. The rocket air interactions are analyzed using the same symmetry planes as well as cross section planes along the mixing duct as shown in Figure 33. All axes are non-dimensionalized by the mixing duct diameter. Plane 3 will serve as the datum plane and distances stated will be relative to this plane. For example, 5 [Dia] downstream would mean 5 mixing duct diameters downstream of plane 3. Moreover, unless otherwise specified all values will be obtained by massflow averaging over the entire cross section for values quoted inside the mixing duct. Finally, the results will be shown as whole sections rather than the 45 degree sections used in the simulation.

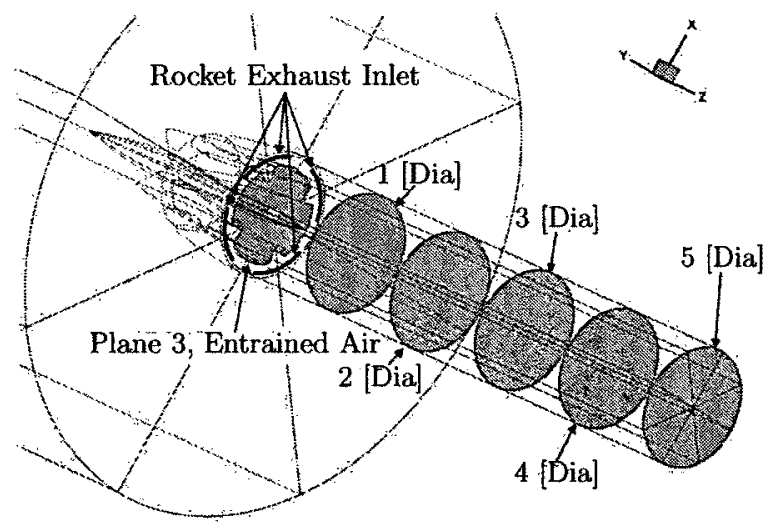

Figure 33: Exchange Inlet/Mixing Duct Locations 


\subsubsection{Outlet Pressure Variation}

The mixing duct outlet pressure is varied according to Table 9 to study the changes in mixing characteristic for flight condition 3. The Mach number contour plots are shown in Figures 34 and 35 for an outlet pressure of $65[\mathrm{kPa}]$ and $100[\mathrm{kPa}]$, respectively. These two cases are studied here in detail because they mark the maximum and minimum outlet pressures simulated. Moreover, the freestream Mach number is highlighted by the 0.4 Contour line.

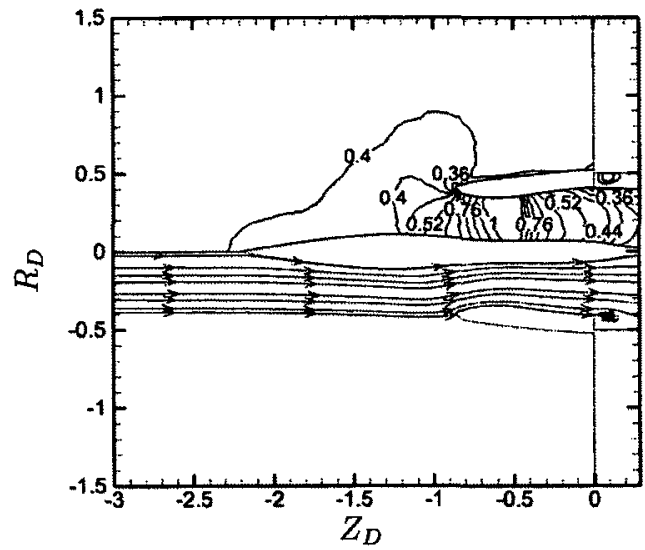

(a) Symmetry Plane 1

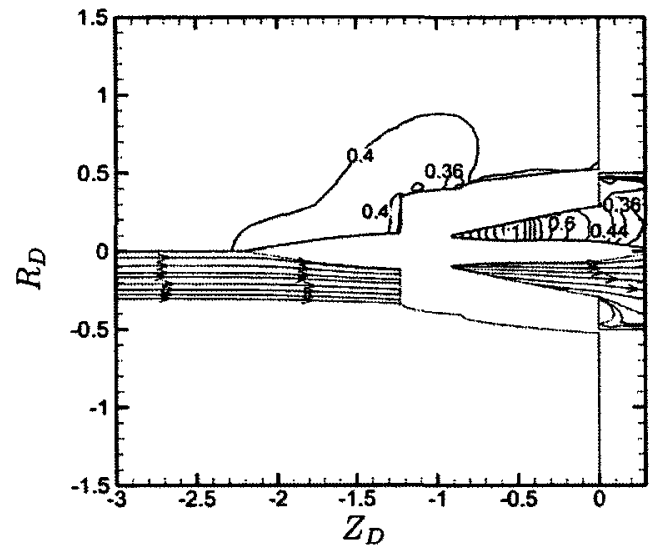

(b) Symmetry Plane 2

Figure 34: Mach Number Contour Plot in Exchange Inlet at FC1 (65 [kPa])

In the $65[\mathrm{kPa}]$ case, the air moves past the centrebody and cowl without any abrupt changes to the streamlines. It enters the mixing duct at Mach 0.44 and a total pressure of $68.4[\mathrm{kPa}]$. This gives an entrainment ratio of 9.90. The air is accelerated once it enters the intake due to a decrease in the intake area, $A_{a i r}$. The maximum Mach number occurs along the cowl at the throat of the intake at about 0.8 [Dia] upstream. As well, stagnation points are observed in front of the cowl and fairing as expected.

In Figure 35 the plot shows that a larger region of decelerated flow exist in front of the intake. This deceleration of the flow continues through the intake and the 


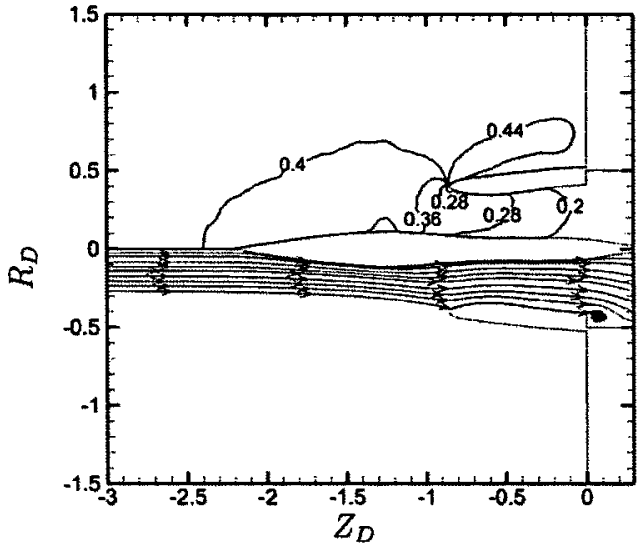

(a) Symmetry Plane 1

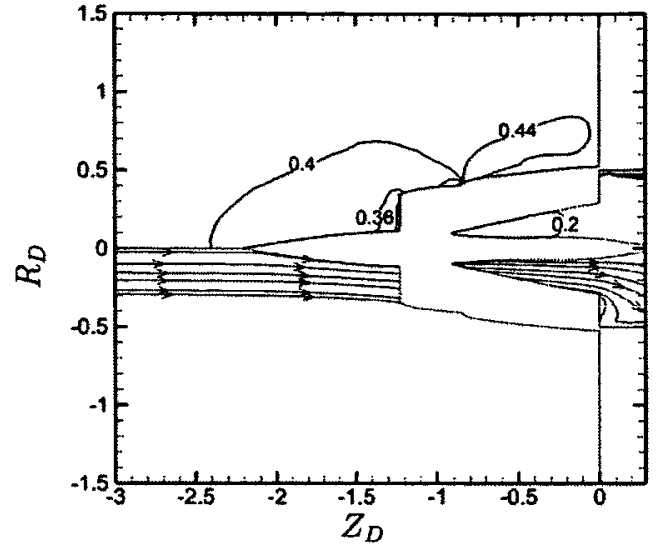

(b) Symmetry Plane 2

Figure 35: Mach Number Contour Plot in Exchange Inlet at FC1 (100 [kPa])

entrained air enters the mixing duct at a Mach number of 0.18 and a total pressure of 112.3 [kPa]. Although the flow is at a lower Mach number the total pressure is higher in this case. This is logical since the flow is moving at a lower velocity and drag is function of velocity. The air does not accelerate inside the intake, unlike with the $65[\mathrm{kPa}]$ case. Even though $A_{\text {air }}$ is decreasing, the streamlines in Figure 35a are expanding its flow area instead of contracting as it enters the intake. This is because less of the airflow is actually entering the intake as a comparison between Figures $34 \mathrm{a}$ and $35 \mathrm{a}$ show. The higher than freestream pressure at the mixing duct outlet is preventing the air from entering. This is likely the reason for the expansion of the decelerated flow region in front of the intake. Comparing the streamlines in Figure 34 to Figure 35 shows that in the $100[\mathrm{kPa}]$ case, the streamlines are deflected away from the centerline. The streamlines are obtained by using points within the intake and thus represents the path of the entrained air. Thus the deflection of the streamlines mean that in the $100[\mathrm{kPa}]$ case, there is less air entrainment since less freestream air is allowed to flow into the intake. This is why the entrainment ratio for the $100[\mathrm{kPa}]$ case decreases to 4.88 , which is $51 \%$ lower than in the $65[\mathrm{kPa}]$ case. 
The contour plots and streamlines within the mixing duct for the 65 [kPa] case are shown in Figure 36. In symmetry plane 1 the flow moves smoothly along the exchange inlet without separation until it reaches plane 3 . However, the current rocket exhaust profile is not completely annular and recirculation develops just downstream of the cowl. This recirculation is less pronounced in symmetry plane 2 as the high velocity rocket exhaust at this location aids in directing the airflow (see Fig. 36b). At approximately 0.5 [Dia] downstream, Fig 36a also shows a distinct expansion of the flow away from the mixing duct wall. This is due to the circumferential flow of the rocket exhaust towards symmetry plane 1 . The rocket flow can be identified in this plane by the high Mach number contours. This high Mach number rocket exhaust increases the exit Mach number at the outlet to 0.70 and the mixture exits at a total pressure of 88.9 [kPa]. Moreover, the air stream does not fall below Mach 0.28 except for the recirculation region behind the cowl.

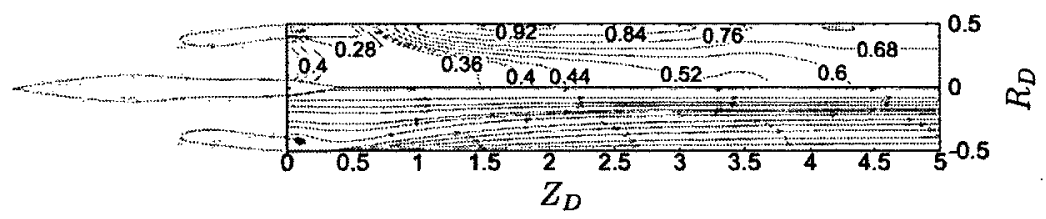

(a) Symmetry Plane 1

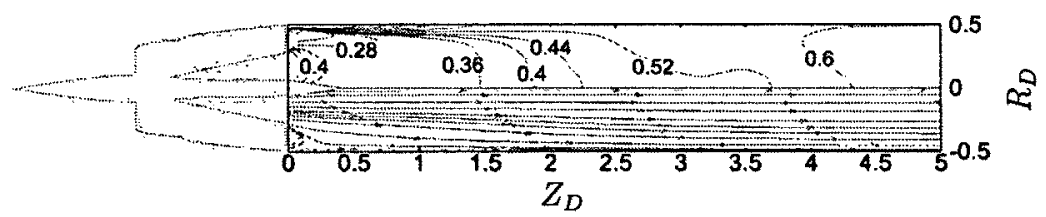

(b) Symmetry Plane 2

Figure 36: Mach Number Contour Plot in Mixing Duct at FC1 (65[kPa])

The Mach number of the rocket exhaust decreases more rapidly along the mixing duct for the $100[\mathrm{kPa}]$ case (Figure 37). It falls below Mach 0.84 by the time it reaches symmetry plane 1 at about 0.5 [Dia] downstream. In the $65[\mathrm{kPa}]$ case, the rocket exhaust is above a Mach number of 0.84 up to about 3 [Dia] downstream. The rapid deceleration of the rocket exhaust in the $100[\mathrm{kPa}]$ case is likely due to the greater 
pressure imposed at the outlet. Using this outlet condition, the Mach number at the outlet is found to be 0.30 and the total pressure is $106.1[\mathrm{kPa}$. This higher exit total pressure compared to the $65[\mathrm{kPa}]$ case is partly due to the low entrainment ratio, since a higher percentage of the flow consists of the rocket exhaust. With the higher outlet pressures, higher than $90[\mathrm{kPa}]$, a second recirculation develops behind the centrebody. This recirculation forces the entrained air to move towards the rocket exhaust as shown in Figure 37. Upon contact with the rocket exhaust the air stream can not go any further. Therefore, the presence of the recirculation region restricts air flow by limiting the flow area available. This then lowers the maximum mass flow rate and the overall Mach number of the entrained air. As seen at later symmetry planes, this flow blockage caused by the large recirculation zone extends across the entire domain from symmetry plane 1 to 2 .

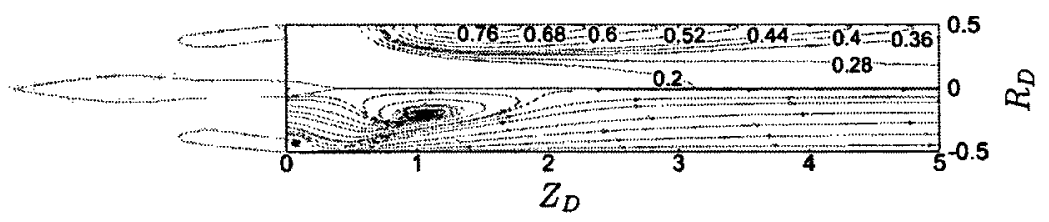

(a) Symmetry Plane 1

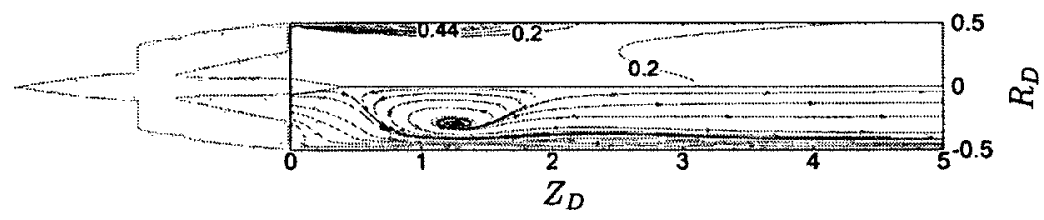

(b) Symmetry Plane 2

Figure 37: Mach number Contour Plot of the Mixing Duct at FC1 (100 [kPa])

Figure 38 shows the temperature, mass fraction and total pressure variations. The figure plots the massflow averaged value, denoted by a symbol, as well as the maximum and minimum values, denoted by the higher and lower error bars, at cross sectional planes within the mixing duct. From Figure 38 it can be seen that the mean temperature and mass fractions are both higher in the $100[\mathrm{kPa}]$ case. Since the entrainment ratio is also lower there is less air flowing into the mixing duct. This 
lower entrainment ratio means that the rocket exhaust does not need to mix with as much air as in the $65[\mathrm{kPa}]$ case. Using the same reasoning, the spread in the maximum and minimum values at each plane is also lower in the $100[\mathrm{kPa}]$ case.

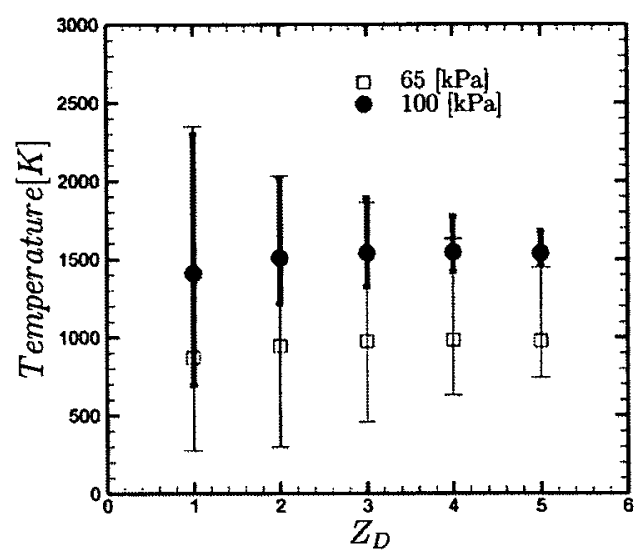

(a) Temperature

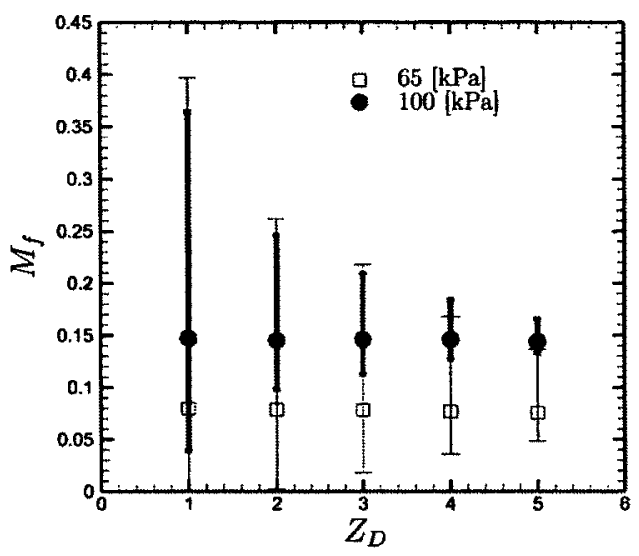

(b) $\mathrm{H}_{2} \mathrm{O}$ Mass Fraction

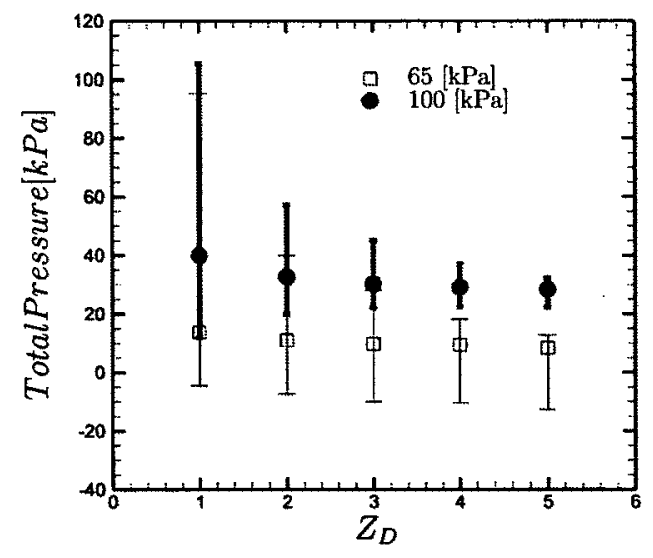

(c) Total Pressure

Figure 38: The Minimum, Mean and Maximum Values in the Mixing Duct

The SMEE plot at the outlet of the mixing duct are shown in Figure 39. At 5 [Dia] downstream, it appears that as the outlet pressure increases the mass averaged SMEE value increases until $90[\mathrm{kPa}]$. Between $90[\mathrm{kPa}]$ and $95[\mathrm{kPa}]$ a second recirculation zone as seen in Figure 37 develops and there is drop in the SMEE value as the outlet pressure continues to rise. It is likely that the second recirculation zone increases total 
pressure losses and as such lowers the SMEE value. The initial increase in SMEE value at 5 [Dia] downstream is likely due to the lower Mach number of the mixture. With a lower Mach number there is a lower pressure loss and thus would increase the SMEE value. This decrease is then offset by the losses from the second recirculation.

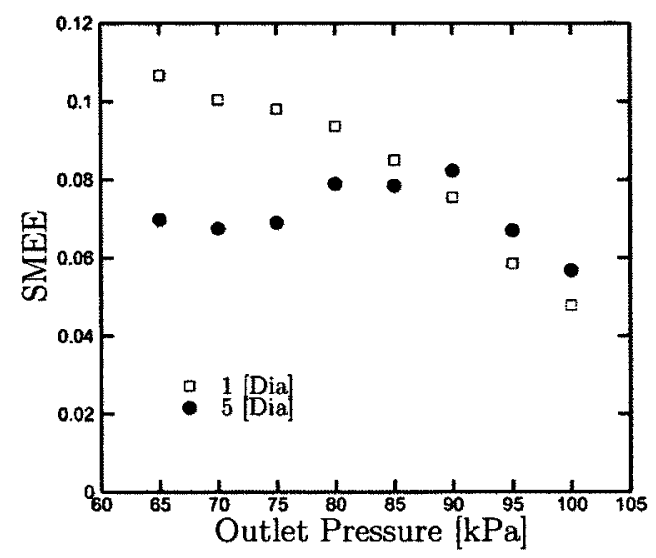

Figure 39: SMEE at 5 [Dia] Downstream

Figure 40 shows the entrainment ratio against the outlet pressure. It decreases slightly as pressure is increased up until $80[\mathrm{kPa}]$. After this point, the increase in pressure causes a drop in the air stream Mach number. It continues to drop until after $90[\mathrm{kPa}]$ where a second recirculation develops. Moreover, a lower entrainment ratio tends to lower the SMEE value as Figure 39 shows, since the SMEE value is also a function of the entrainment ratio. 


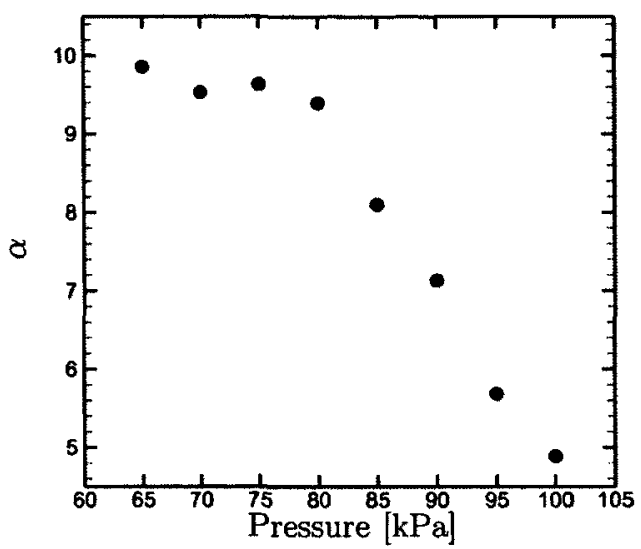

Figure 40: Entrainment Ratio for Different Outlet Pressures

A representation of the variation from the mean value at the outlet plane can be made using Equation 9 for only one property at a time. This is shown in Figure 41 for varying outlet pressures at 5 [Dia] downstream. The EM values shown are for temperature $\left(E M_{T}\right)$, total pressure $\left(E M_{P_{0}}\right)$ and $H_{2} O$ mass fraction $\left(E M_{H_{2} O, M_{f}}\right)$. As the outlet pressure increases both $E M_{T}$ and $E M_{H_{2} O, M_{f}}$ also increases. Moreover, after $90[\mathrm{kPa}]$ there is a sharp increase in the EM values and is attributed to the development of the second recirculation region. This relationship does not exist with the total pressure as it is already very close to unity. At first glance it might appear to disagree with the results from Figure $38 \mathrm{c}$, but this only suggests that the majority of the flow has reached the average total pressure. Even though the minimum and maximum values are far apart, it only exists in a small portion of the flow.

For an effective exchange inlet, it is preferable to have high SMEE, $\alpha$ and EM values. Using Figure 39, it is shown that the highest SMEE value occur with an outlet pressure of $80[\mathrm{kPa}]$ and $90[\mathrm{kPa}]$. This is not always the case since with increasing outlet pressure, $\alpha$ decreases and the EM values increases. Even so, Figure 40 shows that $\alpha$ stays about constant until after $80[\mathrm{kPa}]$. Thus, $80[\mathrm{kPa}]$ is used as the reference outlet pressure for the other flight conditions and will be examined 


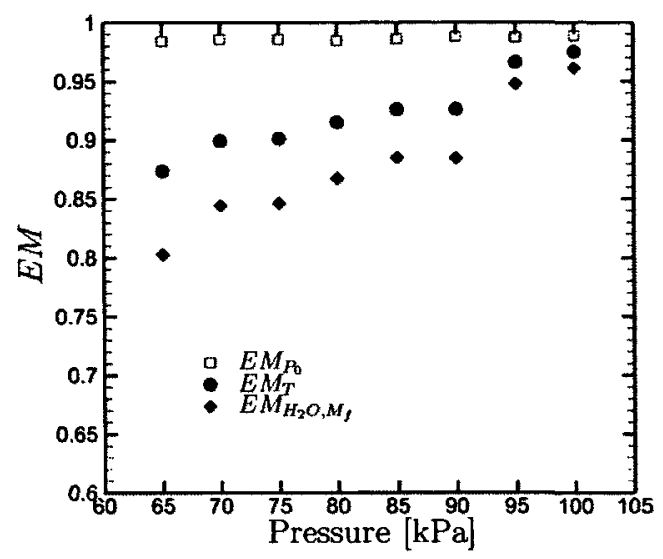

Figure 41: EM values for Total Pressure, Temperature and $\mathrm{H}_{2} \mathrm{O}$ Mass Fraction at 5 [Dia] further due to its significance. The outlet pressure for the other flight conditions are then calculated using equation 12 and 16 . The resulting outlet pressures for flight conditions 2 and 3 are shown in Table 10.

Table 10: Mixing Duct Outlet Reference Pressures

\begin{tabular}{lrrr} 
& 1 & 2 & 3 \\
\hline Pressure (kPa) & 80 & 65.3 & 50.4
\end{tabular}

\subsubsection{Flight Condition 1 at 80 [kPa]}

The Mach number contour plot for the exchange inlet is shown in Figure 42. Here, the air flow resembles that for $65[\mathrm{kPa}]$ in the previous section and the flow enters the mixing duct without separation. The entrained air enters the mixing duct at a Mach number of 0.38 and a total pressure of $85.2[\mathrm{kPa}]$. Furthermore, the entrainment ratio is 9.40. Stagnation zones are present along the cowl and fairing tips just as the flow is directed into the exchange inlet. Once the flow is inside the exchange inlet, the flow gradually accelerates. Initially the flow speeds up but does not accelerate past the sonic point. After reaching a Mach number of about 0.84 near the cowl and 0.76 near 
the centrebody, the flow starts to slow down prior to entering the mixing duct due to an increase in area. As the flow enters the mixing duct, it slows down further with the Mach number dropping down more rapidly near the cowl. Once the flow is inside the mixing duct there is an expansion in area. The subsonic flow then decelerates with some regions falling below a Mach number of 0.28 . This is the same for both symmetry planes.

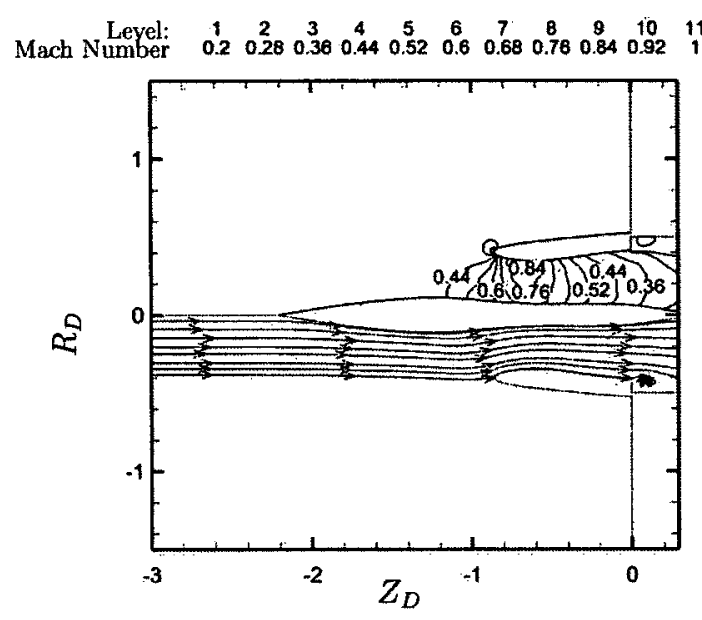

(a) Symmetry Plane 1

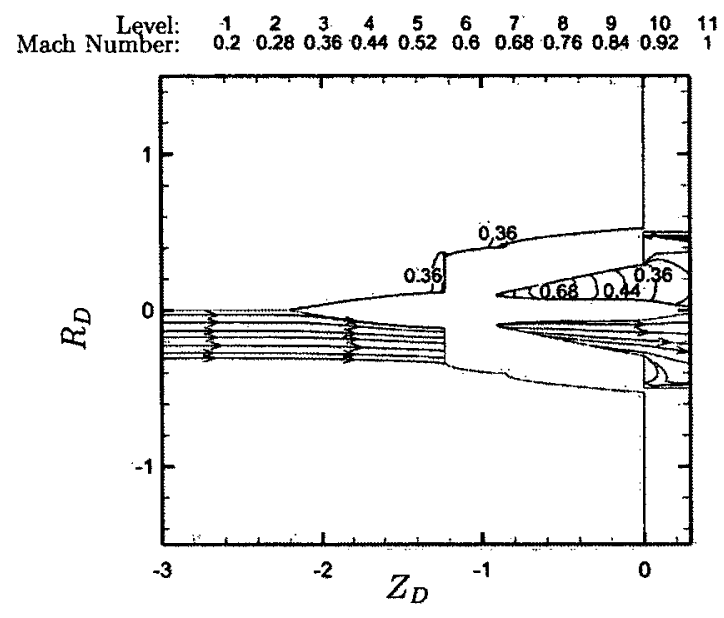

(b) Symmetry Plane 2

Figure 42: Mach Number Contour Plot in Exchange Inlet (80 [kPa])

Figures $43 \mathrm{a}$ and $\mathrm{b}$ examines the flow further downstream. The Mach number contour plot for symmetry plane 1 shows that there is no significant increase in velocity until after about 0.5 [Dia] downstream. As previously mentioned, the rocket exhaust turns circumferentially and enters symmetry plane 1 aft of this location. Once the rocket exhaust is present, the shear between the two dissimilar fluids gradually accelerates the air stream at the center. After about 2.5 [Dia] downstream, all of the entrained air has accelerated past the free stream Mach number of 0.4 . The bottom half of the figure shows the streamlines within the mixing duct. In symmetry plane 1 , the air is pushed towards the centerline by the rocket exhaust as shown by the deflection of the streamlines entering at plane 3 . In symmetry plane 2 the opposite 
happens and the air expands towards the mixing duct wall.

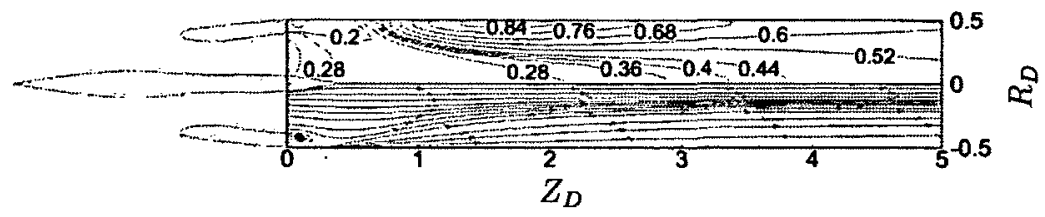

(a) Symmetry Plane 1

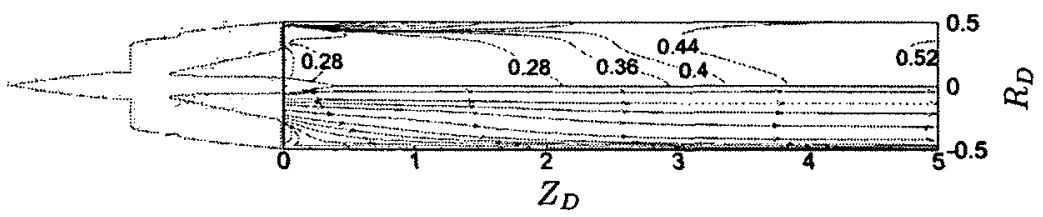

(b) Symmetry Plane 2

Figure 43: Mach Number Contour Plots in Mixing Duct (80 [kPa])

The temperature, total pressure and mass fraction of water contour plots are shown in Figure 44. Here, symmetry plane 1 is shown in the upper half of the plot and symmetry plane 2 is shown in the lower half. They are shown together on one plane for comparison purposes only and does not represent the true geometry. In general, the temperature is higher in symmetry plane 1 than in symmetry plane 2, due to the presence of the rocket exhaust. At 2 [Dia] downstream, the temperature is still concentrated near the walls as the contour lines in symmetry plane 1 show. By 5 [Dia] downstream, the temperature distribution is more uniform and it ranges from about $900[\mathrm{~K}]$ to $1400[\mathrm{~K}]$. This trend is the same for the total pressure and mass fraction plots. Even so, the total pressure distributes more quickly than the temperature or the $\mathrm{H}_{2} \mathrm{O}$ Mass Fraction. This can be seen with the rocket exhaust. It enters at a total pressure of 4.45 [MPa], but decreases to a maximum total pressure of $99.0[\mathrm{kPa}]$ by $1[\mathrm{Dia}]$ downstream.

The EM value is used to analyze the rocket and air interaction further. It measures the variations of each property at a certain point downstream. As each property becomes more uniform, their gradients decrease. This decrease in the property gradient also lower the forces that drive mixing, for example heat transfer is a function of the 


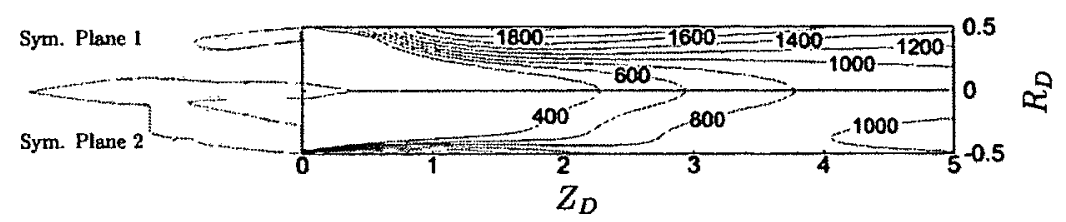

(a) Temperature

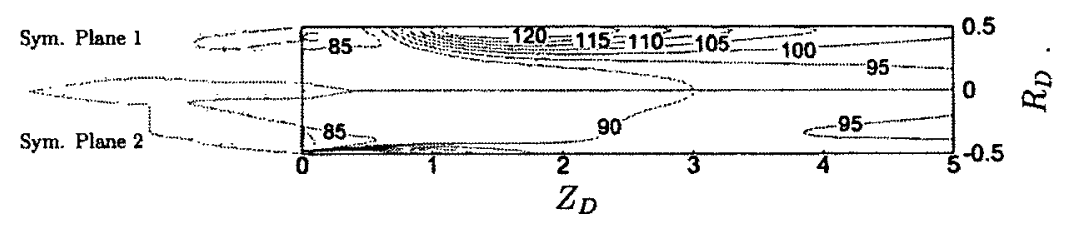

(b) Relative Total Pressure

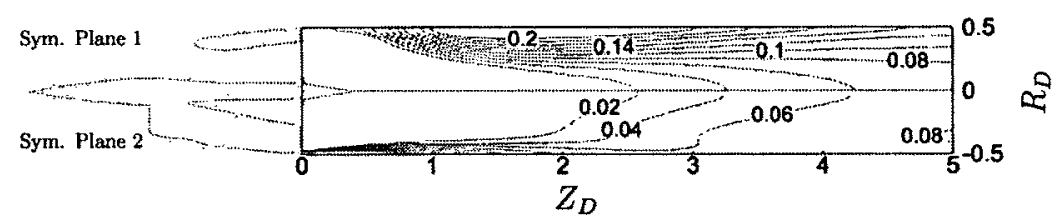

(c) H2O Mass Fraction

Figure 44: Other Contour Plots in Mixing Duct (80 [kPa])

temperature difference between two points. Therefore, the rate of change for the EM value decreases as rocket and air interactions continue. In addition, the upper limit of the EM value must be equal to one. Thus, there is a possibility that the EM values along $\mathrm{Z}$ varies exponentially. Exponential curves are then fitted to the data using this knowledge. The $R^{2}$ values are found to be higher than 0.99 , which suggest a good fit with the data. Then by extrapolation, an estimate can be obtained to determine the duct length required to achieve a certain EM value. These estimates are done for the temperature, total pressure and $\mathrm{H}_{2} \mathrm{O}$ mass fractions and are displayed in Figure 45.

The total pressure mixes relatively quick based on the figure. Both the $E M_{T}$ and $E M_{H 2 O, M_{f}}$ values remain lower than the $E M_{P_{0}}$ value. In particular, at 1 [Dia] downstream the $E M_{H_{2} O, M_{f}}$ value is close to 0.04 , which means that on average the $\mathrm{H}_{2} \mathrm{O}$ mass fraction differs by $96 \%$ from the mean value at that plane. This means that in terms of the mass fraction of water the mixture is still highly unmixed. By 3 [Dia] downstream, the $E M_{H 2 O, M_{f}}$ value is still around 0.65 compared with 0.79 for $E M_{T}$ 


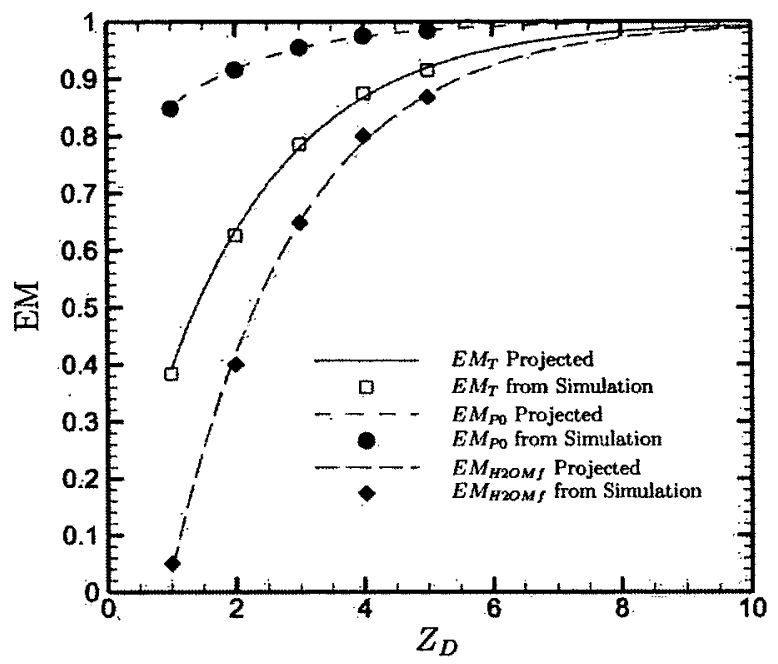

Figure 45: Mass flow Averaged EM along $\mathrm{Z}$

and 0.96 for $E M_{P_{0}}$. It appears that the $\mathrm{H}_{2} \mathrm{O}$ mass fraction mixes relatively slowly as compared with the other two properties. By using the exponential projections, it can be shown that to gain another 0.1 increase in the $E M_{H 2 O, M_{f}}$ value after 5 [Dia], it would take about 3 [Dia] more to achieve. Thus, increasing the mixing duct length beyond 5 [Dia] would only produce minimal gains in terms of mixing.

A combined EM value (see Equation 10) can also be plotted for a cross section in the mixing duct as shown in Figure 46. At 1 [Dia] downstream the flow is split into the air stream core and the rocket exhaust surrounding it as suggested by the low EM regions. The figure also suggest that the flow is not mixed at all since the higher EM values encompass only a narrow region between the air stream and rocket exhaust. Thus, it is likely that this higher EM region represents the shear layer between the two fluids. At 2 diameters downstream, the mixing region starts to increase but the low EM regions are still clearly visible. This means that mixing is under way but there are still regions of flow that are not significantly affected by it. At 3 diameters downstream the lower EM region at the center disappears while the low EM region close to the wall does not. The high EM region now span over a larger area and 
continues to expand through 4 [Dia] down. At 5 [Dia] a significantly large portion of the flow has a EM value above 0.8 , suggesting that the flow is well mixed even if it is not mixed perfectly. 


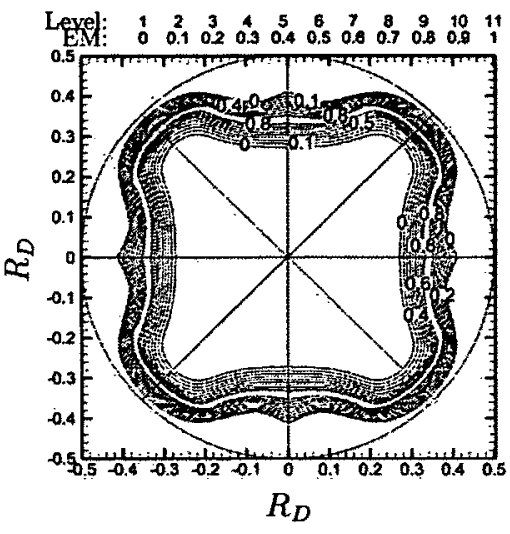

(a) 1 Diameter

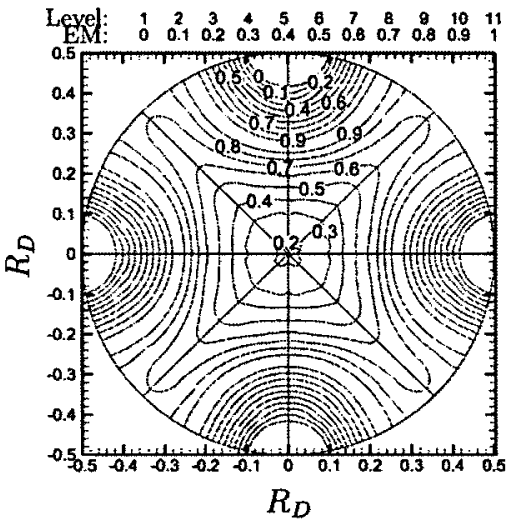

(c) 3 Diameter

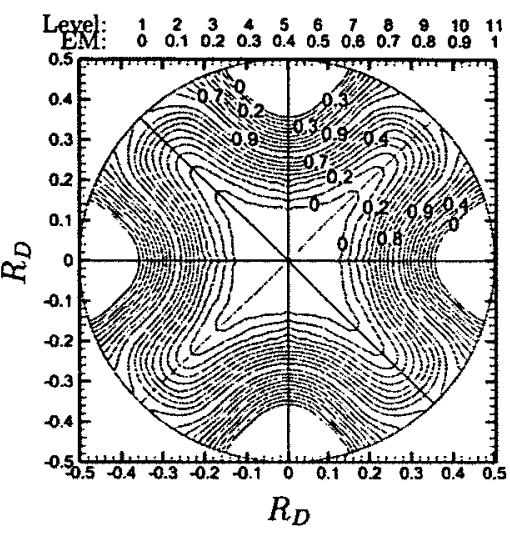

(b) 2 Diameter

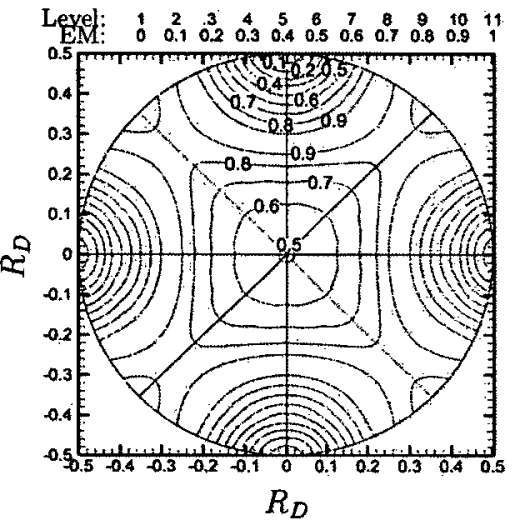

(d) 4 Diameter

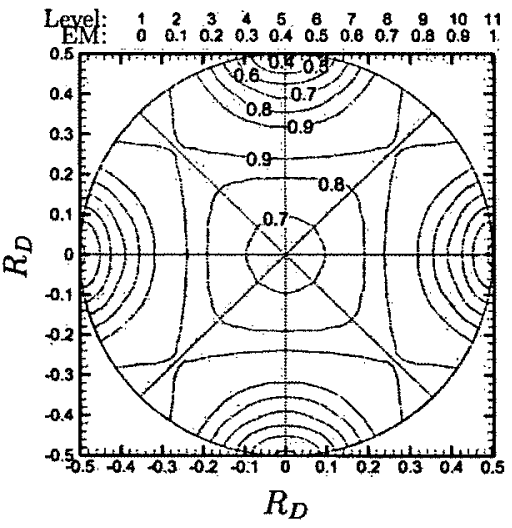

(e) 5 Diameter

Figure 46: EM Contour Plots for Cross Sections at every Diameter Downstream 


\subsubsection{RNG and k- $\omega$ Turbulence Models}

Two other turbulence models are also implemented to study how the flow and interactions might differ between different turbulence models. They are the RNG turbulence model and the $k-\omega$ turbulence model. The Mach number contour plots in Figures 47 and 48 show that for all turbulence models, the entrained air flows smoothly along the centrebody and cowl up until plane 3. Here, the cowl geometry ends abruptly and it causes a recirculation region with a lower Mach number to form. The length of this recirculation region is highest with the RNG model (extending 0.7 [Dia] downstream) and lowest with the $k-\omega$ model (extending 0.5 [Dia] downstream). Moreover, the 0.4 Mach contour line shows that the SST model predict larger stagnation regions in front of the centrebody and fairing.

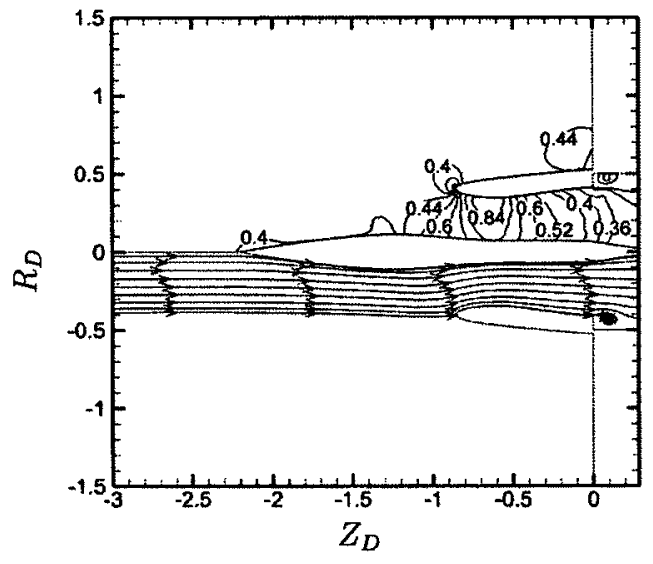

(a) Symmetry Plane 1

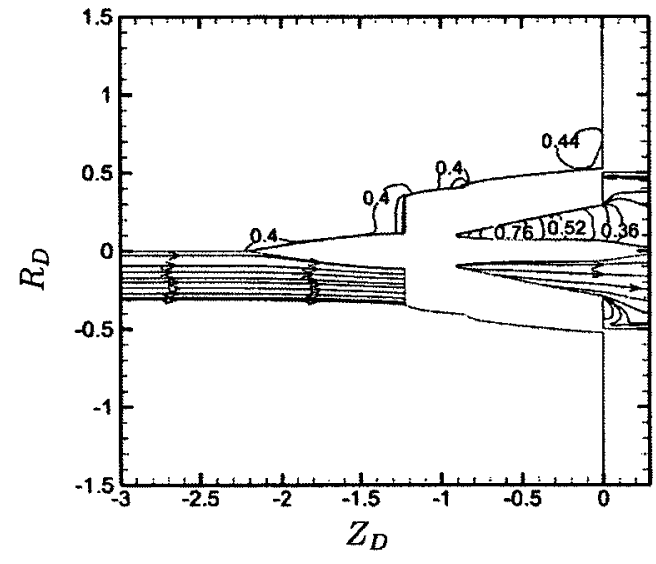

(b) Symmetry Plane 2

Figure 47: Mach Number Contour Plot in Exchange Inlet, RNG 


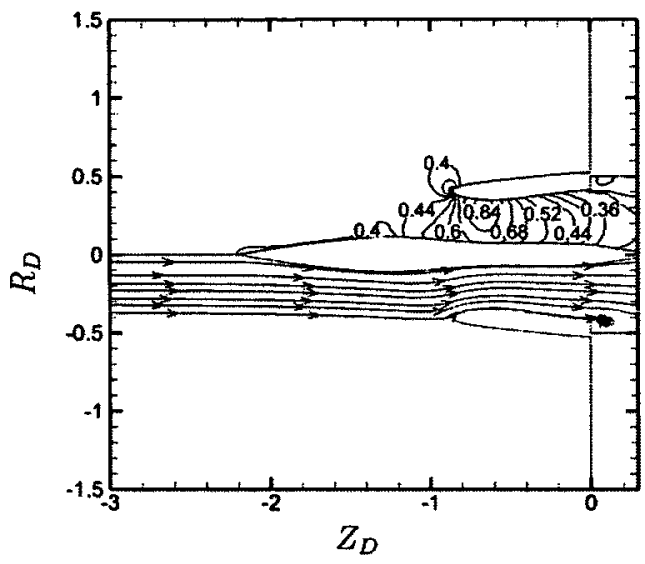

(a) Symmetry Plane 1

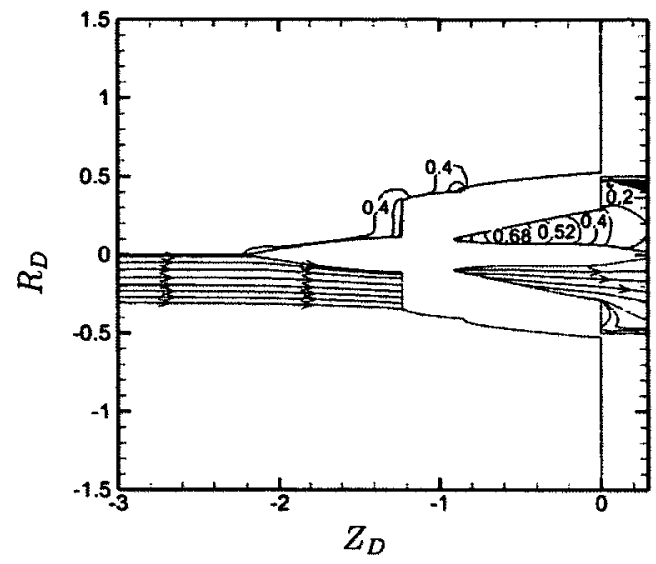

(b) Symmetry Plane 2

Figure 48: Mach Number Contour Plot in Exchange Inlet, $k-\omega$

Figures 49 and 50 shows that the $k-\omega$ turbulence model predicts a higher dissipation than the other two models. Furthermore, judging from the Mach number contours, the RNG turbulence model has the least dissipation. For example, in Figure 49 the rocket exhaust stays above Mach 0.92 until about 2.5 [Dia] downstream. In the case of $k-\omega$ and SST simulations, the maximum Mach number contour lines are 0.76 and 0.84 respectively. Both are lower than what is obtained for the RNG model. The lower dissipation for the RNG case is also seen in Figure 50 for symmetry plane 2 , as the air flow takes longer to gain momentum. This is reflected by contour lines being further downstream in the RNG case. In addition, it appears that both the $k-\omega$ and SST models predict a more uniform flow as the contour lines in Figures 49 at 5 [Dia] downstream shows. 


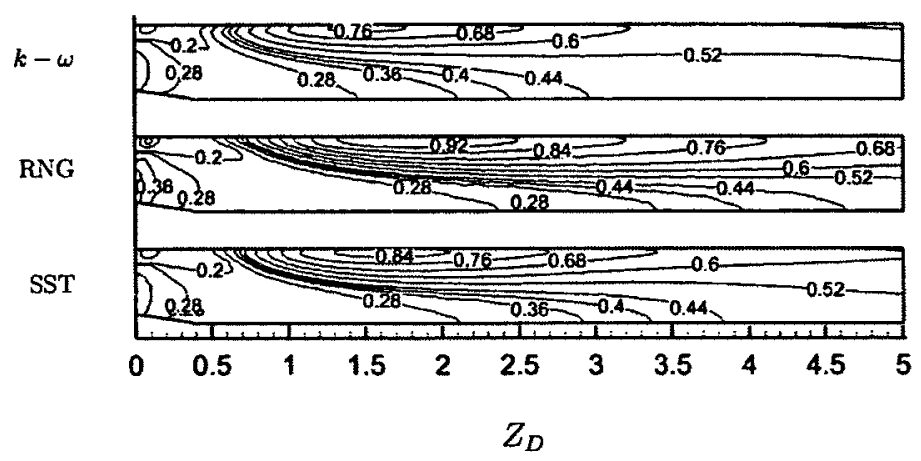

Figure 49: Mixing Duct Comparisons for Symmetry Plane 1

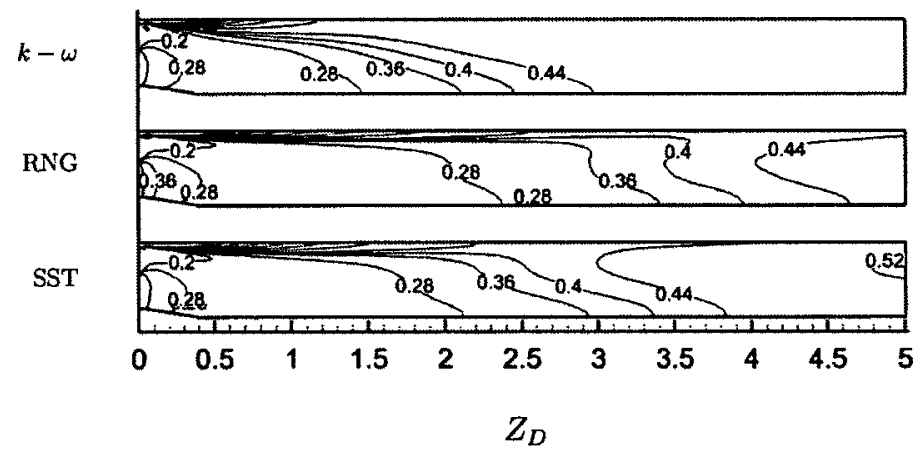

Figure 50: Mixing Duct Comparisons for Symmetry Plane 2

\subsubsection{Other Flight Conditions}

For flight condition 2, the free stream Mach number increases to 0.69 while the mixing duct reference outlet pressure changes to $65.3[\mathrm{kPa}]$. This creates a larger region of decelerated flow in front of the intake. Upon entering, the air accelerates as $A_{\text {air }}$ decreases in the exchange inlet. The flow then accelerates past a Mach number of 0.76 and does not reach sonic. Moreover, the streamlines flow smoothly and remain attached to the centrebody and cowl. The entrained air enters the mixing duct at a 
Mach number of 0.39 and a total pressure of 81.2 [kPa]. In Figure 51 , it is also seen that the flow accelerates outside the intake just behind the tip of the cowl.

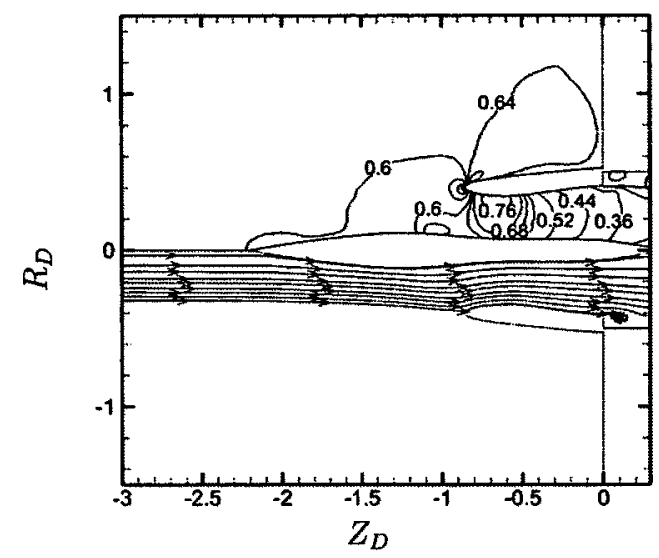

(a) Symmetry Plane 1

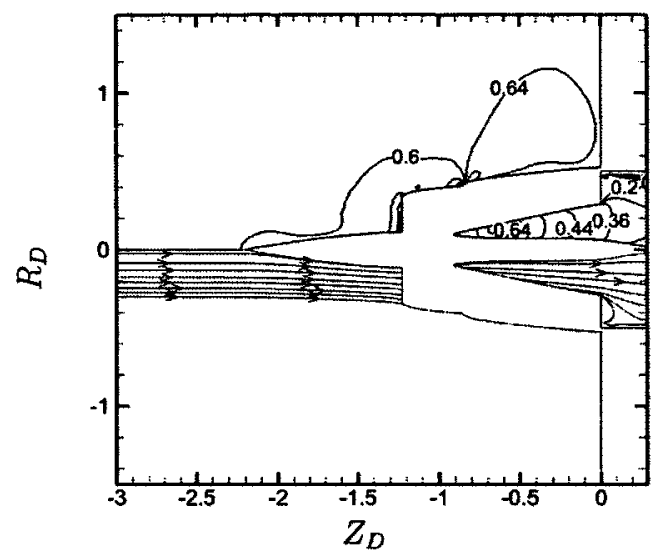

(b) Symmetry Plane 2

Figure 51: Mach Number Contour Plot in the Exchange Inlet at Flight Condition 2

Within the mixing duct, Figure 52 shows that the flow has a higher Mach number compared with Figure 43 for flight condition 1. At 5 [Dia] downstream the massflow averaged Mach number is increased from 0.52 to 0.70 . In addition, the rocket exhaust in symmetry plane 2 has a Mach contour of 0.92 , comparing with 0.84 for flight condition 1. The increase in Mach number within the mixing duct is reasonable, since the flight Mach number increases at flight condition 2. 


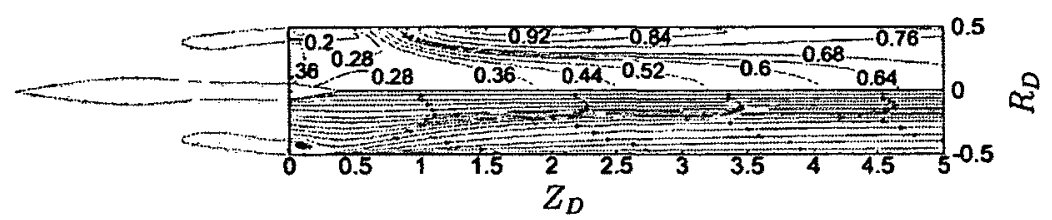

(a) Symmetry Plane 1

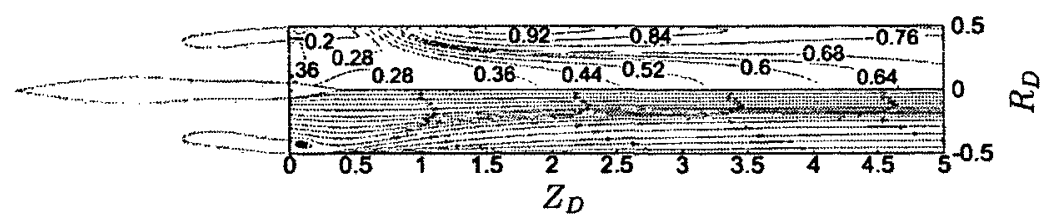

(b) Symmetry Plane 2

Figure 52: Mach number Contour Plot in the Mixing Duct at Flight Condition 2

For flight condition 3 (see Figure 53), there is a larger region of flow that decelerates past the free stream Mach number in front of the intake. As the flow enters the intake, it further decreases to below Mach 0.68 at the entrance to the intake. Once inside, part of the flow is accelerated due to a decrease in the intake area. Then after this region the air once again decelerates since the intake area increases after 0.6 [Dia] upstream. The entrained air enters the mixing duct at a Mach number of 0.44 and a total pressure of $72.0[\mathrm{kPa}]$. Moreover, the streamlines show that there is no separation along the centrebody and cowl. 


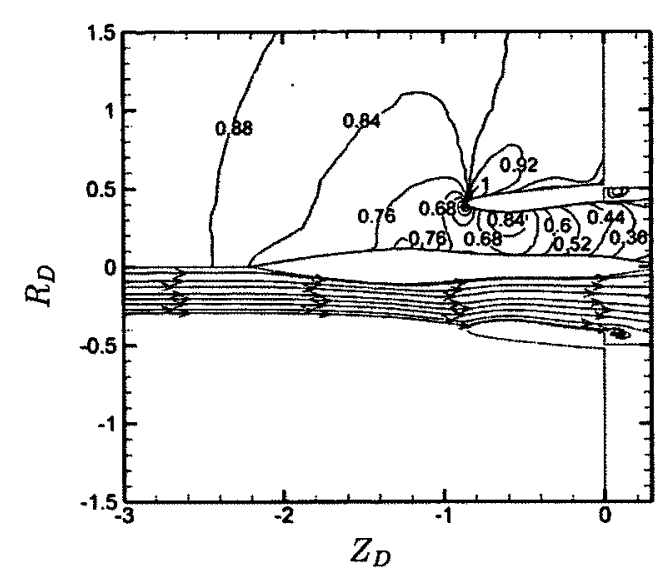

(a) Symmetry Plane 1

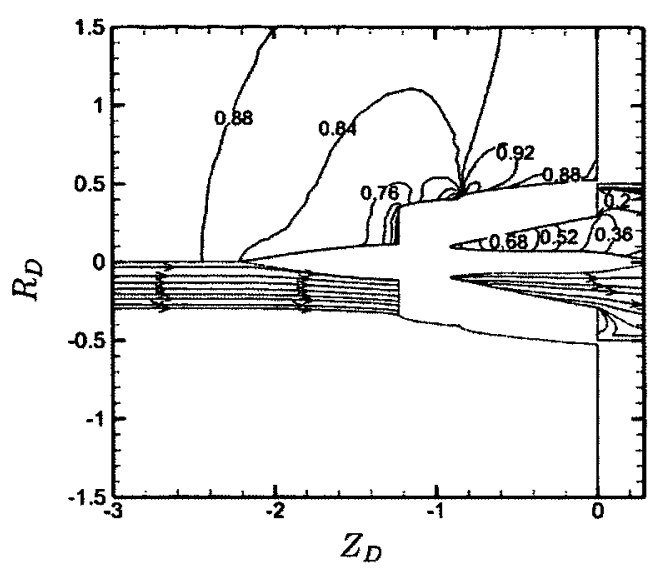

(b) Symmetry Plane 2

Figure 53: Mach number Contour Plot in the Exchange Inlet at Flight Condition 3

Inside the mixing duct the entrained air accelerates due to the presence of the rocket exhaust and reaches a final Mach number of 0.84. Also, the total pressure at the exit increases to 78.7 [kPa]. This produces an entrainment ratio of 8.77 . The 0.92 Mach number contour is longer at this flight condition and reaches to about 4 [Dia] downstream. Moreover, the rocket exhaust again has a circumferential velocity and moves from symmetry plane 2 to 1 along the mixing duct.

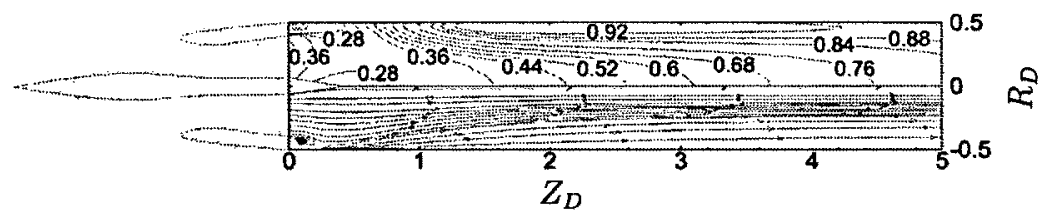

(a) Symmetry Plane 1

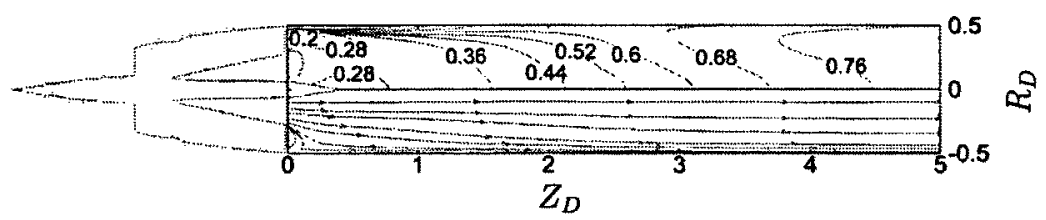

(b) Symmetry Plane 2

Figure 54: Mach number Contour Plot in the Mixing Duct at Flight Condition 3 
For all three flight conditions, the streamlines are similar and only one recirculation zone exist behind the cowl. In addition, the second recirculation zone as seen in the higher outlet pressures cases for flight condition 1 is not present. Moreover, the EM values vary slightly over the 3 flight conditions as seen in Figure 55. The maximum variation of $0.07(9 \%)$ occurs at 4 [Dia] downstream for the $E M_{H_{2} O, M_{f}}$ value. Thus, the EM values follow the same exponential trend and behave similarly for the all 3 flight conditions. Even so, as the free stream velocity increases the EM value appears to decrease as shown in the figure. 


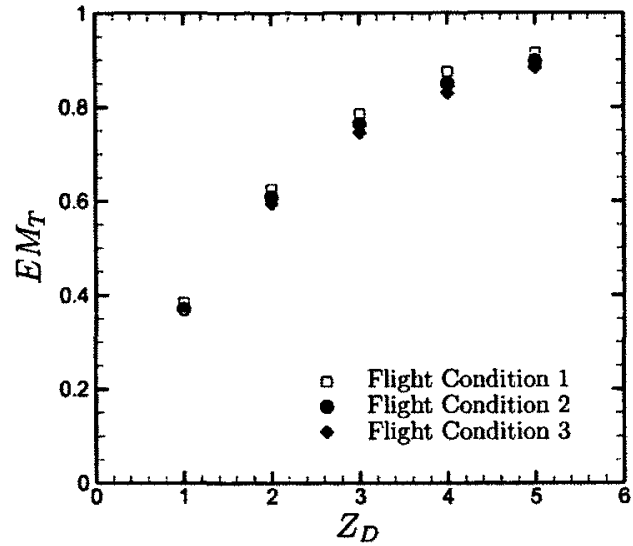

(a) Temperature

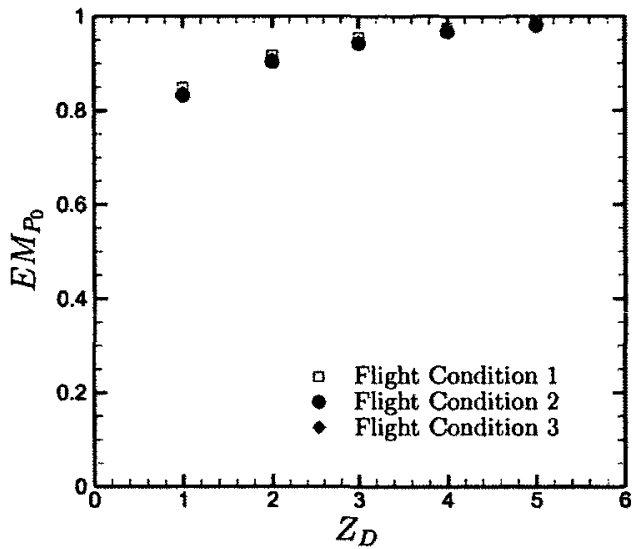

(b) Total Pressure

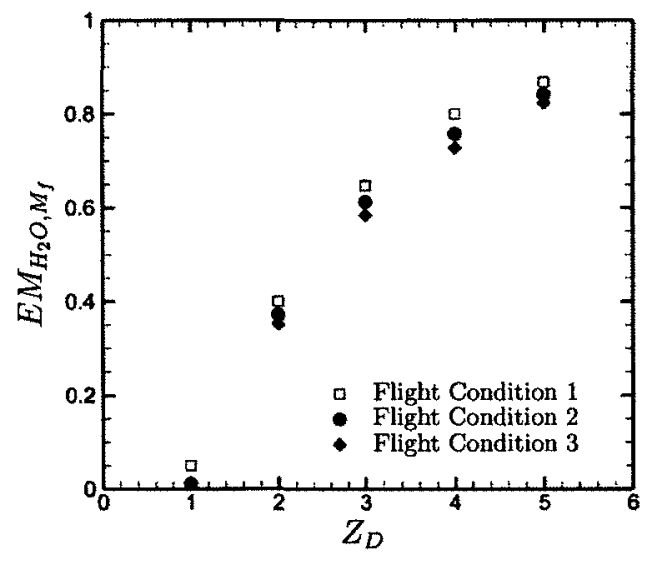

(c) $\mathrm{H}_{2} \mathrm{O}$ Mass Fraction

Figure 55: EM Values for 3 Flight Conditions

\subsubsection{Single Rocket along the Centerline}

The simulation of the exchange inlet for the SRC case is shown in Figure 56. The entrained air accelerates once it enters the modified intake and reaches Mach 1 soon after as $A_{a i r}$ decreases. Then as $A_{a i r}$ starts to increase the pressure also increases in order to match the pressure downstream. Then the flow decelerates quickly at 0.4 [Dia] upstream. This deceleration is abrupt and resembles a normal shockwave. 
The pressure ratio across the shock is approximately 1.8. Since this ratio is less than 2 , it is considered a weak shockwave with nearly isentropic properties [40]. In addition, in both symmetry planes the flow moves smoothly along the center body and cowl without separation until it reaches plane 3 . There is a recirculation region that develops just behind the cowl at plane 3 and is similar to the $R F P_{W}$ cases.

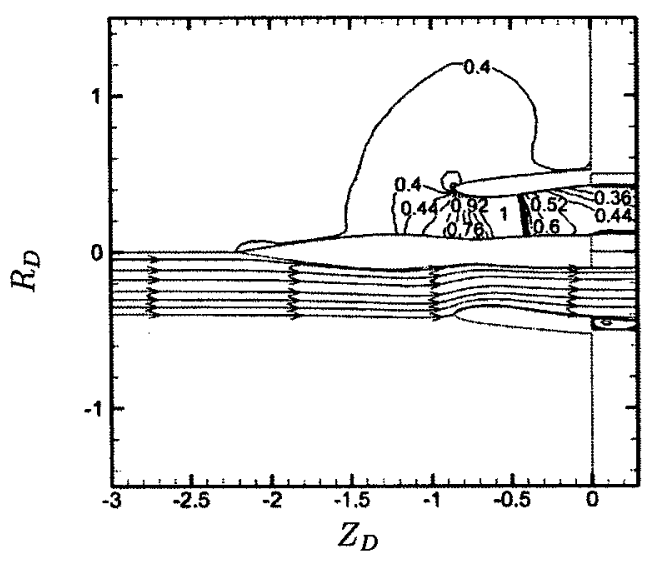

(a) Symmetry Plane 1

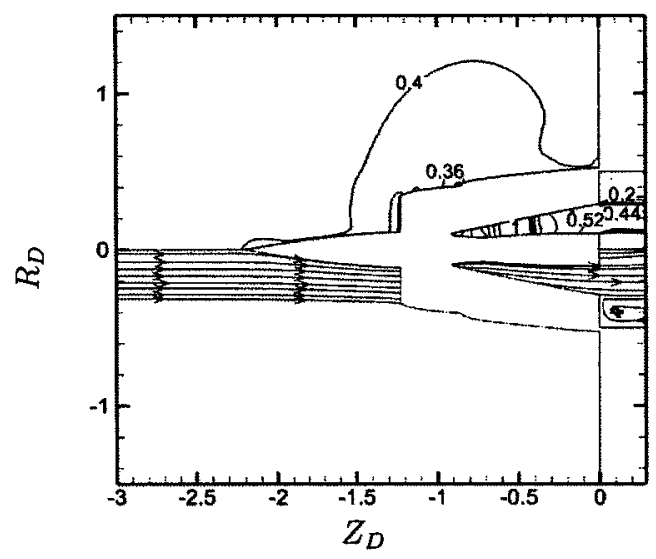

(b) Symmetry Plane 2

Figure 56: Mach number Contour Plot in the Exchange Inlet (SRC)

Figure 57 plots the Mach number contour lines within the mixing duct. The closeness of the contour lines around the rocket exhaust up until 1 [Dia] downstream show that the two streams do not interact much up until this point. Even after 1 [Dia] downstream, the contour lines do not diverge much and portions of the flow that are still below Mach 0.4 is clearly visible. The rocket exhaust portion of the flow is supersonic up until 3.5 [Dia] downstream. This is much higher than in the $R P F_{W}$ case. One reason might be because the rocket exhaust has a higher total pressure and Mach number entering the mixing duct. After the low interaction region, the rocket flow starts to mix with air more. By about 4 [Dia] downstream most of the flow is now greater than the freestream Mach number of 0.4. The temperature and mass fractions also behave similarly with the majority of the flow reaching $1095[\mathrm{~K}]$ 
and $8.7 \% \mathrm{H}_{2} \mathrm{O}$ mass fraction at 5 [Dia] downstream.

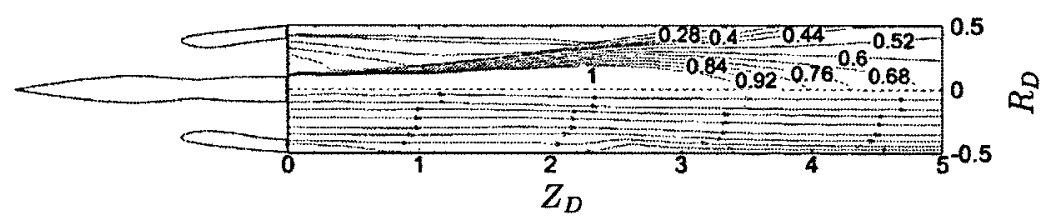

(a) Symmetry Plane 1

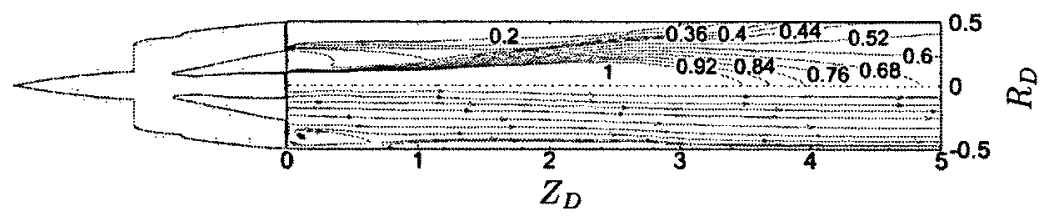

(b) Symmetry Plane 2

Figure 57: Mach number Contour Plot in the Mixing Duct (SRC)

The pressure contour plots in Figure 58 show that the pressure reaches the back pressure further downstream than in the $R F P_{W}$ case. This occurs at about 3.5 [Dia] downstream compared to 3 [Dia]. Furthermore, there is a fluctuation in pressure aft of the rocket exhaust inlet. These fluctuations peak at a maximum of $115[\mathrm{kPa}]$ and a minimum of $46[\mathrm{kPa}]$ with each consecutive variation having a smaller amplitude. This phenomena resembles that of a shock train where pressure is increased nonmonotonically and can exist in supersonic duct flow [43].

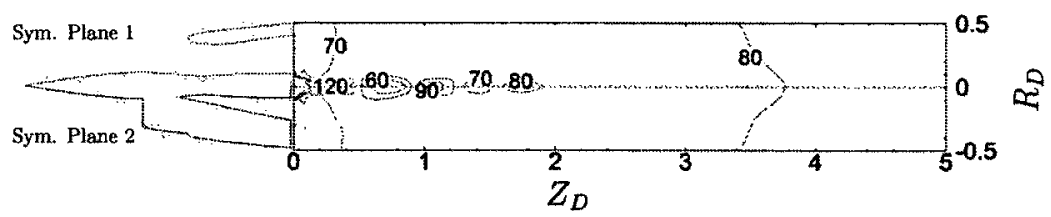

Figure 58: SRC Pressure Contours within Mixing Duct

The effect that the pressure variations have on the temperature is apparent in Figure 59. An increase in temperature exists around the region where the pressure variations occur. At about 1.9 [Dia] downstream, the temperature along the centerline increases from a contour level of $1600[\mathrm{~K}]$ to above $2400[\mathrm{~K}]$ within 0.1 [Dia]. The 
temperature continues to increase to a maximum of 3100 [K] at about 2.4 [Dia] downstream. Similar to the Mach number, the temperature stays concentrated along the centerline until about 1 [Dia] downstream where the contour lines start to curve towards the mixing duct walls. This suggest that there is relatively little thermal interaction up until this point. This is also true for the $\mathrm{H}_{2} \mathrm{O}$ mass fraction as well. The high concentration of water stays along the centerline and the contour lines are concentrated and horizontal until about 1 [Dia] downstream. This means that there is minimal rocket and air interactions occurring up to this point.

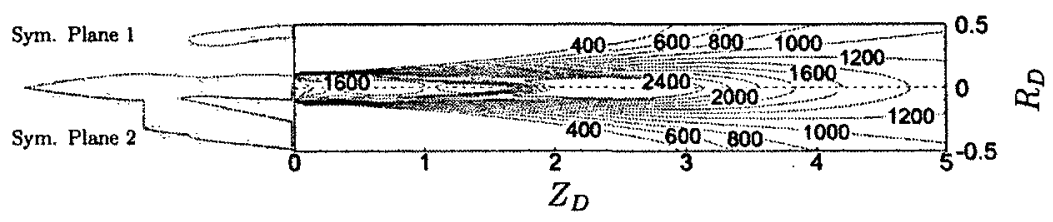

Figure 59: SRC Temperature Contours within Mixing Duct

This behaviour can also be seen with the EM values for each property. This is shown in Figure 60. Looking at 1 [Dia] downstream, the EM values are much lower in the $S R C$ case. In particular, the $E M_{H_{2} O, M_{f}}$ and $E M_{P_{0}}$ values are both negative for the $S R C$ configuration. The $R F P_{W}$ case continues to outperform the $S R C$ case in terms of the EM values up until about 4 [Dia] downstream. Another noticeable difference is with the $E M_{T}$ values. For the $S R C$ case, the $E M_{T}$ values do not follow an exponential relationship until after about 1 [Dia] downstream. This is due to fact that there is minimal rocket air interaction until after this point. 


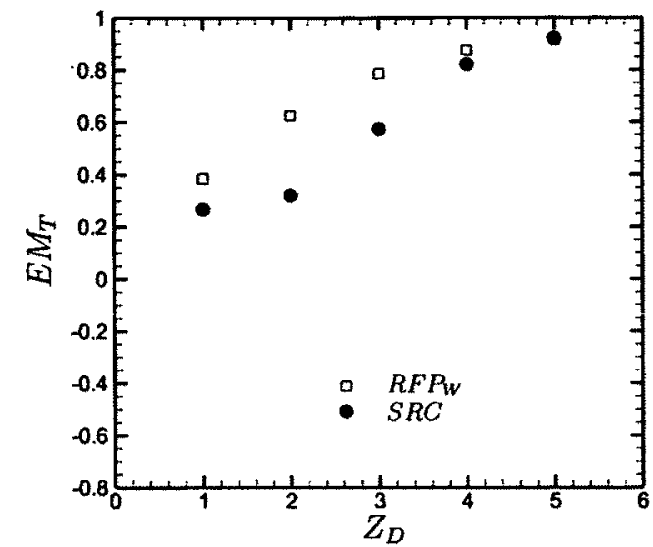

(a) Temperature

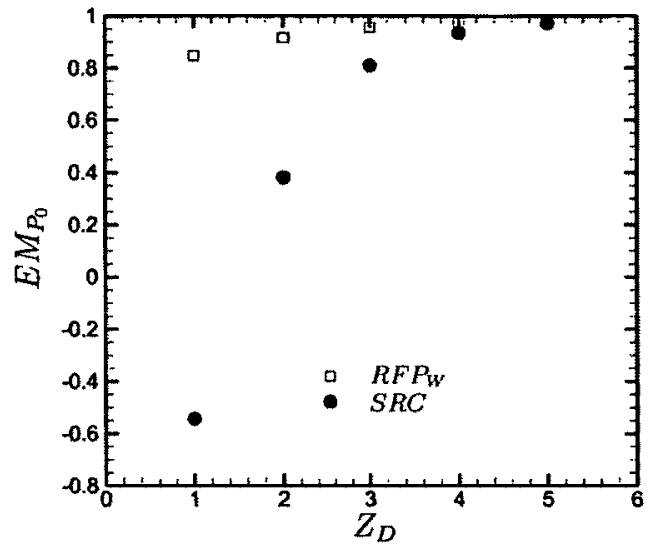

(b) Total Pressure

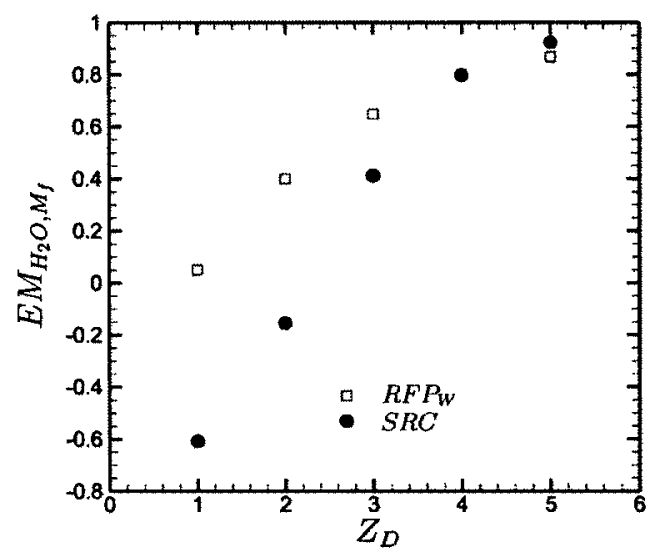

(c) $\mathrm{H}_{2} \mathrm{O}$ Mass Fraction

Figure 60: EM values for Different Configurations

The SMEE value is found to be about 0.07 for the $S R C$ configuration. This is lower than the SMEE value found for the $R P F_{W}$ case of 0.08 . One of the reasons might be because of the pressure variations (see Figure 58). 


\subsection{Summary}

When the mixing duct outlet pressure is varied for flight condition 1 , the entrainment ratio does not drop significantly until after $80[\mathrm{kPa}]$. The EM values improve as the outlet pressure increases and is likely due to a decrease in the entrainment ratio caused by the development of flow structures that impede air entrainment. After about 90 [kPa], a recirculation zone develops aft of the center body and limits the amount of air that is allowed through. The recirculation region allows for more mixture interaction which in turn improves the EM values.

The mass averaged values at 5 [Dia] downstream are shown in Figure 61 and 62. The Mach number and total pressure have opposite trends. As the outlet pressure increases, the Mach number decreases and the total pressure rises. When the Mach number lowers, the pressure losses decrease because the drag force is lower. Moreover, for cases where the outlet pressure is above the free stream static pressure of 77.7 $[\mathrm{kPa}]$, the flow within the engine is being impeded by the geometry aft of the mixing duct. As air entrainment decreases the average total pressure increases due to a higher ratio of rocket exhaust. Thus, the Mach number decrease together with a decrease in the entrainment ratio causes the total pressure to increase with the outlet pressure. The temperature and $\mathrm{H}_{2} \mathrm{O}$ mass fraction both appear to be related to the entrainment ratio and the flow structures that are present. This is because both properties do not increase smoothly like with the total pressure. There is also a large increase after 90 [kPa] which is when the second recirculation develops. 


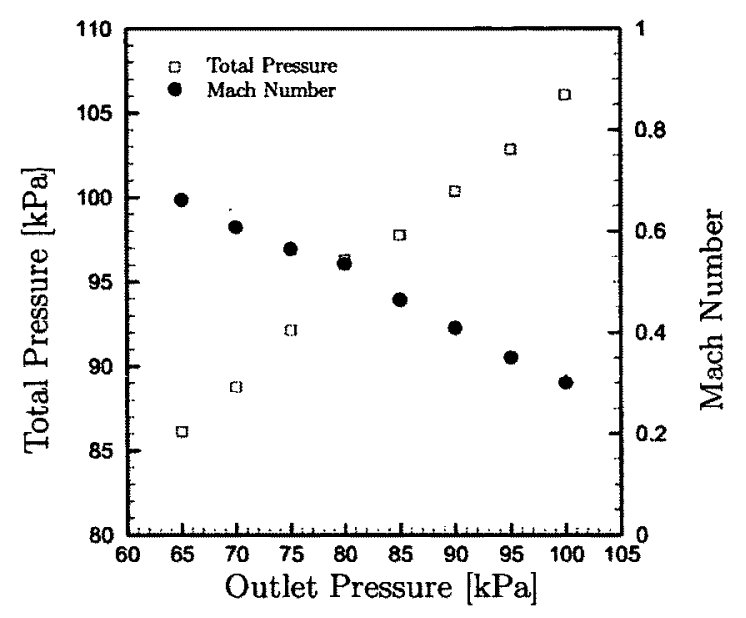

Figure 61: Total Pressure and Mach Number at Various Mixing Duct Outlet Pressures [5 Dia]

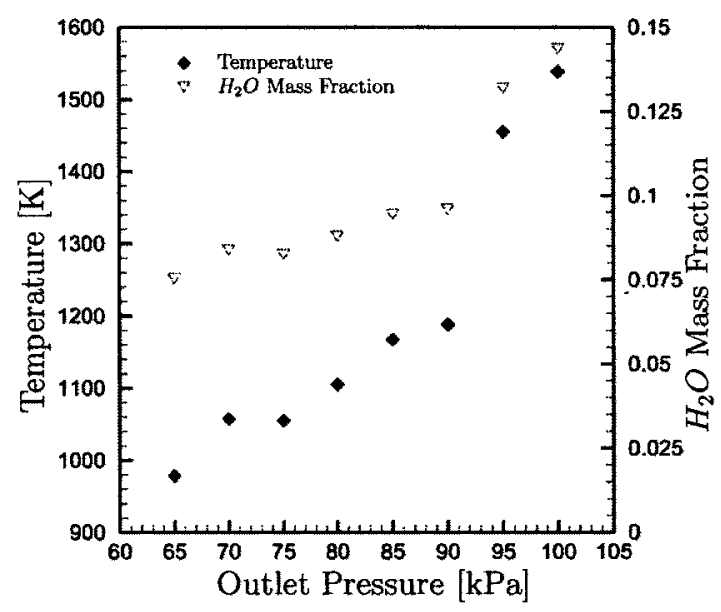

Figure 62: Temperature and $\mathrm{H}_{2} \mathrm{O}$ Mass Fractions at Various Mixing Duct Outlet Pressures [5 Dia]

Comparing with the $S R C$ case, it appears that the current design is more advantageous at mixing within the first few diameters. After about 4 diameters any gains in the EM values that the $R F P_{W}$ case had over the $S R C$ case vanishes. This result is acceptable since after a certain distance all properties should eventually approach uniformity, which agrees with experimental results obtain by Lehman for a centralized rocket [16]. Table 11 taken at 5 [Dia] downstream shows that the difference between 
Table 11: Exchange Inlet and Mixing Duct Summary

\begin{tabular}{rrrr} 
& Total Pressure $[\mathrm{kPa}]$ & Mach Number & Temperature [K] \\
\hline$R F P_{W}$ & 96.3 & 0.535 & 1105 \\
$S R C$ & 98.8 & 0.554 & 1095 \\
Difference & $2.5(2.6 \%)$ & $0.019(3.6 \%)$ & $-10(-0.9 \%)$
\end{tabular}

the $R F P_{W}$ and $S R C$ cases are small comparing with the results from the previous chapter. Even though a total pressure difference of $125 \%$ exists at the end of the rocket flow path, the difference at the end of the mixing duct is about $2.6 \%$. Thus, even though the rocket exhaust enters the mixing duct at a total pressure that is 5.56 [MPa] $(125 \%)$ higher, there is only a gain of $2.5[\mathrm{kPa}](2.6 \%)$ by 5 [Dia] downstream, at the mixing duct outlet. Thus, by $5[\mathrm{Dia}]$ downstream the difference in the total pressures of the rocket exhaust does not offer any clear advantages inside the mixing duct.

Finally, considering weight reduction and mixing performance together for a mixing duct outlet pressure of $80[\mathrm{kPa}$ ] suggests that a shorter than 5 [Dia] mixing duct length is plausible for the $R F P_{W}$ design. Looking at the EM values in Figure 60, anything after 4 [Dia] would mean that there is really no advantage in using the $R F P_{W}$ design. Therefore, between 1 [Dia] to 4 [Dia] the $R F P_{W}$ design offers a higher performance than the $S R C$ design in terms of mixing. Moreover, the outlet pressure causes the EM values to change and is highest with the $E M_{H_{2} O, M_{f}}$ value, with a $7.46 \%$ decrease for $65[\mathrm{kPa}]$ and $10.8 \%$ increase for the $100[\mathrm{kPa}]$. In terms of weight reduction, the mixing duct should be as short as possible. The problem now is that even though the mixing performance is much greater than for an equivalent $S R C$ configuration, for short mixing duct lengths the EM values are still too low. For example, by 1 [Dia] the $E M_{\mathrm{H}_{2} \mathrm{O}, M_{f}}$ is only about 0.05 . This is about $5.7 \%$ of the $E M_{\mathrm{H}_{2} \mathrm{O}, M_{f}}$ value at 5 [Dia]. In addition, Figure 63 shows that at 1 [Dia] downstream the minimum $\mathrm{H}_{2} \mathrm{O}$ 
mass fraction is still at 0 which means that part of the flow is still highly unmixed. By 2 [Dia] downstream the lowest $E M_{H_{2} O, M_{f}}$ value is still at $0.40(46 \%)$, with a minimum $\mathrm{H}_{2} \mathrm{O}$ mass fraction of 0.004 . At 3 [Dia] downstream the $E M_{\mathrm{H}_{2} \mathrm{O}, M_{f}}$ value and $\mathrm{H}_{2} \mathrm{O}$ mass fraction improves to $0.65(75 \%)$ and 0.033 respectively. Finally by 4 [Dia] downstream the $E M_{\mathrm{H}_{2} \mathrm{O}, M_{f}}$ value and $\mathrm{H}_{2} \mathrm{O}$ mass fraction increases to $0.80(92 \%)$ and 0.056 respectively. Thus, as the mixing duct length increases the EM values improve, which is different from the weight reduction criteria. This means that for an effective design, weight reduction should not be the only concern and a compromise must be done between the required EM value and overall engine weight.

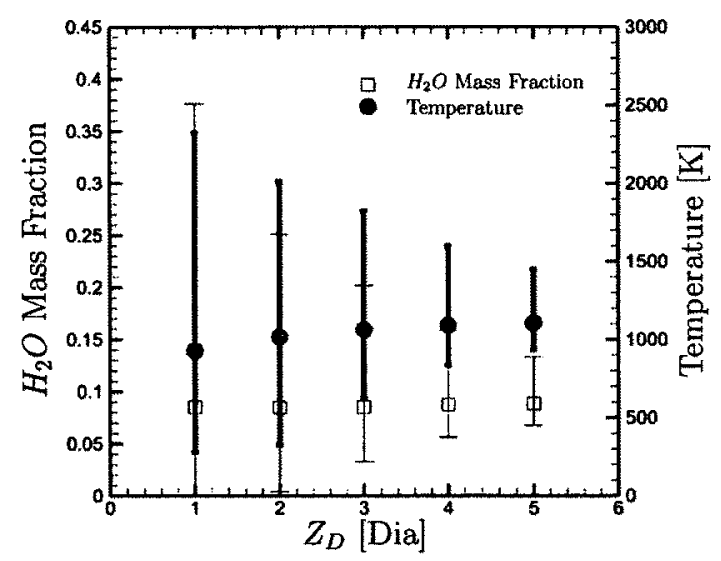

Figure 63: Min Mean Max of Temperature and $\mathrm{H}_{2} \mathrm{O}$ Mass Fraction (80[kPa]) 


\section{Chapter 4}

\section{Conclusion}

The current rocket flow path design is found to contain a shock structure that can be alleviated by changing the rocket flow path parameters. Even so, attention should be paid in trying to minimize the wall surface area since an increase would tend to lower the total pressure at the rocket flow path outlet.

Moreover, the total pressure drop in the $R F P_{W}$ flow path is higher than for the $S R C$ flow path. Even so, its ability to operate as an ejector remains since entrainment is more dependent on the Mach number [10]. The Mach number decrease is less in comparison to the total pressure drop. Furthermore, even with the large difference in total pressure at the rocket flow path outlet, the total pressure at the mixing duct outlet is small in comparison. The difference in the total pressure is $125 \%$ at the end of the rocket flow path and is only about $2.6 \%$ by the end of the mixing duct. Thus, even though the flow entered at a lower total pressure for the $R F P_{W}$ flow path, the effect it has on the final total pressure is much smaller in comparison.

The reason behind using a semi-annular rocket profile is primarily to promote mixing in order to decrease the required mixing duct length. This is found to be plausible by using the current configuration at flight condition 1 . It is also found that for the $R F P_{W}$ case, the EM value reaches a value of 1 exponentially. At 1 [Dia] 
downstream, the EM values for the $R F P_{W}$ case are $0.38,0.85$ and 0.05 for temperature, total pressure and $\mathrm{H}_{2} \mathrm{O}$ mass fraction respectively. For the SRC case, they are $0.27,-0.54$ and -0.61 respectively. Thus, the $R F P_{W}$ design performs better in terms of mixing for all three properties by 1 [Dia] downstream. It continues to outperform the $S R C$ design up to 4 [Dia] downstream. Considering that the $E M_{\mathrm{H}_{2} \mathrm{O}, M_{f}}$ value at 1 [Dia] is only $5.7 \%$ that of the value obtainable at 5 [Dia] downstream and means that on average there is a $95 \%$ difference from the mean $\mathrm{H}_{2} \mathrm{O}$ mass fraction at this location; it would be logical to have a longer mixing duct length. It is notable that by 2 [Dia] downstream, the $E M_{\mathrm{H}_{2} \mathrm{O}, M_{f}}$ value is 0.40 which is $46 \%$ of the value obtained at 5 [Dia]. Therefore, if a EM value between $40 \%$ to $80 \%$ was required then based on the results a value between 2 to 4 mixing duct diameters would be acceptable.

Thus, having both weight reduction and mixing performance in mind, it is reasonable to say that in order for the current design to be advantageous a mixing duct length between 2 [Dia] and 4 [Dia] should be used. Within this range, as the mixing duct length decreases the EM values and the mixing duct weight decreases. Meanwhile, as the mixing duct length increases the EM value increases but the advantage over the $S R C$ case decreases. Thus, the selection of the mixing duct length then depends on what is deemed more important. The information presented here will thus be useful in a weighted trade study at a later stage of the engine design.

Moreover, one can not maximize the entrainment ratio if mixing is considered. This is because the EM values and the entrainment ratio are inversely related. With higher entrainment ratios the average values for temperature, mass fraction and total pressure also decrease. For a RBCC engine, a high EM value is desirable for combustion, but a high entrainment ratio is also desired for thrust augmentation. These factors need to be considered carefully when designing the nozzle and combustion chamber aft of the mixing duct. 


\section{List of References}

[1] M. Byko. "Spaceshipone, the ansari x prize, and the materials of the civilian space race." Journal of the Minerals, Metals and Materials Society (2004).

[2] R. S. Fry. "A century of ramjet propulsion technology evolution." Journal of Propulsion and Power 20 (2004).

[3] C. Bauer, F. Davenne, N. Hopfe, and G. Kurth. "Modeling of a throttleable ducted rocket propulsion system." 47th AIAA/ASME/SAE/ASEE Joint Propulsion Conference and Exhibit (2011).

[4] W. J. D. Escher. "A study of composite propulsion systems for advance launch vehicle applications." Technical report, The Marquardt Corporation (1966).

[5] C. Trefny. "An air-breathing launch vehicle concept for single-stage-to-orbit." 35th AIAA/ASME/SAE/ASEE Joint Propulsion Conference Exhibit (1999).

[6] J. M. Roche and D. N. Kosareo. "Structural sizing a 25,000-lb payload, airbreathing launch vehicle for single-stage-to-orbit." Technical report, Nasa Glenn Research Center (2000).

[7] C. R. McClinton. "High speed/hypersonic aircraft propulsion technology development." Technical report, NATO Research and Technology Organization (2008).

[8] A. Siebenhaar, M. Bulman, and D. Bonnar. "The strutjet rocket based combined cycle engine." Technical report, Marshall Space Flight Center (1998).

[9] B. Henderson. "Fifty years of fluidic injection for jet noise reduction." International Journal of Aeroacoustics 9 (2010).

[10] E. Peterson, V. P. Roan, and J. N. Pfahler. "Experimental investigation of supersonic primary dissimilar-fluid ejectors." 28th AIAA/SAE/ASME/ASEE Joint Propulsion Conference and Exhibit (1992). 
[11] M. Koupriyanov and J. Etele. "Equivalent ratio and constriction effects on rbcc thrust augmentation." ACTA Astronautica (2011).

[12] F. Mohammad, Z. A. Samitha, and S. A. Lal. "A study on supersonic ejector with lobed nozzle." 10th National Conference on technological Trends (2009).

[13] D. Wood. "Preliminary analysis of the rocket plug nozzle combined cycle (rpncc) propulsion system." 44th AIAA/ASME/SAE/ASEE Joint Propulsion Conference and Exhibit (2008).

[14] S. Yungster and C. Trefny. "Analysis of a new rocket-based combined-cycle engine concept at low speeds." 35th AIAA/ASME/SAE/ASEE Joint Propulsion Conference and Exhibit (1999).

[15] R. Munipalli, V. Shankar, D. R. Wilson, H. Kim, F. K. Lu, and P. Hagseth. "A pulsed detonation based multimode engine concept." AIAA/NAL-NASDA-ISAS International Space Planes and Hypersonic Systems and Technologies Conference (2001).

[16] M. Lehman, S. Pal, D. Schwer, and R. J. Santoro. "Focused experimental and analytical studies of the rbcc rocket-ejector mode." Technical report, NASA (1999).

[17] Z. A. Samitha, D. Davis, and P. Balachandran. "Computational study on supersonic mixing using clover nozzle." 47th AIAA Aerospace Sciences Meeting Including the New Horizons Forum and Aerospace Exposition (2009).

[18] G. Hagemann, H. Immich, T. V. Ngiyen, and G. E. Dumnov. "Advance rocket nozzle." Journal of Propulsion and Power 14 (1998).

[19] F. Lu and D. Wilson. "Some perspectives on pulse detonation propulsion systems." In "26th International Symposium on Shock Waves," (2007).

[20] T. H. Yi, D. R. Wilson, and F. K. Lu. "Detonation wave propagation in an ejector-augmented pulse detonation rocket." 46th AIAA Aerospace Sciences Meeting and Exhibit (2008).

[21] J. Etele, J. Sislian, and B. Parent. "Effect of rocket exhaust configurations on ejector performance in rbcc engines." AIAA Journal of Propulsion and Power 21(4), 656-666 (2005). 
[22] W. J. D. Escher and R. E. Schnurstein. "A retrospective on early cryogenic primary rocket subsystem designs as integrated into rocket based combined-cycle (rbcc) engines." 29th AIAA/ASME/SAE/ASEE Joint Propulsion Conference and Exhibit (1993).

[23] D. J. Cerantola and J. Etele. "A nozzle concept to entrain atmospheric air for ejector operation." AIAA 2006-8089, Carleton University. Presented at the $14^{\text {th }}$ AIAA/AHI Space Planes and Hypersonic Systems and Technologies Conference (2006).

[24] T. Waung and J. Etele. "An ejector air intake design method for a novel rbcc rocket nozzle." Aiaa paper 2009-5294, Carleton University (2008).

[25] G. Chorkaway and J. Etele. "Optimization of a novel rbcc propulsion system by genetic algorithm." 27th International Congress of the Aeronautical Sciences (2010).

[26] D. J. Cerantola. Rocket Nozzle Design with Ejector Effect Potential. Master's thesis, Carleton University (2007).

[27] T. S. Waung. An Ejector Air Intake Design Method for a Novel Rocket-Based Combined Cycle Rocket Nozzle. Master's thesis, Carleton University (2010).

[28] J. Etele. Computational Study of Variable Area Ejector Rocket Flowfields. Ph.D. thesis, University of Toronto (2004).

[29] F. R. Menter. "Improved two-equation k- $\omega$ turbulence models for aerodynamic flows." Technical report, NASA Technical Memorandum (1992).

[30] Y. Bartosiewicz, Z. Aidoun, P. Desevaux, and Y. Mercadier. "Numerical and experimental investigations on supersonic ejectors." International Journal of Heat and Fluid Flow (2004).

[31] D. R. Reddy and D. Sree. "Computational study of flow in a rocket-based combined cycle (rbcc) engine inlet." Journal of Computers and Fluids (2006).

[32] C. J. Steffen, R. B. Bond, and J. R. Edwards. "Three dimensional cfd analysis of the gtx combustor." Combustion, Airbreathing Propulsion, Propulsion Systems Hazards, and Modelling and Simulation Subcomittees Joint Meeting (2002).

[33] M. S. Balasubramanyam, D. Lineberry, C. P. Chen, and D. B. Landrum. "Experimental and numerical investigation of a non-axisymmetric strut based ejector." International Journal of Hypersonics (2010). 
[34] A. Inc. Ansys CFX, Release 12.1. Ansys Inc. Documentation, ANSYS Inc. (2009).

[35] J. Etele. "Nozzle code." Technical report, University of Toronto (October 2001).

[36] B. McBride, S. Gordon, and M. Reno. "Coefficients for calculating thermodynamic and transport properties of individual species." Technical report, NASA (1993).

[37] P. M. Knupp. "Remarks on mesh quality." 45th AIAA Aerospace Sciences Meeting and Exhibit (2007).

[38] C. J. Freitas, U. Ghia, I. Celik, P. Roache, and P. Raad. "Asme's quest to quantify numerical uncertainty." 41st Aerospace Sciences Meeting and Exhibit (2003).

[39] F. Dijkstra, A. Maree, M. Caporicci, and H. immich. "Experimental investigation of the thrust enhancement potential of ejector rockets." 33rd AIAA/ASME/SAE/ASEE Joint Propulsion Conference and Exhibit (1997).

[40] F. M. White. Fluid Mechanics. McGraw-Hill Companies, 5th edition (2003).

[41] V. P. Roan. "An ejector performance correlation factor." 27th AIAA/SAE/ASME/ASEE Joint Propulsion Conference and Exhibit (1991).

[42] M. N. Young and S. Idem. "An experimental investigation of cold air-to-air ejectors." 41st AIAA/ASME/SAE/ASEE Joint Propulsion Conference and Exhibit (2011).

[43] K. Matsuo, Y. Miyazato, and H.-D. Kim. "Shock train and pseudo-shock phenomena in internal gas flows." Progress in Aerospace Sciences (1999). 